\title{
Radio Recombination Lines in Galactic H II Regions
}

\author{
Cintia Quireza ${ }^{1,2,3}$, Robert T. Rood $^{3}$, Dana S. Balser $^{4} \&$ T. M. Bania ${ }^{5}$
}

\begin{abstract}
We report radio recombination line $(\mathrm{RRL})$ and continuum observations of a sample of 106 Galactic H II regions made with the NRAO 140 Foot radio telescope in Green Bank, WV. We believe this to be the most sensitive RRL survey ever made for a sample this large. Most of our source integration times range between 6 and 90 hours which yield typical r.m.s. noise levels $\sim 1.0-3.5$ milliKelvins. Our data result from two different experiments performed, calibrated, and analyzed in similar ways. A C II survey was made at $3.5 \mathrm{~cm}$ wavelength to obtain accurate measurements of carbon radio recombination lines. When combined with atomic ( $\mathrm{CI}$ ) and molecular (CO) data, these measurements will constrain the composition, structure, kinematics, and physical properties of the photodissociation regions that lie on the edges of H II regions. A second survey was made at $3.5 \mathrm{~cm}$ wavelength to determine the abundance of ${ }^{3} \mathrm{He}$ in the interstellar medium of the Milky Way. Together with measurements of the ${ }^{3} \mathrm{He}^{+}$hyperfine line we get high precision RRL parameters for $\mathrm{H},{ }^{4} \mathrm{He}$, and $\mathrm{C}$. Here we discuss significant improvements in these data, with both longer integrations and newly observed sources.
\end{abstract}

Subject headings: H II regions - ISM: abundances, clouds, atoms, evolution, lines, and bands, structure — nuclear reactions, nucleosynthesis, abundances — radio lines: ISM

\footnotetext{
${ }^{1}$ Observatório Nacional, Rua General José Cristino 77, 20921-400, Rio de Janeiro, RJ, Brazil.

${ }^{2}$ Instituto de Astronomia, Geofísica e Ciências Atmosféricas (IAG), Universidade de São Paulo, Rua do Matão 1226, 05508-900, São Paulo, SP, Brazil.

${ }^{3}$ Astronomy Department, University of Virginia, P.O.Box 3818, Charlottesville VA 22903-0818, USA.

${ }^{4}$ National Radio Astronomy Observatory, P.O. Box 2, Green Bank WV 24944, USA.

${ }^{5}$ Institute for Astrophysical Research, 725 Commonwealth Avenue, Boston University, Boston MA 02215, USA.
} 


\section{INTRODUCTION}

In molecular clouds, newly formed massive stars are strong emitters of ultraviolet radiation. Massive, early-type stars (O4-B9), emit extreme-ultraviolet $(h \nu>13.6 \mathrm{eV})$ photons that will be absorbed by $\mathrm{H}$ atoms creating a bounded zone of $\mathrm{H}^{+}$that is called an $\mathrm{H}$ II region. Those photons which are not energetic enough to ionize hydrogen and create H II regions penetrate into the surrounding molecular gas where they can dissociate most molecules and ionize atoms with ionization potential below $13.6 \mathrm{eV}$, such as carbon $(11.3 \mathrm{eV})$, silicon $(8.2$ $\mathrm{eV})$, and sulfur $(10.4 \mathrm{eV})$. This produces a photodissociation region (PDR), a neutral hydrogen transition layer between the relatively hot $\left(\sim 10^{4} \mathrm{~K}\right)$ ionized gas in the H II region and the cold $(\sim 10-100 \mathrm{~K})$ gas in the molecular cloud. As the FUV radiation is attenuated across this interface region, the PDR changes chemical composition from totally ionized to totally molecular. The processes of ionization, dissociation, and recombination that occur in a PDR determine its composition, structure and kinematics.

Any astrophysical environment associated with sources of FUV radiation should have a PDR. In addition to giant molecular clouds, examples include reflection nebulae, protoplanetary disks, the neutral gas around planetary nebulae, photodissociated winds from red giant and asymptotic giant branch stars, the interstellar medium in nuclei of star burst galaxies and galaxies with active Galactic nuclei. To date, however, most PDR studies have dealt with the gas that lies at the outer boundaries of dense, luminous H II regions in the Galaxy (see Hollenbach \& Tielens 1999 and references therein for a comprehensive review about PDRs). The physical and chemical processes that regulate dense PDRs are identical to those that occur in the cold and warm neutral gas components of the interstellar medium (see Kulkarni \& Heiles 1987; Dickey \& Lockman 1990; Wolfire et al. 2003).

Observations of a single species in different physical states (ionized, atomic, and molecular) may be used to investigate the effects of FUV radiation on the structure, chemistry, thermal balance, and evolution of the PDR gas. Because the FUV radiation comes from newly formed stars, the study of PDRs probes the process of star formation. In particular, carbon may be used to derive the physical properties of Galactic PDRs. Carbon is the most abundant element with ionization potential lower than that of hydrogen. Its dominant molecular form is $\mathrm{CO}$ which has been used extensively as a tracer of molecular gas and regions of star formation (e.g., Dickel et al. 1978; Viala et al. 1988; Keene et al. 1998; Allen et al. 2004; Kulesa et al. 2005; and Jackson et al 2004. See also Jackson et al. 2006 for a recent survey of $\left.{ }^{13} \mathrm{CO}\right)$.

The fine-structure transition of [C II] at $158 \mu \mathrm{m}$ and the recombination lines of $\mathrm{C}$ II in the radio (e.g. C $91 \alpha$ ) may be used to investigate carbon's singly ionized stage (e.g., Russell et al. 1980; Howe et al. 1991; Stacey et al. 1993; Sorochenko \& Tsivilev 2000; Lehner et al. 
2004). Finally, neutral carbon may be studied using the fine structure transitions of [C I] at $609 \mu \mathrm{m}$ and $370 \mu \mathrm{m}$ (e.g., Phillips \& Huggins 1981; Keene et al. 1985; Genzel et al. 1988; Huang et al. 1999; Jenkins \& Tripp 2001; Papadopoulos et al. 2004).

In this paper we discuss the results of an X-band (8-10 GHz) survey of carbon radio recombination line (RRL) emission from 66 Galactic H II regions. The motivation for this survey was to study more systematically the C II gas in PDRs. We also present CiI RRLs for a sample of 47 Galactic H II regions which are part of a program to measure the abundance of ${ }^{3} \mathrm{He}$ in the Milky Way interstellar medium. These data complement a series of papers (Rood et al. 1984; Bania et al. 1987, 1997; and Balser et al. 1994), in which we reported the observational status of the ${ }^{3} \mathrm{He}$ experiment. All observations were made with the National Radio Astronomy Observatory ${ }^{1}$ (NRAO) 140 Foot radio telescope in Green Bank, WV.

We intend to combine our carbon RRL observations with $158 \mu \mathrm{m}$ transition data from the ISO (Infrared Space Observatory) archives. Because C II RRLs have a different dependence on the density and temperature than the [C II] $158 \mu \mathrm{m}$ far-infrared fine-structure line, measurements of both of these transitions provide an unambiguous way to derive the physical properties of the C II gas. This was done by Natta et al. (1994), who observed the C $91 \alpha$ RRL toward the Orion A H II region. They suggested that the C $91 \alpha$ line originates in a dense $\left(10^{6} \mathrm{~cm}^{-3}\right)$ and warm $(500-1000 \mathrm{~K})$ gas, but their estimate still needs to be confirmed with more high-quality radio line data. Shah (1995) applied the same technique to W3, NGC 6334 and W51; his results indicated that the carbon RRLs form in the same region as the $158 \mu \mathrm{m}$ emission. Finally, in a recent study of carbon RRLs in ultracompact H II regions (UCHs) Roshi et al. (2005) find that the PDR density is typically $\gtrsim 5 \times 10^{5} \mathrm{~cm}^{-3}$ and that these UCHs are embedded in regions of high ambient pressure.

Together with the CII RRLs, we also obtained high precision recombination lines of $\mathrm{H}$ and ${ }^{4} \mathrm{He}$ (henceforth $\mathrm{He}$ ) as well as radio continuum intensities for all the Galactic H II regions in our surveys. These data allow the determination of several physical parameters, such as the electron density, emission measure, H-ionizing luminosity, and mass of H II. Furthermore, we can derive nebular electron temperatures that can be converted to oxygen abundances (Shaver et al. 1983). When combined with accurate distance measurements, these data yield a reliable determination of the electron temperature and oxygen abundance gradients across the Milky Way's disk, providing strong constraints on models for Galactic chemical evolution. The discussion of the physical properties of our Galactic disk H II regions as well as the temperature/abundance radial gradients analysis will be presented in future papers.

\footnotetext{
${ }^{1}$ The National Radio Astronomy Observatory is a facility of the National Science Foundation operated under cooperative agreement by Associated Universities, Inc.
} 
Here we restrict ourselves to a description of the data and compile for our source sample the measured properties of the continuum emission together with the RRL transitions of $H$, $\mathrm{He}$, and $\mathrm{C}$. The spectral line and continuum observations are summarized in $\S 2$, where we describe our observing techniques and data reduction process. We also compile the observed properties of recombination line and continuum emission for our Galactic H in region sample. In $\S 3$ we discuss the overall quality of the data and describe its astrophysical potential. A brief summary follows in $\S 4$.

\section{OBSERVATIONAL TECHNIQUES AND DATA REDUCTION}

\subsection{Radio Recombination Lines}

\subsubsection{CII survey}

Our potential target list included: (i) all major H II regions visible to the 140 Foot telescope; (ii) sources that have CO, C I and C II data; and (iii) sources with embedded B stars as revealed in IRAS HIRES images at 60 and $100 \mu \mathrm{m}$. Our base sample consisted of $\sim 100$ sources in the Milky Way visible from Green Bank with measured X-band Hn $\alpha$ line intensities exceeding $100 \mathrm{mK}$ (Lockman 1989). Our goal was to achieve a spectral r.m.s. noise level of $\sim 2 \mathrm{mK}$. We selected 66 objects distributed throughout the Galactic disk. The majority of these H II regions are located in the first and fourth Galactic quadrants and their Galactocentric distances can reach beyond $\sim 10 \mathrm{kpc}$. At $8.6 \mathrm{GHz}$ the 3'20 HPBW of the 140 Foot telescope is comparable to that of the CO, CI, and CII data. Modeling by Roshi et al. (2005) shows that carbon RL emission near $8.5 \mathrm{GHz}$ is dominated by stimulated emission, and hence we preferentially observe the PDR material that is in front of the H II region thermal continuum.

Our spectral line observations were made with the NRAO 140 Foot radio telescope during the following periods: September and December 1996; January, August, and September 1997; and January, June, and July 1998. The different observing epochs were scattered over the sideral year, and each source was observed in multiple epochs. We do this to average out the baseline structure which is a function of sky frequency and thus changes with the time of the year. ${ }^{2}$ Detailed discussion of the instrumental frequency structure in spectral baselines can be found in a series of papers by Balser et al. (1994, 1997) and Bania et al. (1987, 1997). Basically, systematic effects produce nonrandom frequency structure in the

\footnotetext{
${ }^{2}$ The same is true of the ${ }^{3} \mathrm{He}$ experiment.
} 
instrumental baseline and dominate the radiometer noise at low levels. These systematic effects ultimately limit the detectability of weak and wide spectral lines.

Spectra were taken using the total power position switching observing mode, where a reference position (OFF position) was observed offset $\sim 6$ minutes in right ascension from the target source, and then the telescope was pointed in the direction of the source (ON position). The integration time on the reference position and the target position was 6 minutes each for a total of 12 minutes. Where possible the pointing was determined by peaking on the source continuum radiation. Otherwise local pointing corrections were determined using a nearby pointing calibrator. The measured r.m.s. pointing accuracy was typically $\sim 20^{\prime \prime}$. Receiver-to-receiver and inter epoch calibration was established with continuum observations of NGC 7027 which was assumed to have a flux density of 6 Jy at $8.6 \mathrm{GHz}$ (Peng et al. 2000). For each source we averaged all spectra measured during the different observing periods. The resulting integration time is the sum of integration times in each of these periods and depends on the amount of data, which varies from source to source.

We used the NRAO model IV autocorrelation spectrometer for all the observations. The autocorrelator was divided into four quadrants, each sampling a $10 \mathrm{MHz}$ bandwidth with 256 channels which gives a spectral resolution of $\sim 1.4 \mathrm{~km} \mathrm{~s}^{-1}$ per channel. Two autocorrelator quadrants sampled the $91 \alpha$ band and the other two sampled the $92 \alpha$ band. The pairs of quadrants sampled left and right circular polarizations. Since recombination lines of the same order with similar principal quantum numbers, such as C $91 \alpha$ and C $92 \alpha$, should have basically the same intensity, we could average the C $91 \alpha$ and $\mathrm{C} 92 \alpha$ spectra to attain higher sensitivity. To calibrate $92 \alpha$ relative to $91 \alpha$ we assumed that the intensity of the $\mathrm{H} 92 \alpha$ transition was the same as the intensity of $\mathrm{H} 91 \alpha$ in the bright H II region W3.

The velocity resolutions of the different frequency bands were not the same since they were centered at different sky frequencies. Moreover, the spectra in different frequency bands are not sampled at the same velocity. Therefore it was necessary to regrid one frequency band onto the scale of the other before averaging the $91 \alpha$ and $92 \alpha$ spectra. Several experiments with interpolation schemes gave results in which the r.m.s. noise in the averaged spectrum did not decrease, i.e., the interpolation introduced noise. We finally developed a scheme involving shifts in a discrete number of channels with the size of the shift depending on position in the spectrum. This was done in a way to give optimum results for the $\mathrm{C}$ II line, at the expense of slightly broadening the $\mathrm{H}$ lines. Using this procedure the r.m.s. noise in the average dropped by $\sqrt{2}$ as it should.

The process of averaging the two frequency bands is illustrated in Figure 1, which shows the $91 \alpha, 92 \alpha$, and the averaged spectrum (henceforth labeled $\langle\mathrm{H}\rangle \alpha$ ) for the $\mathrm{H}$ II region G35.194-1.75. Polynomial baseline models were removed from all the spectra. The 
gray bars indicate the regions used for the baseline fits; the $\langle\mathrm{H}\rangle \alpha$ baseline regions were the same as for $91 \alpha$. The $\langle\mathrm{H}\rangle \alpha$ spectrum was formed from $91 \alpha$ and $92 \alpha$ spectra before any baseline was removed. The vertical lines show the expected line centers of the $\mathrm{H}$, He, and $\mathrm{C}$ lines. For the $91 \alpha$ spectrum an additional vertical flag marks the position of the $154 \epsilon$ $(\Delta n=5)$ transition of $\mathrm{H}$. To be consistent, we used the flag marks from the $91 \alpha$ spectrum for the $\langle\mathrm{H}\rangle \alpha$ average data. Gaussian fits to the spectral features are also shown. The H $154 \epsilon$ transition region was excluded from the baseline fits in both the $91 \alpha$ and $\langle\mathrm{H}\rangle \alpha$ spectra. For sources where the $154 \epsilon$ line was weaker than the r.m.s. (it is typically $4-5 \%$ the $\mathrm{H} 91 \alpha$ intensity), we fitted the baseline through that region.

The regions used to determine the spectral baseline must exclude the frequencies near the $\mathrm{H} 154 \epsilon$ line in the $91 \alpha$ and the averaged spectrum, while the $92 \alpha$ spectrum has no similar line. This could conceivably introduce a systematic error, especially in the $\mathrm{H}$ lines. For better control of the quality of the measured parameters of the $\operatorname{Hn} \alpha$ line we decided to analyze the $91 \alpha, 92 \alpha$, and $\langle\mathrm{H}\rangle \alpha$ spectra individually.

We fitted and removed a 6th-order polynomial baseline model through regions in which no lines were expected. (This is equivalent to the 12 th-order fit in the $20 \mathrm{MHz} \mathrm{AC}$ band of the ${ }^{3}$ He experiment. See $\S 2.1 .2$.) Baselines of this order are required to model adequately the real baseline structure produced by the reflections of source continuum radiation off the telescope feedlegs and superstructure. Without such fits one does not recover the expected r.m.s. from the radiometer equation. (For a complete discussion see Rood et al. 1984; Balser et al. 1994; 1997; and Bania et al. 1987.)

The line intensities and full width at half-maximum (FWHM) linewidths were derived using least-squares Gaussian fits. Because they come from different gas components, the $\mathrm{C}$ (PDR) and He (H II region) spectral features can have a variety of morphologies. The $\mathrm{C}$ line is in fact often blended with the He line. The worst case appears when the wings of the He line cover the $\mathrm{C}$ line shape producing a composite spectral feature which can appear as a single very wide line. In many cases the signal to noise ratio of the data is so large that both the $\mathrm{C}$ and He RRLs can be measured even when the two are blended.

We developed an analysis procedure that can extract accurate $\mathrm{He}$ and $\mathrm{C}$ RRL line parameters even when the two spectral features are blended. It is based on the fact that the He emission is generally more intense than C. This procedure is illustrated in Figure 2. We assume that the He line is symmetric, and first fit Gaussians to the $\mathrm{H}$ line and the part of the He line profile nearest the $\mathrm{H}$ line which is also clearly separated from any $\mathrm{C}$ feature. The arrow in the lower spectrum of Figure 2 shows the left boundary of the fitting region. We then subtract these fits from the original spectrum which yields a spectrum with only the $\mathrm{C}$ line. We then make a Gaussian fit to the $\mathrm{C}$ line shown in the second spectrum in order to 
determine its parameters. This Gaussian is then subtracted from the original spectrum. The $\mathrm{H}$ and $\mathrm{He}$ lines in the resulting spectrum are then remeasured with the fitting region now covering the full region of the He line as indicated by the arrow in the third spectrum. The resulting fit is shown in the upper spectrum. In principle we could iterate this procedure, but we find that it is not necessary.

The errors quoted for line intensity and line width are the $\pm 1 \sigma$ uncertainty of the final Gaussian fits. The relative size of this fitting error generally increases as the line intensity decreases. Typical uncertainties in the line intensity and width are: $1 \%$ in both parameters for the $\mathrm{H}$ lines; $4 \%$ and $7 \%$ for the He lines; and $18 \%$ and $25 \%$ for the $\mathrm{C}$ lines. For a small number of sources the He line shape was not well defined and the Gaussian fit was not satisfactory. For these cases the parameters of the He line were obtained by refitting the Gaussian after fixing the He line center and width. The line center was based on the $\mathrm{H}$ velocity and the width was set using the measured $\mathrm{H}$ line width and adopting the mean value of the $\mathrm{He} / \mathrm{H}$ line width ratio. For these special cases we used the median value of all the fitting errors for spectral features with similar intensities.

The baseline removal and the calibration and regridding required to average the two transitions introduces the potential for some systematic error. We performed many tests to determine how large this was. Because of the large sample and high quality of the data, we could see subtle effects. The effect of the systematic error on the parameter values for individual H II regions is, however, always comparable to or smaller than the random error due to radiometer noise.

In order to further assess the quality of our measurement of the line intensities and widths, we visually inspected all the data and defined quality factors (QFs) for the spectrum as a whole and each transition. The QFs are a subjective rating based on the signal-to-noise ratio, the structure of the baseline, the crowding of spectral lines, and the accuracy of the Gaussian fit to the line shape. Quality $A$ sources are our best spectra and quality $E$ sources are our worse cases. We have not yielded to the grade inflation so often found in educational institutions. Some of our spectra are very, very good - sometimes the spectra have so little noise they cannot be distinguished from the Gaussian fits. A $Q F=$ A meets a very high standard. The QFs for the overall spectrum and each of the lines are relative within each category, so $\mathrm{QF}(\mathrm{C})=\mathrm{B}$ for the $\mathrm{C}$ line does not necessarily mean the same thing as $\mathrm{QF}=\mathrm{B}$ for the entire spectrum, beyond the fact that both are in the second grouping. In all cases spectra with QFs of D and E give low confidence line parameter determinations and should be used with caution.

There is an additional factor affecting the $\mathrm{C}$ lines. In measuring weak He lines we are aided by knowing its expected center frequency to high precision and its intensity and 
FWHM to a factor of two before we try to make a fit. This is not the case for the C linestheir precise positions are not known and anticipated intensities range from zero to stronger than the He line. C lines should be narrow, but as we will see below, the widths are highly variable. The narrowness makes it more difficult to distinguish $\mathrm{C}$ lines from noise features. Because of these factors the details of how the baseline and line profile are modeled can affect the existence or not of $\mathrm{C}$ lines. For this reason we introduce a "reliability factor" (RF) as a measure of how confident we are of the reality of a $\mathrm{C}$ line. These are designated excellent, good, fair, poor (E, G, F, P). Lines rated $\mathrm{E}$ or $\mathrm{G}$ are almost certainly real. In sources with $\mathrm{RF}=\mathrm{F}$ there is a small chance that the $\mathrm{C}$ line is not real. For sources with $\mathrm{RF}=\mathrm{P}$ there is a fairly good chance that the reported line is not real. In our discussion below we exclude $\mathrm{RF}=\mathrm{P}$ lines. The $\mathrm{QF}$ we introduced earlier refers to the quality of the line if it is real.

\subsection{2. ${ }^{3}$ He survey}

This survey is part of an on-going program to measure the abundance of ${ }^{3} \mathrm{He}$ in the Milky Way interstellar medium. Our progress is described in a series of papers (Rood et al. 1984; Bania et al. 1987; 1997; 2002; and Balser et al. 1994). As part of this effort we obtain very sensitive measurements of a number of recombination lines in Galactic H II regions. Observations were made with the NRAO 140 Foot telescope during different epochs from February 1982 through July, 1999. At first we observed weak H and He recombination lines primarily for the purpose of characterizing the baseline frequency structure, monitoring the system performance, and developing data reduction procedures. By the mid 1980's, however, it became clear that the recombination lines were a useful tool for probing the structure of H II regions, so we established a uniform intensity scale calibration for all the recombination lines we observed in the entire survey (Bania et al. 1997).

Here we report new observations of RRLs that represent substantial improvements over our previously reported measurements: (1) we added more integration time for some sources; and (2) we increased the number of $\mathrm{H}$ II regions in the original sample by 25 objects. Because of this the line parameters we report for some sources are different than previously published. In no case do these new line parameters exceed our published errors. The improved data reported here supersede all our previously reported recombination line measurements for these objects.

Our current source sample includes $47 \mathrm{H}$ II regions. Our targets are sources with reasonably well determined distances and they are well distributed throughout the Galactic disk. The selection criteria varied over time as we realized the optimum source characteristics for detecting the very weak ${ }^{3} \mathrm{He}^{+}$line. Low density, large angular size, distant sources are 
best. Many classic $\mathrm{H}$ II regions such as Orion A and M17S are dreadful ${ }^{3} \mathrm{He}^{+}$targets when observed by traditional design radio telescopes like the 140 Foot. The integration times are quite large, so the source sample is smaller in number than the C II survey. The velocity resolution is a factor of 2 larger than the $\mathrm{C}$ II survey so the $\mathrm{C}$ lines are more likely to be unresolved in velocity width. On the other hand, no other survey reaches such low levels so the data are an important complement to the $\mathrm{C}$ II survey. As in the $\mathrm{C}$ II survey, most of the $\mathrm{H}$ II regions of the ${ }^{3} \mathrm{He}$ survey are located in the first and fourth Galactic quadrants. Because we were searching for a ${ }^{3} \mathrm{He}$ abundance gradient, the survey also has many more sources with galactocentric distances greater than $8.5 \mathrm{kpc}$ with a few as far out as $\sim 19 \mathrm{kpc}$. A few sources are located at the far side of the Galactic Center.

All the recombination line observations reported here were made with the NRAO 140 Foot telescope which has a HPBW of $\sim 3$ '.20 at these wavelengths. Our new observations were made during 17 observing sessions spanning the period between 1996 July and 1999 July. These new data were obtained and analyzed in the same way as described by Rood et al. (1984), Bania et al. (1987, 1997), and Balser et al. (1994). We used the same procedures as described in $\S 2.1 .1$ to acquire the spectra. The autocorrelator was divided into four quadrants, each sampling $20 \mathrm{MHz}$ wide sections of 256 channels each, providing a spectral resolution of $\sim 2.7 \mathrm{~km} \mathrm{~s}^{-1}$. We observed left and right circular polarizations of the ${ }^{3} \mathrm{He}^{+}$line in two quadrants and various recombination lines in the other two.

Here we report the results for only the $91 \alpha$ spectra. This spectral band sampled the C $91 \alpha$, He $91 \alpha, \mathrm{H} 91 \alpha$, and H $154 \epsilon$ RRL transitions. For each source we averaged all spectra measured during and following August 1992. Because uniformity is an important characteristic of the results presented here we chose not to include data before this period when our observing and data analysis procedures were different. Therefore, in addition to the new epochs listed above, we included the observations made between August 1992 and March 1996 which are reported in Bania et al. 1997 (epochs 8-12 in that paper). The amount of new data varies from source to source. Some objects such as W3 were observed during all observing periods. Others, Orion A for example, have a small amount of data because they were observed only for system tests.

Typical spectra are shown in Bania et al. (1997). A 12th-order polynomial baseline model was removed from each averaged spectrum. The spectral bandwidths for the ${ }^{3} \mathrm{He}$ and C II surveys are 20 and $10 \mathrm{MHz}$, respectively. For this reason the order of the polynomial used in the ${ }^{3} \mathrm{He}$ survey is double that of the polynomial used in the C II survey. Finally, we assigned QFs for the ${ }^{3} \mathrm{He}$ survey spectra using the same criteria described in $\S 2.1 .1$. 


\subsubsection{Radio Recombination Line Properties}

Table 1 compiles properties for our complete sample of Galactic H II regions which combines the $\mathrm{C}$ II and ${ }^{3} \mathrm{He}$ sources. Listed are the Galactic and equatorial (epoch 1950.0) coordinates, the total integration time, the r.m.s. noise in the spectral baseline region and the QF for the spectra. The last column of Table 1 identifies the source's survey membership. The two surveys have 7 objects in common. Also, five extended, morphologically complex $\mathrm{H}$ II regions were observed at two or three different positions. Specifically, these sources are M16 (M16 and M16N), M17 (M17N and M17S), NGC 6334 (NGC 6334-A and NGC 6334-D), Rosette (Rosette-A and Rosette-B), and S209 (S209, S209N and S209S). Altogether we have taken spectra toward 119 directions for a sample of 106 distinct HII region complexes.

Tables 2, 3 and 4 summarize the observed properties of the H, He, and C RRLs, respectively. Listed for each source are the peak intensity $\left(T_{\mathrm{L}}\right.$ in milliKelvins of antenna temperature), the full width at half maximum line width $\left(\Delta v\right.$ in $\left.\mathrm{km} \mathrm{s}^{-1}\right)$, and the radial velocity relative to the Local Standard of Rest ${ }^{3}\left(V_{L S R}\right.$ in $\left.\mathrm{km} \mathrm{s}^{-1}\right)$ measured at line center along with their associated standard deviations. Velocities in the $6 \& 7$ th columns of table 2 correspond to the LSR velocity and the $1 \sigma$ error, assumed for the source, respectively. Also listed is the quality factor (QF) for the line measurement.

Figures 3-4 show examples of different types of C RRL spectra that have been obtained in these surveys. Because the C RRL lineshapes can be quite complex we have also classified each source's lineshape morphology. The combination of spectral crowding, linewidths, and velocity field structure together produces a variety of composite spectral features. In many cases the $\mathrm{C}$ and $\mathrm{He}$ is blended into what appears to be a single very wide line whose width begins to approach that of the smallest scale instrumental baseline frequency structure. In other cases these lines are completely distinct one from the other. We distinguished three different morphologies for the C lineshape. The C emission line is deemed "resolved" (r) whenever it is completely distinct from any He emission. In this case the wings of both lines are not superposed. The C line morphology is "semi-blended" (sb) whenever the C and He line profiles overlap. It is nonetheless always possible to identify the center of both lines. Finally, the morphology is "blended" (b) whenever the C and He line profiles both overlap and have a linewidth wherein it is difficult to identify the $\mathrm{C}$ line center. Table 4 compiles the morphology classification and reliability factor $(\mathrm{RF})$ for the carbon recombination lines.

Each spectrum in Figures 1-4 is labeled with 4 letters. From left to right these indicate

\footnotetext{
${ }^{3}$ The 140 Foot velocities cited here are in the kinematic LSR frame using the radio definition of the Doppler shift. The kinematic LSR is defined by a Solar motion of $20.0 \mathrm{~km} \mathrm{~s}^{-1}$ towards $(\alpha, \delta)=\left(18^{\mathrm{h}},+30^{\circ}\right)[1900.0]$.
} 
the overall spectrum quality factor $(\mathrm{QF}=\mathrm{A}-\mathrm{E})$, the reliability factor $(\mathrm{RF}=\mathrm{E}, \mathrm{G}, \mathrm{F}, \mathrm{P})$, the $\mathrm{C}$ line quality factor $(\mathrm{QF}(\mathrm{C})=\mathrm{A}-\mathrm{E})$, and the $\mathrm{C}$ line morphology ( $\mathrm{r}, \mathrm{sb}, \mathrm{b})$. We have purposefully chosen some of our lower quality data to illustrate what we mean by our QF and RF ratings. In Figures $3 \& 4$ there are a few points worth commenting on:

- The H II region G49.4 is in the highest category of each ranking. Both the $\mathrm{C}$ and He line data are indistinguishable from the Gaussian fit.

- Before deconvolution one might be inclined to think that the $\mathrm{C}$ line we identified from the M17N spectrum was due to a separate velocity component of the He line. While one sees evidence for a separate velocity component on the high velocity side (right) of both the $\mathrm{H}$ and He lines, there is, however, no evidence for this $\mathrm{C}$ component. The signal to noise ratio is high enough that our deconvolution procedure recovers a relatively weak, Gaussian shaped C line that could have easily been overlooked.

- The H II regions G81.681+0.54 and G10.315-0.15 have, respectively, semi-blended and blended $\mathrm{C}$ lines because of the large width of the He lines. G75.834+0.40 (Figure 2) has a "normal" He line width and the $\mathrm{C}$ line is blended because the $\mathrm{C}$ line velocity is offset.

- Sources with rather similar looking features such as G10.315-0.15 and G353.398-0.3 can end up with different RFs. Additional information beyond the final averaged spectrum is used to determine the RF. For example, the $91 \alpha$ and $92 \alpha$ spectra are examined separately for consistency.

- Many of the $\mathrm{C}$ lines with $\mathrm{RF}=\mathrm{P}$ are real. For example, Balser (private communication) has obtained a very long integration on S206 using the Green Bank Telescope, which shows the $\mathrm{C}$ line with a very high signal to noise ratio.

The 7 objects common to the two surveys provide a means to assess the accuracy of the measured line parameters. In some cases the two surveys used slightly different positions for the sources that might compromise a comparison. Nevertheless, the spectral line data and total power continuum (see $\S 2.2$ ) are in good agreement for these common sources. Exceptions occur when the signal to noise ratio is low. In some cases discrepancies occur for the weak, narrow $\mathrm{C}$ line which can be more easily affected by a narrow noise feature than the wider $\mathrm{H}$ or He lines of comparable intensity.

We give two measurements of carbon lines for M16 and G23.706+0.17 in Table 4. The PDRs in our sample have unknown density structure and velocity fields. We therefore tried to measure every single signal that might reasonably be a carbon line. In both M16 and 
G23.706+0.17 the $\mathrm{C}$ lines are very weak; it is possible that neither of them is real. If real, however, these lines must be produced by physically distinct components since they appear at different Doppler shifts. The M16 carbon lines at $25.3 \mathrm{~km} \mathrm{~s}^{-1}$ and $38.2 \mathrm{~km} \mathrm{~s}^{-1}$ have intensities of 3.9 and $2.8 \mathrm{mK}$, respectively, with an r.m.s. of $1.4 \mathrm{mK}$. (We did not detect the

$38.2 \mathrm{~km} \mathrm{~s}^{-1}$ line in the C II survey.) For G23.706+0.17 the $\mathrm{C}$ lines are found at $100.1 \mathrm{~km} \mathrm{~s}^{-1}$ and $116.9 \mathrm{~km} \mathrm{~s}^{-1}$; their respective intensities are $1.5 \mathrm{mK}$ and $3.6 \mathrm{mK}$ with an r.m.s. of 1.0 $\mathrm{mK}$.

\subsection{Radio Continuum}

When combined with RRL data, radio continuum measurements provide essential information for calculating the physical properties of H II regions. We therefore made two independent radio continuum emission surveys with the NRAO 140 Foot radio telescope for our sample of Galactic H II regions. In both surveys we made cross scans in right ascension (RA) and declination (DEC) through the center of the source. Data were obtained for right and left circular polarizations. The nominal frequency of these continuum data was 8665 $\mathrm{MHz}$ and we typically observed with a $300 \mathrm{MHz}$ bandwidth. We typically achieved an r.m.s. sensitivity of $10 \mathrm{mK}$ antenna temperature. This radiometer r.m.s. can often be compromised by much larger uncertainties caused by source confusion and by difficulties in establishing the continuum background emission which must be subtracted in order to get the true source continuum. The flux density scale was determined by continuum observations of NGC 7027 which was assumed to have a flux density of 6 Jy (Peng et al. 2000).

The first survey was made during the same epochs as the line data (see $\S 2.1 .1 \& 2.1 .2$ ). The continuum measurements were interleaved with spectral line scans at $\sim 2$ hour intervals. We normally used the switched power (SP) technique. That is, during the continuum cross scans the Cassegrain subreflector was nutated (at $\sim 2.5 \mathrm{~Hz}$ ) to an OFF position. The OFF was $\sim 8^{\prime}$ from the position along the path through the center of the source. The direction of the beam throw was position angle 202.5 (recall that the 140 Foot is an equatorial mounted telescope).

The switched power technique has a distinct advantage over non-nutated total power (TP) scans. The effect of the atmosphere is more effectively removed with the SP technique. This is especially important under marginal weather conditions where one needs to be especially vigilant about maintaining intensity calibration. The disadvantage of the SP technique is that for extended sources the OFF position may still be within the source itself and in crowded parts of the Galaxy the OFF may include other sources. These effects are relatively easily identified in the resulting continuum scans. They also make data analysis difficult 
because the continuum emission from the OFF position, whether due to substructure within the H II region itself or from an "intruder" source, is subtracted from the signal coming from the ON position.

Depending on the intensity and sky position of this unexpected OFF contribution, the true shape of the source continuum emission structure in these intensity versus sky position cross scans may be altered. Emission in the OFF can also corrupt data at the position extremes of the scan, making it difficult or even impossible to fit a baseline. These effects can drastically compromise the continuum measurement.

For these reasons we made a second continuum survey. The C II survey objects were observed in March 1999; ${ }^{3}$ He sources were observed in May 1999. These data were obtained for all sources near transit (nearly zero hour angle) and under good weather conditions. We were thus able to observe with the total power (TP) technique. Since the subreflector was not nutated, these data do not suffer from any of the continuum confusion or self-chopping issues describe above for the SP technique.

In both the total and switched power surveys, RA and DEC scans for both polarizations were individually analyzed. Polynomial baseline models were fitted through regions having no continuum emission from the source. The order of the polynomial used varied from a linear to a 3rd-order fit. Higher order fits were used whenever the baseline regions were sufficiently large. For extended sources and sources in crowded fields, these baseline regions were sometimes very limited. In many cases distinguishing between the source continuum emission and the sky and continuum background level was quite tricky. To aid this process, we identified the position of each of our target sources in continuum maps and compared our observations with features in these maps. We used continuum maps at $5 \mathrm{GHz}$ (Altenhoff et al. 1979; Haynes et al. 1978) and 2.7 GHz (Fürst et al. 1990; Reich et al. 1990).

After removing the polynomial baseline, we measured the continuum intensity and angular size (full width at half-maximum; FWHM) using a least-square Gaussian fit to the RA and DEC cross scans. For each scan a single Gaussian was fit to the central peak; the fit was confined to an angular range comparable to the telescope beam size. For SP data we also averaged over the different observing epochs. Before averaging, these scans were checked for quality. Specifically, for each source we checked for consistency in the fitted parameters for different scans. Generally the agreement was satisfactory. Scans with discordant parameters were reanalyzed and excluded in cases where the inconsistency persisted. These discarded data generally had pointing problems or bad Gaussian fits.

As we did for the RRL spectra, we also visually inspected our continuum scans and assigned quality factors to the data. The continuum QFs are based on the accuracy of 
the Gaussian fit to the emission feature, the uncertainty in the baseline models and the contrast between the target source emission and any emission from possible sub-structures or nearby confusing sources. Again, quality $A$ sources are our best measurements and quality $E$ sources are our worse cases. We deem that sources with QFs of $D$ and $E$ give low confidence continuum emission parameter determinations.

Near the end of our surveys we discovered an offset between the SP and TP intensity scales. Based on calibration sources NGC 7027 and Virgo A the SP intensity was $1.15 \pm 0.06$ times greater than that of the TP intensity. This offset had not been noticed by other observers or NRAO staff. Because the 140 Foot telescope was closed, we were not able to find the source of this offset. Since the basic calibration of the telescope for our surveys was made using the SP technique, we used this correction factor to convert all TP intensities and the associated errors to the SP intensity scale.

Tables 5 and 6 summarize the observed properties of the continuum emission for our source sample. Listed for both the TP and SP surveys are the peak continuum intensity in Kelvins of antenna temperature and the FWHM observed angular size in arcmin together with the associated errors determined from the Gaussian fits for both of the RA and DEC scans. TP continuum scans are already corrected by the 1.15 scale factor just described. The geometric mean for the average RA and DEC values is also presented. The quoted errors in the continuum intensity are the Gaussian fitting errors. Due to baseline problems and complex structures uncertainties in the peak intensity are certainly larger. Such errors might be $10 \%$, or even higher than $20 \%$ in the worst cases. Since we have no way to quantify those uncertainties, we crudely estimate this error by quality factors (QF) for the continuum data. These QFs are listed separately in Tables 5 and 6.

Any comparison of the continuum observations of the 7 sources in common between the $\mathrm{C}$ II and ${ }^{3} \mathrm{He}$ surveys is compromised by the slightly different positions used and the fact that most of these sources have complicated structure which appears in the OFF beam of the SP observations. The best comparison can be made with the TP observations where we calculate an average intensity ratio between the ${ }^{3} \mathrm{He}$ and $\mathrm{C}$ II survey to be $0.97 \pm 0.03$.

Finally, we suggest how to best use these continuum data. As a source was tracked on the sky during these surveys, there were small corrections for changes in the telescope gain with elevation and also corrections due to weather. Since the data were taken in an interleaved manner, these corrections were the same for the average SP continuum and the line measurements. Thus, when calculating properties that depend on the line-to-continuum ratio, such as the electron temperature, we suggest using the SP continuum measurements. On the other hand, for calculating properties that depend only on the continuum data we suggest using the TP measurements. These are our most accurate continuum parameters 
since they were taken during good weather conditions at transit where the calibration is most accurate.

\section{Characterization of the Data}

In a series of papers to follow we will discuss astrophysical results derived from the data compiled here. Still we feel that it is important to give some impression of the overall quality of the data and the sort of conclusions that can eventually be drawn.

Figure 5 shows the distribution of the ratio of $\mathrm{He}$ to $\mathrm{H}$ line intensities. The lower plot shows a histogram of the distribution and the Gaussian which best fits that histogram. It is important to determine whether the width of this distribution is due to an intrinsic source to source spread or to the errors in individual H II region parameter values. In order to better illustrate the size of the errors we construct in the upper panel a pseudo-histogram plotting each data point along with its error bars. Within each histogram bin points are added in order of increasing $T_{L}(\mathrm{H})$; the $n$th point is plotted at $y=n$ and $x=T_{L}(\mathrm{He}) / T_{L}(\mathrm{H})$. The histogram and Gaussian are repeated for reference.

The error bars for the Figure 5 sources are typically much narrower than the width of the observed distribution. The average error is 0.005 , less than one half the observed width of $0.013 .{ }^{4}$ This indicates an intrinsic spread in $T_{L}(\mathrm{He}) / T_{L}(\mathrm{H})$. Near the peak and toward higher values the spread is well modeled as a Gaussian and could be due to variations in the He abundance, degree of ionization, turbulence, or other property of the H II region. There is an obvious skew in the direction of low values for $T_{L}(\mathrm{He}) / T_{L}(\mathrm{H})$. This is probably due to the fact that some of the He is not ionized in these $\mathrm{H}$ II regions. We suspect that there is a real paucity of sources with $T_{L}(\mathrm{He}) / T_{L}(\mathrm{H})<0.04$. We have high enough sensitivity that we would have detected such sources unless they are relatively uncommon.

Figure 6 shows the analogous distribution for $\mathrm{C}$ lines. The distribution is again much broader than can be attributed to measurement errors alone. The average error of 0.007 is about half the observed width. The observed distribution is well modeled as Gaussian except for a tail toward high values. The drop off toward small values is most likely due to lack of sensitivity.

The line width distributions are shown in Figures 7 and 8. Both have substantial intrinsic width, and neither distribution is well described as a Gaussian. For He the distribution of

\footnotetext{
${ }^{4}$ When referring to the widths of the distributions we quote the value for $\sigma$ in the best Gaussian fit. The FWHM of the distribution is $2.35 \sigma$.
} 
$\Delta v(\mathrm{He}) / \Delta v(\mathrm{H})$ drops off sharply for values $<0.7$ and $\gtrsim 1$. Line widths arise from thermal broadening and turbulence. The H II regions G10.315-0.15 and G81.681+0.54 (Figure 3) have intrinically wide $\mathrm{He}$ lines. In the absence of turbulence $\Delta v(\mathrm{He}) / \Delta v(\mathrm{H})=0.5$. $\mathrm{H}$ II regions with $\Delta v(\mathrm{He}) / \Delta v(\mathrm{H})$ approaching 1 must either be very highly turbulent or the ionized $\mathrm{He}$ and $\mathrm{H}$ are not co-spatial.

Since the $\mathrm{C}$ lines arise from the PDR one expects them to be narrower both because of the lower temperature and the higher mass of $\mathrm{C}$. The mass effect alone would yield a $\mathrm{C}$ line a factor of $\sim 3.5$ more narrow than $\mathrm{H}$. In the $\mathrm{C}$ II survey the most likely line width is 0.24 the mean $\mathrm{H}$ line width or roughly $6.2 \mathrm{~km} \mathrm{~s}^{-1}$, and in the ${ }^{3} \mathrm{He}$ survey it is 0.31 the mean $\mathrm{H}$ line or $7.5 \mathrm{~km} \mathrm{~s}^{-1}$. In the combined survey the most likely width is 0.26 the $\mathrm{H}$ line width. The resolution of the two surveys was respectively 1.4 and $2.7 \mathrm{~km} \mathrm{~s}^{-1}$, so the $\mathrm{C}$ lines are typically resolved in velocity. The lower panel of Figure 8 shows histograms demonstrating how the two surveys independently contribute to the combined survey. The higher resolution C II survey does turn up more sources with narrower lines, but curiously yields no sources with velocity widths less than the resolution of the ${ }^{3} \mathrm{He}$ survey. Both surveys show a scatter of sources with larger widths, ranging up to $\sim 12 \mathrm{~km} \mathrm{~s}^{-1}$. We do not have the sensitivity to detect even larger widths.

The line velocity distributions relative to the $\mathrm{H}$ line are shown in Figures 9 and 10. For He the peak of the Gaussian fit is near zero and the width of the Gaussian fit is consistent with that expected from the individual source errors (Figure 9). This suggests that overall the $\mathrm{H}$ and He density and ionization distributions are similar over the 3.20 telescope beam. Figure 10 shows that the PDR gas, probed by the C RRLs, is typically moving several km s${ }^{-1}$ relative to the $\mathrm{H}$ II region, with a few velocities ranging up to $10 \mathrm{~km} \mathrm{~s}^{-1}$. The distribution of velocities is roughly symmetric around zero with $\sigma=3.2 \mathrm{~km} \mathrm{~s}^{-1}$. From these data alone we have no way to distinguish between gas flowing toward or away from the H II regions. We also have no definitive detection of sources with multiple velocity components. Naively one might have expected to find a few sources with PDR's both in front and beyond the H II region. ${ }^{5}$ If the carbon emission line is dominated by stimulated emission, we would predominantly observe PDRs in front of the H II regions. Figure 11 shows that the $\mathrm{C}$ line intensity is strongly correlated with the $\mathrm{H}$ II region continuum intensity, which indicates that stimulated emission is occurring. This is consistent with similar observations toward 11 ultracompact H II regions by Roshi et al. (2005).

\footnotetext{
${ }^{5}$ In some cases the angular size of the H II region is larger than the telescope beam, which might lead us to miss some PDR material with small radial velocity.
} 


\section{SUMMARY}

We report high precision radio recombination line and continuum observations made with the NRAO 140 Foot telescope near $8.5 \mathrm{GHz}$ for 106 Galactic H II regions. Most of our source integration times range between 6 and 90 hours which yields typical r.m.s. noise levels $\sim 1.0-3.5$ milliKelvins. These data come from two different surveys that were observed and analyzed in similar ways. Our sample consists of H II regions located throughout the Galactic disk with a wide range of physical properties. Hydrogen recombination emission was detected in all $106 \mathrm{H}$ II regions with line intensities 27-4277 mK. Helium was detected in $77 \mathrm{HII}$ regions with line intensities $3-468 \mathrm{mK}$. We detected carbon in 74 objects with intensities 1-200 $\mathrm{mK}$.

We thank the staff of NRAO Green Bank for their help, support and friendship. The

${ }^{3} \mathrm{He}$ research has been sporadically supported by the National Science Foundation. The most recent grant was AST 00-98047. CQ is grateful to the Department of Astronomy at the University of Virginia, for their hospitality. Her work was partly supported by the Levinson Fund of the Peninsula Community Foundation and FAPESP.

\section{REFERENCES}

Allen,R.J., Heaton, H.I., \& Kaufman, M.J. 2004 ApJ, 608, 314

Altenhoff, W.J., Downes, D., Pauls, T., \& Schraml, J. 1979, A\&AS, 35, 23

Balser, D.S., Bania, T.M., Brockway, C.J., Rood, R.T., \& Wilson, T.L. 1994, ApJ, 430, 667

Balser, D.S., Bania, T.M., Rood, R.T., \& Wilson, T.L. 1997, ApJ, 483, 320

Bania, T.M., Rood, R.T., \& Balser, D.S. 2002, Nature, 415, 54

Bania, T.M., Rood, R.T., \& Wilson, T.L. 1987, ApJ, 323, 30

Bania, T.M., Balser, D.S., Rood, R.T., Wilson, T.L., \& Wilson, T.J. 1997, ApJS, 113, 353

Dickel, J.R., Dickel, H.R., \& Wilson, W.J. 1978, ApJ, 223, 840

Dickey, J.M., \& Lockman, F.J. 1990, ARA\&A, 28, 215

Fürst, E., Reich, W., Reich, P., \& Reif, K. 1990, ApJS, 85, 691-803

Genzel, R., Harris, A.I., Jaffe, D.T., \& Stutzki, J. 1988, ApJ, 332, 1049 
Haynes, R.F., Caswell, J.L., \& Simons, W.J. 1978, Aust. J. Phys. Atrophys. Suppl., 45, 1

Hollenbach, D.J., \& Tielens, A.G.G.M. 1999, Rev. Mod. Phys., 71, 1

Howe, J.E., Jaffe, D.T., Genzel, R., \& Stacey, G. 1991, ApJ, 373, 158

Huang, M., Bania, T.M., Bolatto, A. et al. 1999, ApJ, 517, 282

Jackson, J.M., Simon, R., Shah, R.Y., Rathborne, J., Heyer, M.H., Clemens, D.P., \& Bania, T.M. 2004, ASP Conf. Ser. 317: Milky Way Surveys: The Structure and Evolution of our Galaxy, 317, 49

Jackson, J.M., Rathborne, J.M., Shah, R.Y., Simon, R., Bania, T.M., Clemens, D.P., Chambers, D.P., Johnson , A.M., Dormody, M., Lavoie, R. \& Heyer M. 2006, astroph/0602160 (accepted ApJ)

Jenkins, E.B., \& Tripp, T.M. 2001, ApJS, 137, 297

Keene, J., Blake, G.A., Phillips, T.G., Huggins, P.J., \& Beichman, C.A. 1985, ApJ, 299, 967

Keene, J., Schilke, P., Kooi, J., Lis, D.C., Mehringer, D.M., \& Phillips, T.G. 1998, ApJ, 494, L107

Kulesa, C.A., Hungerford, A.L., Walker, C.K., Zang, X., \& Lane, A.P. 2005, ApJ, 625, 194

Kulkarni, S.R. \& Heiles, C. 1987, in Interstellar Processes, ed. Hollenbach, D.J., \& Thronson, H.A. (Reidel, Dordrecht), 87

Lehner, N., Wakker, B.P., \& Savage, B.D. 2004, ApJ, 615, 767

Lockman, F.J. 1989, ApJS, 71, 469

Natta, A., Walmsley, C.M., \& Tielens, A.G.G.M. 1994, ApJ, 428, 209

Papadopoulos, P.P, Thi, W.-F., \& Viti, S. 2004, MNRAS, 351, 147

Peng, B., Kraus, A., Krichbaum, T. P., \& Witzel, A. 2000, A\&AS, 145, 1

Phillips, T.G., \& Huggins, P.J. 1981, ApJ, 251, 533

Reich, W., Fürst, E., Reich, P., \& Reif, K. 1990, ApJS, 85, 633

Rood, R.T., Bania, T.M., \& Wilson, T.L. 1984, ApJ, 280, 629

Roshi, D.A., Balser, D.S., Bania, T.M., Goss, W.M., \& De Pree, C.G. 2005, ApJ, 625, 181 
Russell, R.W., Melnick, G., Gull, G.E., \& Harwit, M. 1980, ApJ, 240, L99

Shah, R.Y. 1995, Senior Thesis, Boston University: "Pressure Constraints on Photodissociation Region Models via Carbon Radio Recombination Lines"

Shaver, P.A., McGee, R.X., Newton, L.M., Danks, A.C., \& Pottasch, S.R. 1983, MNRAS, 204,53

Sorochenko, R.L. \& Tsivilev, A.P. 2000, Astron. Rep., 44, 7, 426

Stacey, G.J., Jaffe, D.T., Geis, N., Genzel, R., Harris, A.I., Poglitsch, A., Stutzki, J., \& Townes, C.H. 1993, ApJ, 404, 219

Viala, Y.P., Letzelter, C., Eidelsberg, M., \& Rostas, F. 1988, A\&A, 193, 265

Wolfire, M.G., McKee, C.F., Hollenbach, D., \& Tielens, A.G.G.M. 2003, ApJ, 587, 278 
Table 1. Properties of Galactic H II Regions

\begin{tabular}{|c|c|c|c|c|c|c|c|c|c|}
\hline Source & Name & $\begin{array}{c}1 \\
\left({ }^{\circ}\right)\end{array}$ & $\begin{array}{l}\mathrm{b} \\
\left({ }^{\circ}\right)\end{array}$ & $\begin{array}{c}\mathrm{RA}(1950.0) \\
(\mathrm{hr} \min \mathrm{s})\end{array}$ & $\begin{array}{c}\operatorname{DEC}(1950.0) \\
\left({ }^{\circ} \prime \prime \prime\right)\end{array}$ & $\begin{array}{c}t_{i n t g}^{\dagger} \\
(h r)\end{array}$ & $\begin{array}{l}r m s^{\dagger} \\
(\mathrm{mK})\end{array}$ & $\mathrm{QF}^{\sharp}$ & survey \\
\hline G0.605+0.325 & $\ldots$ & 0.605 & +0.329 & 174237.7 & $-28 \quad 1352.0$ & 38.0 & 0.47 & $E$ & ${ }^{3} \mathrm{He}$ \\
\hline G0.665-0.035 & Sgr B2 & 0.665 & -0.035 & 174410.7 & $-2822 \quad 17.0$ & 8.4 & 3.28 & $C$ & ${ }^{3} \mathrm{He}$ \\
\hline G1.13-0.1 & $\ldots$ & 1.119 & -0.098 & 174530.0 & -280101.0 & 55.4 & 1.16 & $B$ & ${ }^{3} \mathrm{He}$ \\
\hline $\mathrm{G} 2.90+0.0$ & $\ldots$ & 2.901 & -0.003 & 174916.7 & -262629.0 & 59.0 & 0.73 & $D$ & ${ }^{3} \mathrm{He}$ \\
\hline G3.270-0.101 & $\ldots$ & 3.270 & -0.100 & 175029.2 & -261024.0 & 59.9 & 0.83 & $C$ & ${ }^{3} \mathrm{He}$ \\
\hline G5.899-0.427 & $\ldots$ & 5.900 & -0.427 & 175736.5 & -240416.0 & 16.8 & 3.24 & $C$ & $\mathrm{C}_{\text {II }}$ \\
\hline G5.956-1.265 & $\ldots$ & 5.956 & -1.264 & 180055.3 & -242621.0 & 12.8 & 3.17 & $B$ & $\mathrm{C}_{\text {II }}$ \\
\hline G5.973-1.178 & M8 & 5.974 & -1.178 & 180037.6 & -242253.0 & 12.8 & 3.72 & $B$ & $\mathrm{C}_{\text {II }}$ \\
\hline G8.137+0.228 & $\ldots$ & 8.138 & +0.228 & 175959.6 & $-2148 \quad 18.0$ & 16.0 & 3.02 & $C$ & $\mathrm{C}_{\text {II }}$ \\
\hline G10.159-0.34 & W31 A & 10.159 & -0.347 & 180625.0 & -201948.0 & 12.8 & 4.79 & $A$ & $\mathrm{C}_{\text {II }}$ \\
\hline G10.315-0.15 & $\ldots$ & 10.316 & -0.150 & 180600.1 & -200547.0 & 19.2 & 2.03 & $B$ & $\mathrm{C}_{\text {II }}$ \\
\hline G10.617-0.38 & W31 B & 10.618 & -0.384 & 180730.0 & -195650.0 & 19.2 & 2.28 & $D$ & $\mathrm{C}_{\text {II }}$ \\
\hline G12.807-0.20 & W33 & 12.807 & -0.202 & 181119.5 & -175640.0 & 12.8 & 4.25 & $C$ & $\mathrm{C}_{\text {II }}$ \\
\hline $\mathrm{G} 13.875+0.28$ & $\ldots$ & 13.876 & +0.283 & 181141.9 & -164628.0 & 15.2 & 2.92 & $C$ & $\mathrm{C}_{\text {II }}$ \\
\hline G14.626+0.08 & $\ldots$ & 14.627 & +0.092 & 181355.2 & $-16 \quad 1236.0$ & 12.0 & 3.21 & $D$ & $\mathrm{C}_{\text {II }}$ \\
\hline $\mathrm{G} 15.035-0.68^{\mathrm{a}}$ & M17 S & 15.035 & -0.677 & 181732.0 & -161300.0 & 1.4 & 14.09 & $C$ & ${ }^{3} \mathrm{He}$ \\
\hline $\mathrm{G} 15.095-0.71^{\mathrm{a}}$ & $\mathrm{M} 17 \mathrm{~N}$ & 15.095 & -0.711 & $1817 \quad 47.1$ & -161053.0 & 22.8 & 2.76 & $B$ & ${ }^{3} \mathrm{He}$ \\
\hline G15.181-0.62 & $\ldots$ & 15.182 & -0.622 & 181737.7 & -160345.0 & 13.6 & 2.48 & $D$ & $\mathrm{C}_{\text {II }}$ \\
\hline G15.198-0.76 & $\ldots$ & 15.198 & -0.766 & 181811.1 & -160656.0 & 12.0 & 4.08 & $D$ & $\mathrm{C}_{\text {II }}$ \\
\hline G16.936+0.76 & M16 & 16.936 & +0.758 & 181603.4 & -135138.0 & 3.2 & 5.58 & $D$ & $\mathrm{C}_{\text {II }}$ \\
\hline $\mathrm{G} 16.936+0.76^{\mathrm{a}, b}$ & M16 & 16.936 & +0.760 & 181603.4 & -135138.0 & 27.0 & 1.39 & $C$ & ${ }^{3} \mathrm{He}$ \\
\hline $\mathrm{G} 16.984+0.93^{\mathrm{a}, b}$ & M16 N & 16.984 & +0.934 & 181530.9 & -134403.0 & 20.8 & 1.48 & $C$ & ${ }^{3} \mathrm{He}$ \\
\hline G16.995+0.86 & $\ldots$ & 16.995 & +0.869 & 181546.5 & -134522.0 & 12.8 & 2.62 & $C$ & $\mathrm{C}_{\text {II }}$ \\
\hline G18.143-0.28 & $\ldots$ & 18.144 & -0.286 & 182212.4 & -131741.0 & 34.2 & 2.11 & $C$ & $\mathrm{C}_{\text {II }}$ \\
\hline G18.686+1.96 & $\mathrm{S} 54$ & 18.687 & +1.965 & 181508.0 & -114449.0 & 33.6 & 1.92 & $C$ & $\mathrm{C}_{\text {II }}$ \\
\hline G19.066-0.28 & $\cdots$ & 19.066 & -0.281 & 182357.7 & -122836.0 & 19.2 & 2.79 & $C$ & C II \\
\hline G19.608-0.23 & $\ldots$ & 19.608 & -0.233 & 182450.2 & -115836.0 & 9.6 & 3.87 & $D$ & $\mathrm{C}_{\text {II }}$ \\
\hline G20.733-0.09 & $\ldots$ & 20.734 & -0.087 & 182627.4 & -105449.0 & 42.4 & 0.99 & $A$ & ${ }^{3} \mathrm{He}$ \\
\hline $\mathrm{G} 23.421-0.21^{\mathrm{b}}$ & $\ldots$ & 23.421 & -0.214 & 183200.2 & -083544.0 & 20.8 & 2.90 & $C$ & $\mathrm{C}_{\text {II }}$ \\
\hline $\mathrm{G} 23.421-0.21^{\mathrm{b}}$ & $\ldots$ & 23.421 & -0.214 & 183200.2 & -083544.0 & 48.2 & 1.10 & $B$ & ${ }^{3} \mathrm{He}$ \\
\hline G23.706+0.17 & $\ldots$ & 23.706 & +0.173 & 183109.7 & -080951.0 & 50.8 & 0.95 & $C$ & ${ }^{3} \mathrm{He}$ \\
\hline $\mathrm{G} 24.467+0.48$ & $\ldots$ & 24.467 & +0.491 & 183127.2 & -072033.0 & 14.4 & 3.42 & $B$ & $\mathrm{C}_{\text {II }}$ \\
\hline $\mathrm{G} 24.484+0.21$ & $\ldots$ & 24.484 & +0.213 & 183228.7 & -072724.0 & 35.7 & 1.21 & $D$ & ${ }^{3} \mathrm{He}$ \\
\hline $\mathrm{G} 24.805+0.09$ & $\ldots$ & 24.805 & +0.101 & 183329.0 & -071330.0 & 23.2 & 2.77 & $C$ & $\mathrm{C}_{\text {II }}$ \\
\hline $\mathrm{G} 25.382-0.18^{\mathrm{b}}$ & 3C385 & 25.383 & -0.177 & 183532.6 & -065028.0 & 3.2 & 9.56 & $D$ & $\mathrm{C}_{\text {II }}$ \\
\hline $\mathrm{G} 25.382-0.18^{\mathrm{b}}$ & $3 \mathrm{C} 385$ & 25.378 & -0.178 & 183532.8 & -065045.0 & 25.5 & 1.61 & $A$ & ${ }^{3} \mathrm{He}$ \\
\hline $\mathrm{G} 25.766+0.21$ & $\ldots$ & 25.766 & +0.212 & 183452.5 & -061916.0 & 15.6 & 1.70 & $C$ & ${ }^{3} \mathrm{He}$ \\
\hline G28.790+3.48 & $\mathrm{S} 64 / \mathrm{W} 40$ & 28.790 & +3.486 & 182851.6 & -020729.0 & 11.2 & 3.00 & $B$ & $\mathrm{C}_{\text {II }}$ \\
\hline G29.944-0.04 & .. & 29.945 & -0.039 & 184331.2 & -024356.0 & 48.2 & 1.12 & $A$ & ${ }^{3} \mathrm{He}$ \\
\hline G30.776-0.03 & W43 & 30.777 & -0.028 & 184500.4 & -015916.0 & 14.0 & 2.37 & $A$ & ${ }^{3} \mathrm{He}$ \\
\hline G32.797+0.19 & $\ldots$ & 32.798 & +0.192 & 184756.8 & -000531.0 & 12.8 & 3.45 & $D$ & $\mathrm{C}_{\text {II }}$ \\
\hline G34.254+0.14 & NRAO 584 & 34.254 & +0.144 & 185047.8 & +011046.0 & 21.6 & 3.20 & $B$ & $\mathrm{C}_{\text {II }}$ \\
\hline G35.194-1.75 & W48 & 35.194 & -1.750 & 185915.3 & +010829.0 & 12.8 & 3.56 & $A$ & $\mathrm{C}_{\text {II }}$ \\
\hline $\mathrm{G} 40.505+2.54$ & S76 & 40.505 & +2.539 & 185348.0 & +074941.0 & 51.0 & 0.87 & $C$ & ${ }^{3} \mathrm{He}$ \\
\hline $\mathrm{G} 43.169+0.00^{\mathrm{b}}$ & W49 & 43.170 & +0.002 & 190752.1 & +090108.0 & 10.4 & 4.51 & $A$ & $\mathrm{C}_{\text {II }}$ \\
\hline
\end{tabular}


Table 1-Continued

\begin{tabular}{|c|c|c|c|c|c|c|c|c|c|}
\hline Source & Name & $\begin{array}{c}1 \\
\left({ }^{\circ}\right)\end{array}$ & $\begin{array}{c}\mathrm{b} \\
\left({ }^{\circ}\right)\end{array}$ & $\begin{array}{c}\mathrm{RA}(1950.0) \\
(\mathrm{hr} \min \mathrm{s})\end{array}$ & $\begin{array}{c}\operatorname{DEC}(1950.0) \\
\left({ }^{\circ} \prime \prime \prime\right)\end{array}$ & $\begin{array}{c}t_{\text {intg }}^{\dagger} \\
(h r)\end{array}$ & $\begin{array}{l}r m s^{\dagger} \\
(\mathrm{mK})\end{array}$ & $\mathrm{QF}^{\sharp}$ & survey \\
\hline $\mathrm{G} 43.169+0.00^{\mathrm{b}}$ & W49 & 43.171 & +0.003 & 190752.0 & +0901 14.0 & 13.6 & 2.70 & $A$ & ${ }^{3} \mathrm{He}$ \\
\hline $\mathrm{G} 45.451+0.06$ & $\mathrm{~K} 47$ & 45.451 & +0.060 & 191159.5 & +110349.0 & 28.0 & 2.31 & $C$ & $\mathrm{C}_{\text {II }}$ \\
\hline G46.495-0.25 & $\ldots$ & 46.495 & -0.247 & 191506.0 & +115027.0 & 17.2 & 1.75 & $C$ & ${ }^{3} \mathrm{He}$ \\
\hline G48.930-0.28 & $\cdots$ & 48.930 & -0.284 & 191958.2 & +135803.0 & 23.2 & 2.74 & $B$ & $\mathrm{C}_{\mathrm{II}}$ \\
\hline G48.997-0.29 & $\ldots$ & 48.998 & -0.293 & 192008.0 & +140120.0 & 30.4 & 2.13 & $B$ & $\mathrm{C}_{\text {II }}$ \\
\hline G49.204-0.34 & $\ldots$ & 49.205 & -0.343 & 192043.3 & +141050.0 & 28.8 & 1.93 & $B$ & C II \\
\hline $\mathrm{G} 49.384-0.30^{\mathrm{b}}$ & $\ldots$ & 49.384 & -0.298 & 192054.3 & +142140.0 & 3.2 & 6.72 & $C$ & $\mathrm{C}_{\text {II }}$ \\
\hline $\mathrm{G} 49.384-0.30^{\mathrm{b}}$ & $\ldots$ & 49.375 & -0.305 & 192055.0 & +142055.0 & 65.2 & 1.04 & $A$ & ${ }^{3} \mathrm{He}$ \\
\hline G49.486-0.38 b & W51 & 49.487 & -0.378 & 192124.4 & +142440.0 & 3.2 & 10.11 & $A$ & $\mathrm{C}_{\mathrm{II}}$ \\
\hline $\mathrm{G} 49.486-0.38^{\mathrm{b}}$ & W51 & 49.488 & -0.380 & 192124.4 & +142448.0 & 23.2 & 2.15 & $A$ & ${ }^{3} \mathrm{He}$ \\
\hline G49.582-0.38 & $\cdots$ & 49.583 & -0.381 & 192135.8 & +142944.0 & 6.4 & 4.25 & $A$ & $\mathrm{C}_{\text {II }}$ \\
\hline $\mathrm{G} 61.470+0.09$ & $\mathrm{~S} 88$ & 61.471 & +0.091 & 194442.4 & +250502.0 & 25.3 & 2.28 & $C$ & $\mathrm{C}_{\text {II }}$ \\
\hline $\mathrm{G} 63.168+0.46$ & $\mathrm{~S} 90$ & 63.168 & +0.461 & 194708.0 & +264400.0 & 79.8 & 0.64 & $A$ & ${ }^{3} \mathrm{He}$ \\
\hline G70.300+1.60 & $\mathrm{K} 3-50$ & 70.301 & +1.601 & 195951.3 & +332441.0 & 15.2 & 3.21 & $C$ & $\mathrm{C}_{\text {II }}$ \\
\hline G75.834+0.40 & $\ldots$ & 75.834 & +0.402 & 201946.3 & +372135.0 & 28.8 & 1.94 & $C$ & $\mathrm{C}_{\text {II }}$ \\
\hline G76.383-0.62 & S106 & 76.384 & -0.623 & 202534.2 & +371246.0 & 18.8 & 2.52 & $D$ & C II \\
\hline $\mathrm{G} 79.293+1.30^{\mathrm{b}}$ & DR 7 & 79.294 & +1.297 & 202621.9 & +404142.0 & 49.0 & 1.69 & $B$ & $\mathrm{C}_{\text {II }}$ \\
\hline $\mathrm{G} 79.293+1.30^{\mathrm{b}}$ & DR 7 & 79.293 & +1.296 & 202621.9 & +404142.0 & 32.6 & 1.17 & $B$ & ${ }^{3} \mathrm{He}$ \\
\hline G81.681+0.54 & DR 21 & 81.681 & +0.540 & 203714.0 & +420906.0 & 36.8 & 2.02 & $A$ & $\mathrm{C}_{\text {II }}$ \\
\hline G93.060+2.81 & $\cdots$ & 93.060 & +2.810 & 211045.5 & +521635.0 & 38.8 & 0.97 & $C$ & ${ }^{3} \mathrm{He}$ \\
\hline G102.88-0.72 & $\mathrm{S} 132$ & 102.875 & -0.721 & 221743.5 & +555207.0 & 59.1 & 0.75 & $E$ & ${ }^{3} \mathrm{He}$ \\
\hline G107.18-0.95 & S142 & 107.182 & -0.952 & 224551.7 & +574929.0 & 72.0 & 0.75 & $E$ & ${ }^{3} \mathrm{He}$ \\
\hline $\mathrm{G} 110.11+0.04$ & $\mathrm{~S} 156$ & 110.105 & +0.045 & 230304.3 & +595820.0 & 35.9 & 0.98 & $D$ & ${ }^{3} \mathrm{He}$ \\
\hline $\mathrm{G} 111.53+0.82$ & S158/NGC 7538 & 111.527 & +0.816 & 231121.8 & +611338.0 & 50.8 & 0.98 & $A$ & ${ }^{3} \mathrm{He}$ \\
\hline $\mathrm{G} 112.24+0.23$ & S162/NGC 7635 & 112.219 & +0.224 & 231828.1 & +605511.0 & 45.2 & 0.81 & $C$ & ${ }^{3} \mathrm{He}$ \\
\hline $\mathrm{G} 118.15+4.96$ & S171 A & 118.120 & +5.023 & 235834.9 & +670835.0 & 75.3 & 0.80 & $C$ & ${ }^{3} \mathrm{He}$ \\
\hline G133.72+1.21 & W3 & 133.720 & +1.223 & 022156.9 & +615240.0 & 82.4 & 0.89 & $A$ & ${ }^{3} \mathrm{He}$ \\
\hline G133.790+1.4 & $\ldots$ & 133.789 & +1.410 & 022304.0 & +620142.0 & 45.8 & 0.89 & $A$ & ${ }^{3} \mathrm{He}$ \\
\hline G150.59-0.95 & S206 & 150.592 & -0.950 & 035929.8 & +511038.0 & 44.6 & 0.95 & $B$ & ${ }^{3} \mathrm{He}$ \\
\hline $\mathrm{G} 151.587-0.2^{\mathrm{a}}$ & S209 N & 151.587 & -0.221 & 040719.7 & +510334.0 & 20.0 & 1.33 & $C$ & ${ }^{3} \mathrm{He}$ \\
\hline $\mathrm{G} 151.59-0.23^{\mathrm{a}}$ & S209 & 151.605 & -0.240 & 040719.7 & +510158.0 & 69.1 & 0.65 & $B$ & ${ }^{3} \mathrm{He}$ \\
\hline G151.636-0.5 & S209 S & 151.636 & -0.473 & 040628.0 & +505023.0 & 105.2 & 0.59 & $E$ & ${ }^{3} \mathrm{He}$ \\
\hline G155.36+2.61 & $\mathrm{S} 212$ & 155.356 & +2.610 & 043646.8 & +502158.0 & 96.6 & 0.63 & $D$ & ${ }^{3} \mathrm{He}$ \\
\hline G169.19-0.90 & $\mathrm{S} 228$ & 169.190 & -0.902 & 051001.8 & +372332.0 & 70.9 & 0.90 & $E$ & ${ }^{3} \mathrm{He}$ \\
\hline $\mathrm{G} 173.60+2.80$ & $\mathrm{~S} 235$ & 173.599 & +2.797 & 053737.8 & +354935.0 & 58.2 & 0.73 & $D$ & ${ }^{3} \mathrm{He}$ \\
\hline $\mathrm{G} 189.97+0.40$ & $\mathrm{~S} 252$ & 189.969 & +0.395 & 060611.8 & +203059.0 & 89.8 & 0.70 & $E$ & ${ }^{3} \mathrm{He}$ \\
\hline $\mathrm{G} 201.6+1.6$ & $\ldots$ & 201.661 & +1.645 & 063350.0 & +104903.0 & 97.1 & 0.61 & $D$ & ${ }^{3} \mathrm{He}$ \\
\hline G206.122-2.3 & Rosette B & 206.122 & -2.329 & 062800.0 & +050115.0 & 78.2 & 0.73 & $D$ & ${ }^{3} \mathrm{He}$ \\
\hline G206.618-1.8 ${ }^{\mathrm{a}}$ & Rosette A & 206.618 & -1.789 & 063051.1 & +045000.0 & 70.8 & 0.67 & $D$ & ${ }^{3} \mathrm{He}$ \\
\hline G209.01-19.4 & Ori A & 209.009 & -19.385 & 053249.0 & -052516.0 & 0.2 & 32.36 & $B$ & ${ }^{3} \mathrm{He}$ \\
\hline G213.71-12.6 & MONR 2 & 213.699 & -12.607 & 060519.0 & -062229.0 & 24.8 & 1.66 & $D$ & ${ }^{3} \mathrm{He}$ \\
\hline G220.508-2.8 & $\mathrm{S} 291$ & 220.508 & -2.776 & 065257.3 & -075630.0 & 72.0 & 1.02 & $E$ & ${ }^{3} \mathrm{He}$ \\
\hline G223.7-1.9 & $\ldots$ & 223.699 & -1.923 & 070157.6 & -102250.0 & 6.2 & 2.78 & $E$ & ${ }^{3} \mathrm{He}$ \\
\hline G227.79-0.12 & S298/NGC 2359 & 227.785 & -0.116 & 071617.0 & -130902.0 & 108.8 & 0.63 & $E$ & ${ }^{3} \mathrm{He}$ \\
\hline G231.48-4.40 & RCW 6 & 231.480 & -4.401 & 070741.9 & -182457.0 & 56.4 & 0.80 & $D$ & ${ }^{3} \mathrm{He}$ \\
\hline
\end{tabular}




\section{Table 1 -Continued}

\begin{tabular}{|c|c|c|c|c|c|c|c|c|c|}
\hline Source & Name & $\begin{array}{c}1 \\
\left({ }^{\circ}\right)\end{array}$ & $\begin{array}{l}\mathrm{b} \\
\left({ }^{\circ}\right)\end{array}$ & $\begin{array}{c}\mathrm{RA}(1950.0) \\
(\mathrm{hr} \min \mathrm{s})\end{array}$ & $\begin{array}{c}\operatorname{DEC}(1950.0) \\
\left({ }^{\circ} \prime \prime \prime\right)\end{array}$ & $\begin{array}{l}t_{\text {intg }}^{\dagger} \\
(h r)^{-}\end{array}$ & $\begin{array}{l}r m s^{\dagger} \\
(\mathrm{mK})\end{array}$ & $\mathrm{QF}^{\sharp}$ & survey \\
\hline $\mathrm{G} 243.16+0.37$ & S311 & 243.158 & +0.371 & 075018.4 & -261753.0 & 57.6 & 0.90 & $B$ & ${ }^{3} \mathrm{He}$ \\
\hline G345.03+1.54 & $\cdots$ & 345.032 & +1.543 & 165425.6 & -401816.0 & 2.4 & 7.59 & $D$ & $\mathrm{C}$ II \\
\hline G345.23+1.03 & $\ldots$ & 345.233 & +1.042 & 165709.3 & -402746.0 & 19.2 & 3.28 & $E$ & $\mathrm{C}_{\text {II }}$ \\
\hline G345.31+1.47 & $\cdots$ & 345.309 & +1.476 & 165536.9 & -400751.0 & 30.4 & 2.30 & $C$ & $\mathrm{C}_{\text {II }}$ \\
\hline G345.40+1.41 & $\ldots$ & 345.310 & +1.473 & 165611.6 & -400548.0 & 3.2 & 7.63 & $D$ & $\mathrm{C}_{\text {II }}$ \\
\hline G345.43-0.94 & $\cdots$ & 345.426 & -0.934 & 170604.3 & -413053.0 & 12.8 & 4.52 & $A$ & $\mathrm{C}_{\text {II }}$ \\
\hline G345.54+0.10 & $\ldots$ & 346.539 & +0.100 & 170513.9 & -400003.0 & 9.6 & 4.27 & $E$ & $\mathrm{C}_{\text {II }}$ \\
\hline G347.96-0.44 & $\ldots$ & 347.965 & -0.436 & 171152.3 & -391029.0 & 12.8 & 3.47 & $D$ & $\mathrm{C}_{\text {II }}$ \\
\hline G348.23-0.98 & $\ldots$ & 348.232 & -0.981 & 171457.1 & -391629.0 & 19.2 & 3.74 & $C$ & $\mathrm{C}_{\text {II }}$ \\
\hline G348.72-1.03 & $\ldots$ & 348.717 & -1.030 & $17 \quad 1636.1$ & -385429.0 & 20.0 & 5.20 & $B$ & $\mathrm{C}_{\text {II }}$ \\
\hline G350.13+0.09 & $\ldots$ & 350.129 & +0.091 & 171606.5 & -370630.0 & 6.4 & 6.96 & $D$ & $\mathrm{C}_{\text {II }}$ \\
\hline G351.063+0.6 & $\ldots$ & 351.063 & +0.663 & 171627.8 & -360050.0 & 9.6 & 4.31 & $D$ & $\mathrm{C}_{\text {II }}$ \\
\hline G351.192+0.7 & $\cdots$ & 351.193 & +0.709 & 171638.7 & -355255.0 & 17.6 & 3.23 & $A$ & $\mathrm{C}_{\text {II }}$ \\
\hline $\mathrm{G} 351.201+0.4$ & $\ldots$ & 351.201 & +0.485 & 171734.8 & -360015.0 & 9.6 & 4.04 & $C$ & $\mathrm{C}_{\text {II }}$ \\
\hline $\mathrm{G} 351.246+0.7^{\mathrm{a}}$ & NGC 6334 A & 351.246 & +0.673 & 171657.8 & -355145.0 & 19.4 & 2.42 & $B$ & ${ }^{3} \mathrm{He}$ \\
\hline G351.358+0.6 & $\mathrm{S} 8$ & 351.358 & +0.667 & $17 \quad 17 \quad 17.2$ & -354614.0 & 12.8 & 4.71 & $A$ & $\mathrm{C}_{\text {II }}$ \\
\hline $\mathrm{G} 351.368+0.7^{\mathrm{a}}$ & NGC $6334 \mathrm{D}$ & 351.368 & +0.650 & 171723.0 & -354620.0 & 17.2 & 2.46 & $A$ & ${ }^{3} \mathrm{He}$ \\
\hline G351.467-0.4 & $\cdots$ & 351.468 & -0.458 & 172210.7 & -361928.0 & 12.6 & 3.25 & $C$ & $\mathrm{C}_{\text {II }}$ \\
\hline G351.613-1.2 & $\ldots$ & 351.613 & -1.268 & 172554.8 & -363926.0 & 9.5 & 4.58 & $A$ & $\mathrm{C}_{\text {II }}$ \\
\hline G351.64-1.26 & $\cdots$ & 351.643 & -1.254 & 172556.0 & -363730.0 & 8.8 & 5.14 & $B$ & $\mathrm{C}_{\text {II }}$ \\
\hline G351.69-1.17 & $\ldots$ & 351.696 & -1.164 & 172542.3 & -363150.0 & 24.6 & 2.67 & $B$ & $\mathrm{C}_{\text {II }}$ \\
\hline G352.61-0.17 & $\cdots$ & 352.611 & -0.170 & 172410.3 & -351258.0 & 11.2 & 3.61 & $C$ & $\mathrm{C}_{\mathrm{II}}$ \\
\hline G353.035+0.7 & $\ldots$ & 353.036 & +0.749 & 172138.2 & -342050.0 & 18.4 & 3.06 & $C$ & $\mathrm{C}_{\text {II }}$ \\
\hline G353.08+0.36 & $\cdots$ & 353.083 & +0.359 & 172319.8 & -343140.0 & 6.4 & 4.16 & $C$ & $\mathrm{C}_{\text {II }}$ \\
\hline G353.14+0.66 & $\ldots$ & 353.136 & +0.662 & 172215.9 & -341849.0 & 9.6 & 4.72 & $B$ & $\mathrm{C}_{\text {II }}$ \\
\hline G353.186+0.8 & $\mathrm{S} 11$ & 353.187 & +0.888 & 172129.8 & -340838.0 & 9.5 & 6.61 & $B$ & $\mathrm{C}_{\text {II }}$ \\
\hline G353.21+0.91 & $\cdots$ & 353.206 & +0.906 & 172128.7 & -340703.0 & 18.4 & 4.48 & $B$ & $\mathrm{C}_{\text {II }}$ \\
\hline G353.398-0.3 & $\ldots$ & 353.399 & -0.390 & $1727 \quad 12.2$ & -344106.0 & 12.6 & 3.70 & $C$ & $\mathrm{C}_{\text {II }}$ \\
\hline G353.43-0.37 & $\cdots$ & 353.431 & -0.367 & 172711.8 & -343843.0 & 12.8 & 3.31 & $C$ & $\mathrm{C}$ II \\
\hline
\end{tabular}

${ }^{\dagger} t_{\text {intg }}$ and $r m s$ correspond to the spectral line data.

\#Spectral line quality factor. See text. QF is an evaluation of the quality of the parameters measured for the spectra as a whole. It is based on the signal-to-noise ratio, the structure of the baseline, the crowding of spectral lines, and the accuracy of the Gaussian fit to the line shape.

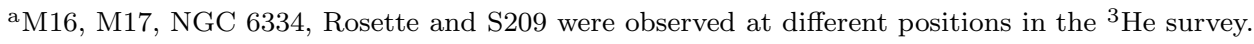

${ }^{\mathrm{b}}$ Observed in both $\mathrm{C}$ II and ${ }^{3} \mathrm{He}$ surveys. 
Table 2. Hydrogen Radio Recombination Line Parameters

\begin{tabular}{|c|c|c|c|c|c|c|c|}
\hline Source & $\begin{array}{c}T_{L} \\
(\mathrm{mK})\end{array}$ & $\begin{array}{c}\sigma T_{L} \\
(\mathrm{mK})\end{array}$ & $\begin{array}{c}\Delta v \\
\left(\mathrm{~km} \mathrm{~s}^{-1}\right)\end{array}$ & $\begin{array}{c}\sigma \Delta v \\
\left(\mathrm{~km} \mathrm{~s}^{-1}\right)\end{array}$ & $\begin{array}{c}V^{\ddagger} \\
\left(\mathrm{km} \mathrm{s}^{-1}\right)\end{array}$ & $\begin{array}{c}\sigma V^{\ddagger} \\
\left(\mathrm{km} \mathrm{s}^{-1}\right)\end{array}$ & $\mathrm{QF}^{\sharp}$ \\
\hline G0.605+0.325 & 14.92 & 0.58 & 26.03 & 1.17 & -2.88 & 0.50 & $D$ \\
\hline G0.665-0.035 & 474.49 & 4.03 & 40.54 & 0.40 & 64.31 & 0.17 & $C$ \\
\hline G1.13-0.1 & 141.84 & 0.81 & 24.53 & 0.16 & -19.91 & 0.07 & $B$ \\
\hline $\mathrm{G} 2.90+0.0$ & 26.76 & 0.38 & 22.98 & 0.37 & -2.08 & 0.16 & $C$ \\
\hline G3.270-0.101 & 50.16 & 0.63 & 25.34 & 0.37 & 7.10 & 0.16 & $B$ \\
\hline G5.899-0.427 & 219.48 & 1.50 & 22.50 & 0.18 & 9.90 & 0.06 & $B$ \\
\hline G5.956-1.265 & 464.75 & 3.90 & 26.15 & 0.25 & 2.61 & 0.07 & $B$ \\
\hline G5.973-1.178 & 526.18 & 4.15 & 26.53 & 0.24 & 2.69 & 0.07 & $B$ \\
\hline $\mathrm{G} 8.137+0.228$ & 186.96 & 0.96 & 25.44 & 0.15 & 20.31 & 0.06 & $B$ \\
\hline G10.159-0.34 & 914.96 & 4.04 & 31.25 & 0.17 & 13.29 & 0.04 & $B$ \\
\hline G10.315-0.15 & 263.87 & 1.22 & 31.64 & 0.17 & 10.25 & 0.06 & $B$ \\
\hline G10.617-0.38 & 152.54 & 1.10 & 26.71 & 0.22 & -1.09 & 0.08 & $B$ \\
\hline G12.807-0.20 & 789.00 & 6.20 & 30.69 & 0.30 & 34.86 & 0.10 & $C$ \\
\hline $\mathrm{G} 13.875+0.28$ & 152.73 & 1.30 & 22.47 & 0.22 & 50.28 & 0.08 & $C$ \\
\hline $\mathrm{G} 14.626+0.08$ & 148.47 & 1.08 & 17.42 & 0.30 & 37.07 & 0.10 & $C$ \\
\hline G15.035-0.68 ${ }^{\mathrm{a}}$ & 3619.15 & 24.61 & 35.30 & 0.28 & 16.76 & 0.12 & $C$ \\
\hline G15.095-0.71 & 1573.09 & 10.70 & 35.30 & 0.28 & 19.82 & 0.12 & $B$ \\
\hline G15.181-0.62 & 166.13 & 1.39 & 28.37 & 0.34 & 16.95 & 0.12 & $C$ \\
\hline G15.198-0.76 & 127.07 & 1.34 & 22.68 & 0.30 & 23.73 & 0.12 & $C$ \\
\hline G16.936+0.76 b & 179.09 & 2.79 & 24.26 & 0.50 & 26.04 & 0.18 & $C$ \\
\hline $\mathrm{G} 16.936+0.76^{\mathrm{a}, c}$ & $=175.06$ & 2.35 & 26.17 & 0.41 & 26.03 & 0.17 & $C$ \\
\hline $\mathrm{G} 16.984+0.93^{\mathrm{a}, c}$ & $=178.52$ & 0.97 & 23.65 & 0.15 & 25.36 & 0.06 & $B$ \\
\hline $\mathrm{G} 16.995+0.86$ & 168.74 & 1.25 & 24.92 & 0.21 & 24.98 & 0.08 & $C$ \\
\hline G18.143-0.28 & 176.71 & 1.16 & 25.17 & 0.21 & 53.53 & 0.07 & $C$ \\
\hline $\mathrm{G} 18.686+1.96$ & 154.85 & 0.89 & 28.35 & 0.19 & 27.58 & 0.06 & $B$ \\
\hline G19.066-0.28 & 164.75 & 1.75 & 25.25 & 0.31 & 64.36 & 0.11 & $C$ \\
\hline G19.608-0.23 & 168.48 & 1.68 & 26.53 & 0.41 & 42.46 & 0.11 & $C$ \\
\hline G20.733-0.09 & 141.03 & 0.46 & 26.51 & 0.10 & 55.96 & 0.04 & $A$ \\
\hline $\mathrm{G} 23.421-0.21^{\mathrm{b}}$ & 202.34 & 0.99 & 24.33 & 0.15 & 101.75 & 0.05 & $B$ \\
\hline $\mathrm{G} 23.421-0.21^{\mathrm{c}}$ & 212.30 & 0.95 & 23.78 & 0.13 & 102.14 & 0.05 & $B$ \\
\hline $\mathrm{G} 23.706+0.17$ & 70.89 & 0.88 & 26.83 & 0.39 & 104.35 & 0.16 & $C$ \\
\hline $\mathrm{G} 24.467+0.48$ & 140.77 & 0.82 & 29.22 & 0.53 & 100.09 & 0.11 & $B$ \\
\hline $\mathrm{G} 24.484+0.21$ & 85.69 & 1.01 & 25.99 & 0.35 & 116.00 & 0.15 & $C$ \\
\hline $\mathrm{G} 24.805+0.09$ & 161.89 & 1.15 & 24.90 & 0.21 & 108.21 & 0.07 & $B$ \\
\hline G25.382-0.18 & 323.46 & 2.53 & 22.92 & 0.21 & 59.60 & 0.09 & $B$ \\
\hline $\mathrm{G} 25.382-0.18^{\mathrm{c}}$ & 317.79 & 0.85 & 25.59 & 0.10 & 59.30 & 0.04 & $B$ \\
\hline G25.766+0.21 & 110.63 & 1.42 & 27.31 & 0.40 & 111.44 & 0.17 & $C$ \\
\hline $\mathrm{G} 28.790+3.48$ & 276.39 & 1.30 & 21.90 & 0.12 & 0.10 & 0.05 & $A$ \\
\hline G29.944-0.04 & 233.17 & 0.96 & 29.75 & 0.14 & 96.79 & 0.06 & $A$ \\
\hline G30.776-0.03 & 783.82 & 2.23 & 32.52 & 0.11 & 92.02 & 0.04 & $A$ \\
\hline G32.797+0.19 & 101.74 & 1.01 & 28.51 & 0.41 & 15.46 & 0.15 & $C$ \\
\hline G34.254+0.14 & 333.52 & 1.08 & 24.31 & 0.11 & 53.99 & 0.05 & $B$ \\
\hline G35.194-1.75 & 412.13 & 1.89 & 23.55 & 0.14 & 46.66 & 0.04 & $A$ \\
\hline $\mathrm{G} 40.505+2.54$ & 88.35 & 0.48 & 22.91 & 0.14 & 23.31 & 0.06 & $A$ \\
\hline $\mathrm{G} 43.169+0.00^{\mathrm{b}}$ & 918.69 & 4.03 & 29.27 & 0.15 & 8.70 & 0.04 & $A$ \\
\hline
\end{tabular}


Table 2-Continued

\begin{tabular}{|c|c|c|c|c|c|c|c|}
\hline Source & $\begin{array}{c}T_{L} \\
(\mathrm{mK})\end{array}$ & $\begin{array}{l}\sigma T_{L} \\
(\mathrm{mK})\end{array}$ & $\begin{array}{c}\Delta v \\
\left(\mathrm{~km} \mathrm{~s}^{-1}\right)\end{array}$ & $\begin{array}{c}\sigma \Delta v \\
\left(\mathrm{~km} \mathrm{~s}^{-1}\right)\end{array}$ & $\begin{array}{c}V^{\ddagger} \\
\left(\mathrm{km} \mathrm{s}^{-1}\right)\end{array}$ & $\begin{array}{c}\sigma V^{\ddagger} \\
\left(\mathrm{km} \mathrm{s}^{-1}\right)\end{array}$ & $\mathrm{QF}^{\sharp}$ \\
\hline $\mathrm{G} 43.169+0.00^{\mathrm{c}}$ & 813.59 & 2.66 & 28.64 & 0.11 & 8.64 & 0.05 & $A$ \\
\hline $\mathrm{G} 45.451+0.06$ & 177.68 & 1.01 & 27.32 & 0.18 & 55.93 & 0.05 & $B$ \\
\hline G46.495-0.25 & 110.71 & 1.00 & 20.09 & 0.21 & 57.09 & 0.09 & $B$ \\
\hline G48.930-0.28 & 254.50 & 1.28 & 26.74 & 0.17 & 65.86 & 0.06 & $B$ \\
\hline G48.997-0.29 & 234.05 & 1.17 & 24.43 & 0.16 & 66.86 & 0.05 & $B$ \\
\hline G49.204-0.34 & 256.76 & 1.05 & 30.32 & 0.15 & 67.79 & 0.05 & $A$ \\
\hline $\mathrm{G} 49.384-0.30^{\mathrm{b}}$ & 233.32 & 1.93 & 31.55 & 0.30 & 67.38 & 0.13 & $C$ \\
\hline $\mathrm{G} 49.384-0.30^{\mathrm{c}}$ & 394.59 & 0.87 & 28.44 & 0.07 & 53.76 & 0.03 & $A$ \\
\hline $\mathrm{G} 49.486-0.38^{\mathrm{b}}$ & 1692.06 & 2.88 & 30.87 & 0.06 & 58.71 & 0.03 & $A$ \\
\hline $\mathrm{G} 49.486-0.38^{\mathrm{c}}$ & 1700.73 & 2.07 & 30.57 & 0.04 & 58.40 & 0.02 & $A$ \\
\hline G49.582-0.38 & 593.99 & 1.94 & 29.73 & 0.11 & 56.96 & 0.04 & $A$ \\
\hline G61.470+0.09 & 142.21 & 0.78 & 25.49 & 0.16 & 27.49 & 0.07 & $B$ \\
\hline $\mathrm{G} 63.168+0.46$ & 87.58 & 0.54 & 23.94 & 0.17 & 17.24 & 0.07 & $A$ \\
\hline $\mathrm{G} 70.300+1.60$ & 194.09 & 1.21 & 27.86 & 0.22 & -23.11 & 0.08 & $C$ \\
\hline G75.834+0.40 & 185.51 & 0.60 & 30.00 & 0.11 & -3.66 & 0.05 & $B$ \\
\hline G76.383-0.62 & 126.25 & 1.27 & 36.77 & 0.54 & 3.48 & 0.19 & $C$ \\
\hline $\mathrm{G} 79.293+1.30^{\mathrm{b}}$ & 157.17 & 0.93 & 30.72 & 0.21 & -39.17 & 0.07 & $B$ \\
\hline $\mathrm{G} 79.293+1.30^{\mathrm{c}}$ & 154.84 & 0.93 & 30.24 & 0.21 & -39.27 & 0.09 & $A$ \\
\hline $\mathrm{G} 81.681+0.54$ & 363.26 & 1.15 & 34.97 & 0.13 & 0.06 & 0.04 & $A$ \\
\hline G93.060+2.81 & 26.87 & 0.51 & 24.79 & 0.54 & -63.35 & 0.23 & $C$ \\
\hline G102.88-0.72 & 9.92 & 0.35 & 23.95 & 0.98 & -49.48 & 0.42 & $D$ \\
\hline G107.18-0.95 & 17.47 & 0.30 & 29.33 & 0.59 & -37.54 & 0.25 & $D$ \\
\hline $\mathrm{G} 110.11+0.04$ & 31.93 & 0.40 & 37.41 & 0.55 & -49.55 & 0.23 & $C$ \\
\hline $\mathrm{G} 111.53+0.82$ & 327.44 & 0.92 & 27.38 & 0.09 & -59.74 & 0.04 & $A$ \\
\hline $\mathrm{G} 112.24+0.23$ & 39.17 & 0.44 & 25.94 & 0.36 & -44.32 & 0.15 & $B$ \\
\hline $\mathrm{G} 118.15+4.96$ & 34.95 & 0.38 & 20.68 & 0.26 & -7.04 & 0.11 & $B$ \\
\hline $\mathrm{G} 133.72+1.21$ & 912.91 & 2.60 & 27.45 & 0.09 & -40.68 & 0.04 & $A$ \\
\hline G133.790+1.4 & 220.68 & 1.84 & 28.11 & 0.27 & -47.65 & 0.12 & $B$ \\
\hline G150.59-0.95 & 79.42 & 0.44 & 27.44 & 0.17 & -25.78 & 0.07 & $A$ \\
\hline $\mathrm{G} 151.587-0.2^{\mathrm{a}}$ & 53.02 & 0.75 & 27.48 & 0.45 & -49.12 & 0.19 & $B$ \\
\hline $\mathrm{G} 151.59-0.23^{\mathrm{a}}$ & 79.75 & 0.39 & 28.27 & 0.16 & -49.69 & 0.07 & $A$ \\
\hline G151.636-0.5 & 10.97 & 0.26 & 27.00 & 0.74 & -57.99 & 0.32 & $C$ \\
\hline $\mathrm{G} 155.36+2.61$ & 18.14 & 0.27 & 25.12 & 0.43 & -43.08 & 0.18 & $C$ \\
\hline G169.19-0.90 & 15.54 & 0.44 & 23.16 & 0.75 & -14.96 & 0.32 & $D$ \\
\hline $\mathrm{G} 173.60+2.80$ & 41.16 & 0.40 & 20.52 & 0.23 & -23.07 & 0.10 & $B$ \\
\hline $\mathrm{G} 189.97+0.40$ & 21.48 & 0.35 & 24.56 & 0.46 & 10.52 & 0.20 & $C$ \\
\hline G201.6+1.6 & 16.74 & 0.17 & 25.33 & 0.46 & 25.29 & 0.20 & $B$ \\
\hline $\mathrm{G} 206.122-2.3^{\mathrm{a}}$ & 22.84 & 0.39 & 23.62 & 0.47 & 18.06 & 0.20 & $C$ \\
\hline G206.618-1.8 ${ }^{\mathrm{a}}$ & 20.75 & 0.33 & 26.83 & 0.49 & 17.10 & 0.21 & $C$ \\
\hline G209.01-19.4 & 4276.50 & 11.29 & 26.78 & 0.08 & -2.69 & 0.04 & $A$ \\
\hline G213.71-12.6 & 161.41 & 1.64 & 28.78 & 0.34 & 11.60 & 0.14 & $D$ \\
\hline G220.508-2.8 & 3.27 & 0.58 & 18.80 & 4.77 & 66.46 & 1.70 & $E$ \\
\hline G223.7-1.9 & 9.33 & 1.45 & 19.99 & 3.81 & 15.94 & 1.53 & $E$ \\
\hline G227.79-0.12 & 5.73 & 0.26 & 35.27 & 1.86 & 48.10 & 0.79 & $E$ \\
\hline $\mathrm{G} 231.48-4.40$ & 20.55 & 0.47 & 21.39 & 0.56 & 55.03 & 0.24 & $C$ \\
\hline
\end{tabular}


Table 2-Continued

\begin{tabular}{|c|c|c|c|c|c|c|c|}
\hline Source & $\begin{array}{c}T_{L} \\
(\mathrm{mK})\end{array}$ & $\begin{array}{l}\sigma T_{L} \\
(\mathrm{mK})\end{array}$ & $\begin{array}{c}\Delta v \\
\left(\mathrm{~km} \mathrm{~s}^{-1}\right)\end{array}$ & $\begin{array}{c}\sigma \Delta v \\
\left(\mathrm{~km} \mathrm{~s}^{-1}\right)\end{array}$ & $\begin{array}{c}V^{\ddagger} \\
\left(\mathrm{km} \mathrm{s}^{-1}\right)\end{array}$ & $\begin{array}{c}\sigma V^{\ddagger} \\
\left(\mathrm{km} \mathrm{s}^{-1}\right)\end{array}$ & $\mathrm{QF}^{\sharp}$ \\
\hline $\mathrm{G} 243.16+0.37$ & 62.35 & 0.44 & 22.43 & 0.18 & 52.88 & 0.08 & $A$ \\
\hline G345.03+1.54 & 59.27 & 2.91 & 21.85 & 1.28 & -13.34 & 0.56 & $D$ \\
\hline G345.23+1.03 & 177.09 & 2.04 & 29.11 & 0.39 & -11.54 & 0.13 & $C$ \\
\hline G345.31+1.47 & 155.33 & 0.95 & 24.14 & 0.17 & -13.39 & 0.06 & $B$ \\
\hline G345.40+1.41 & 347.23 & 2.31 & 22.59 & 0.18 & -14.30 & 0.08 & $C$ \\
\hline G345.43-0.94 & 829.36 & 2.71 & 26.26 & 0.11 & -23.09 & 0.04 & $A$ \\
\hline G345.54+0.10 & 21.69 & 1.38 & 27.55 & 2.09 & 4.05 & 0.89 & $E$ \\
\hline G347.96-0.44 & 77.96 & 1.67 & 17.84 & 0.63 & -96.63 & 0.19 & $D$ \\
\hline G348.23-0.98 & 259.19 & 1.44 & 28.17 & 0.18 & -17.85 & 0.06 & $C$ \\
\hline G348.72-1.03 & 814.39 & 3.48 & 24.62 & 0.17 & -12.00 & 0.04 & $B$ \\
\hline G350.13+0.09 & 200.87 & 1.79 & 25.60 & 0.53 & -70.10 & 0.14 & $C$ \\
\hline G351.063+0.6 & 120.54 & 1.42 & 42.70 & 1.88 & -3.36 & 0.38 & $D$ \\
\hline G351.192+0.7 & 533.02 & 1.25 & 25.87 & 0.07 & 0.54 & 0.03 & $A$ \\
\hline G351.201+0.4 & 298.89 & 1.88 & 22.08 & 0.18 & -7.66 & 0.06 & $B$ \\
\hline $\mathrm{G} 351.246+0.7^{\mathrm{a}}$ & 585.35 & 2.01 & 24.12 & 0.10 & 0.56 & 0.04 & $A$ \\
\hline G351.358+0.6 & 872.66 & 2.78 & 23.92 & 0.09 & -3.43 & 0.02 & $A$ \\
\hline $\mathrm{G} 351.368+0.7^{\mathrm{a}}$ & 646.95 & 1.93 & 22.70 & 0.08 & -3.10 & 0.03 & $A$ \\
\hline G351.467-0.4 & 95.92 & 0.87 & 23.29 & 0.51 & -21.44 & 0.12 & $C$ \\
\hline G351.613-1.2 & 600.22 & 1.72 & 28.10 & 0.10 & -14.34 & 0.04 & $A$ \\
\hline G351.64-1.26 & 664.51 & 2.91 & 28.35 & 0.14 & -13.93 & 0.04 & $B$ \\
\hline G351.69-1.17 & 246.18 & 1.31 & 23.63 & 0.15 & -11.95 & 0.05 & $A$ \\
\hline G352.61-0.17 & 76.09 & 1.43 & 20.90 & 0.93 & -81.51 & 0.25 & $C$ \\
\hline G353.035+0.7 & 219.39 & 0.95 & 28.71 & 0.14 & -7.91 & 0.06 & $B$ \\
\hline G353.08+0.36 & 233.71 & 3.33 & 22.47 & 0.37 & -2.75 & 0.11 & $C$ \\
\hline G353.14+0.66 & 781.79 & 2.24 & 28.57 & 0.09 & -3.79 & 0.03 & $A$ \\
\hline G353.186+0.8 & 1095.99 & 5.61 & 30.78 & 0.18 & -3.71 & 0.05 & $A$ \\
\hline G353.21+0.91 & 1094.73 & 5.35 & 30.99 & 0.17 & -3.63 & 0.05 & $B$ \\
\hline G353.398-0.3 & 269.57 & 1.55 & 23.98 & 0.16 & -16.15 & 0.06 & $B$ \\
\hline G353.43-0.37 & 267.90 & 1.23 & 24.23 & 0.13 & -15.66 & 0.05 & $B$ \\
\hline
\end{tabular}

${ }^{\ddagger}$ Note that $V=V_{\mathrm{LSR}}$.

$\sharp$ Hydrogen line quality factor. See text. QF is a qualitative evaluation of the quality of the parameters measured for the $\mathrm{H}$ line. Most based in the accuracy of the Gaussian fit to the line shape.

${ }^{a}$ M16, M17, NGC 6334, Rosette and S209 were observed at different positions in the ${ }^{3}$ He survey.

b Observed in the CII survey.

${ }^{\mathrm{c}}$ Observed in the ${ }^{3}$ He survey. 
Table 3. Helium Radio Recombination Line Parameters

\begin{tabular}{|c|c|c|c|c|c|c|c|}
\hline Source & $\begin{array}{c}T_{L} \\
(\mathrm{mK})\end{array}$ & $\begin{array}{c}\sigma T_{L} \\
(\mathrm{mK})\end{array}$ & $\begin{array}{c}\Delta v \\
\left(\mathrm{~km} \mathrm{~s}^{-1}\right)\end{array}$ & $\begin{array}{c}\sigma \Delta v \\
\left(\mathrm{~km} \mathrm{~s}^{-1}\right)\end{array}$ & $\begin{array}{c}V \\
\left(\mathrm{~km} \mathrm{~s}^{-1}\right)\end{array}$ & $\begin{array}{c}\sigma V \\
\left(\mathrm{~km} \mathrm{~s}^{-1}\right)\end{array}$ & $\mathrm{QF}^{\sharp}$ \\
\hline G0.605+0.325 & 5.23 & 1.30 & 4.82 & 1.34 & -3.68 & 0.63 & E \\
\hline G0.665-0.035 & 26.89 & 5.10 & 27.51 & 8.55 & 63.74 & 3.30 & $B$ \\
\hline G1.13-0.1 & 11.26 & 0.91 & 20.22 & 2.03 & -19.96 & 0.81 & $C$ \\
\hline $\mathrm{G} 2.90+0.0$ & 1.87 & 0.46 & 17.13 & 1.96 & -8.55 & 2.62 & $D$ \\
\hline G3.270-0.101 & 5.20 & 0.44 & 18.88 & 2.16 & 4.88 & 1.95 & $D$ \\
\hline G5.899-0.427 & 20.75 & 1.35 & 18.85 & 2.00 & 9.17 & 0.61 & $C$ \\
\hline G5.956-1.265 & 46.90 & 1.24 & 19.15 & 0.67 & 0.89 & 0.26 & $B$ \\
\hline G5.973-1.178 & 51.70 & 1.82 & 19.76 & 0.97 & 0.78 & 0.29 & $C$ \\
\hline $\mathrm{G} 8.137+0.228$ & 18.42 & 0.71 & 22.64 & 1.32 & 21.83 & 0.55 & $C$ \\
\hline G10.159-0.34 & 37.82 & 1.39 & 25.41 & 1.21 & 10.17 & 0.42 & $B$ \\
\hline G10.315-0.15 & 19.88 & 0.82 & 29.55 & 1.66 & 10.02 & 0.57 & $B$ \\
\hline G10.617-0.38 & 10.79 & 0.29 & 22.18 & 1.47 & -0.81 & 0.39 & $D$ \\
\hline G12.807-0.20 & 50.74 & 1.09 & 22.52 & 0.58 & 35.83 & 0.29 & $B$ \\
\hline $\mathrm{G} 13.875+0.28$ & 13.27 & 1.17 & 15.38 & 1.57 & 50.54 & 0.39 & C \\
\hline G14.626+0.08 & 12.07 & 0.37 & 12.98 & 0.86 & 37.12 & 0.60 & C \\
\hline G15.035-0.68 & 398.44 & 0.35 & 29.31 & 3.36 & 15.18 & 1.21 & C \\
\hline G15.095-0.71 ${ }^{\mathrm{a}}$ & 155.98 & 4.42 & 33.55 & 1.12 & 19.33 & 0.47 & $B$ \\
\hline G15.181-0.62 & 13.09 & 0.29 & 21.14 & 1.40 & 17.20 & 0.40 & $D$ \\
\hline G15.198-0.76 & 14.75 & 0.33 & 16.90 & 1.12 & 25.64 & 1.09 & $D$ \\
\hline $\mathrm{G} 16.936+0.76^{\mathrm{b}}$ & 20.30 & 0.28 & 22.39 & 1.48 & 26.31 & 0.39 & $D$ \\
\hline $\mathrm{G} 16.936+0.76^{\mathrm{a}, c}$ & 16.74 & 0.43 & 19.50 & 2.23 & 27.63 & 1.54 & C \\
\hline $\mathrm{G} 16.984+0.93^{\mathrm{a}, c}$ & 19.19 & 1.02 & 22.26 & 1.44 & 25.75 & 0.58 & $C$ \\
\hline G16.995+0.86 & 15.65 & 1.02 & 18.04 & 1.46 & 27.66 & 0.62 & $C$ \\
\hline G18.143-0.28 & 10.31 & 0.60 & 20.33 & 1.55 & 54.04 & 0.41 & C \\
\hline G18.686+1.96 & 14.13 & 0.69 & 23.20 & 1.40 & 27.13 & 0.37 & $C$ \\
\hline G19.066-0.28 & 7.27 & 1.01 & 11.13 & 1.79 & 65.71 & 0.90 & $C$ \\
\hline G19.608-0.23 & 15.72 & 0.30 & 19.77 & 1.31 & 41.28 & 0.74 & $D$ \\
\hline G20.733-0.09 & 8.82 & 0.46 & 21.88 & 1.55 & 55.26 & 1.92 & $B$ \\
\hline $\mathrm{G} 23.421-0.21^{\mathrm{b}}$ & 21.25 & 0.87 & 30.22 & 2.26 & 101.47 & 0.56 & C \\
\hline $\mathrm{G} 23.421-0.21^{\mathrm{c}}$ & 12.25 & 1.03 & 20.29 & 2.07 & 102.31 & 0.84 & $B$ \\
\hline $\mathrm{G} 23.706+0.17$ & 6.33 & 0.43 & 19.99 & 2.29 & 106.09 & 2.00 & $C$ \\
\hline $\mathrm{G} 24.467+0.48$ & $\ldots$ & $\ldots$ & $\ldots$ & $\ldots$ & $\ldots$ & $\ldots$ & . \\
\hline $\mathrm{G} 24.484+0.21$ & 6.44 & 0.41 & 21.58 & 2.47 & 114.01 & 3.32 & $D$ \\
\hline $\mathrm{G} 24.805+0.09$ & 12.04 & 0.89 & 20.42 & 2.54 & 108.10 & 0.50 & $C$ \\
\hline $\mathrm{G} 25.382-0.18^{\mathrm{b}}$ & 27.39 & 2.39 & 15.91 & 1.64 & 59.32 & 0.50 & $D$ \\
\hline $\mathrm{G} 25.382-0.18^{\mathrm{c}}$ & 29.39 & 1.00 & 18.47 & 0.75 & 58.26 & 0.31 & $A$ \\
\hline $\mathrm{G} 25.766+0.21$ & 6.92 & 2.09 & 12.80 & 4.56 & 111.35 & 1.89 & $B$ \\
\hline $\mathrm{G} 28.790+3.48$ & 22.33 & 1.47 & 13.19 & 1.02 & -0.56 & 0.55 & $C$ \\
\hline G29.944-0.04 & 16.70 & 1.04 & 26.42 & 2.10 & 97.97 & 0.82 & $B$ \\
\hline G30.776-0.03 & 66.09 & 1.73 & 31.20 & 0.95 & 91.26 & 0.40 & $B$ \\
\hline $\mathrm{G} 32.797+0.19$ & 12.18 & 0.28 & 23.68 & 1.57 & 15.73 & 0.40 & $D$ \\
\hline $\mathrm{G} 34.254+0.14$ & 33.17 & 0.98 & 22.46 & 1.36 & 53.44 & 0.28 & $B$ \\
\hline G35.194-1.75 & 43.96 & 1.24 & 17.13 & 0.59 & 47.20 & 0.21 & $B$ \\
\hline $\mathrm{G} 40.505+2.54$ & 3.12 & 0.46 & 17.07 & 1.95 & 20.38 & 1.37 & C \\
\hline $\mathrm{G} 43.169+0.00^{\mathrm{b}}$ & 91.82 & 1.98 & 22.70 & 0.63 & 8.86 & 0.22 & $B$ \\
\hline
\end{tabular}


Table 3-Continued

\begin{tabular}{|c|c|c|c|c|c|c|c|}
\hline Source & $\begin{array}{c}T_{L} \\
(\mathrm{mK})\end{array}$ & $\begin{array}{c}\sigma T_{L} \\
(\mathrm{mK})\end{array}$ & $\begin{array}{c}\Delta v \\
\left(\mathrm{~km} \mathrm{~s}^{-1}\right)\end{array}$ & $\begin{array}{c}\sigma \Delta v \\
\left(\mathrm{~km} \mathrm{~s}^{-1}\right)\end{array}$ & $\begin{array}{c}V \\
\left(\mathrm{~km} \mathrm{~s}^{-1}\right)\end{array}$ & $\begin{array}{c}\sigma V \\
\left(\mathrm{~km} \mathrm{~s}^{-1}\right)\end{array}$ & $\mathrm{QF}^{\sharp}$ \\
\hline $\mathrm{G} 43.169+0.00^{\mathrm{c}}$ & 84.39 & 3.00 & 24.03 & 1.32 & 8.63 & 0.51 & $B$ \\
\hline $\mathrm{G} 45.451+0.06$ & 18.42 & 1.00 & 20.86 & 1.84 & 55.50 & 0.42 & $C$ \\
\hline G46.495-0.25 & 11.71 & 1.08 & 17.27 & 1.83 & 56.54 & 0.78 & $C$ \\
\hline G48.930-0.28 & 25.77 & 1.19 & 19.20 & 1.20 & 66.75 & 0.44 & $C$ \\
\hline G48.997-0.29 & 21.73 & 0.66 & 18.16 & 0.72 & 66.00 & 0.33 & $B$ \\
\hline G49.204-0.34 & 22.10 & 0.71 & 27.53 & 1.25 & 67.72 & 0.36 & $B$ \\
\hline G49.384-0.30 b & $\ldots$ & $\ldots$ & $\ldots$ & $\ldots$ & $\ldots$ & $\ldots$ &. \\
\hline $\mathrm{G} 49.384-0.30^{\mathrm{c}}$ & 34.35 & 0.96 & 23.93 & 0.79 & 53.83 & 0.33 & $A$ \\
\hline $\mathrm{G} 49.486-0.38^{\mathrm{b}}$ & 165.41 & 3.38 & 29.18 & 0.95 & 58.95 & 0.34 & $B$ \\
\hline $\mathrm{G} 49.486-0.38^{\mathrm{c}}$ & 163.14 & 2.29 & 26.91 & 0.57 & 58.46 & 0.22 & $A$ \\
\hline G49.582-0.38 & 58.76 & 1.77 & 24.86 & 1.33 & 56.46 & 0.33 & $B$ \\
\hline G61.470+0.09 & 11.48 & 0.63 & 20.82 & 1.68 & 30.24 & 0.62 & $C$ \\
\hline $\mathrm{G} 63.168+0.46$ & 8.91 & 0.64 & 17.36 & 1.45 & 16.36 & 0.61 & $A$ \\
\hline $\mathrm{G} 70.300+1.60$ & 19.58 & 1.24 & 28.32 & 4.06 & -23.37 & 0.82 & $C$ \\
\hline $\mathrm{G} 75.834+0.40$ & 19.60 & 0.61 & 27.18 & 1.48 & -3.38 & 0.40 & $C$ \\
\hline G76.383-0.62 & 13.88 & 0.26 & 27.13 & 1.79 & 3.90 & 0.82 & $D$ \\
\hline $\mathrm{G} 79.293+1.30^{\mathrm{b}}$ & 15.63 & 0.57 & 27.45 & 1.33 & -38.99 & 0.44 & $C$ \\
\hline $\mathrm{G} 79.293+1.30^{\mathrm{c}}$ & 17.70 & 1.02 & 26.08 & 1.94 & -38.95 & 0.76 & $B$ \\
\hline G81.681+0.54 & 26.30 & 0.64 & 32.82 & 1.17 & 0.58 & 0.37 & $B$ \\
\hline G93.060+2.81 & 2.67 & 0.62 & 16.90 & 4.52 & -63.05 & 1.91 & $D$ \\
\hline G102.88-0.72 & 1.00 & 0.45 & 17.85 & 2.04 & -50.46 & 0.78 & $E$ \\
\hline G107.18-0.95 & 1.21 & 0.41 & 21.86 & 2.50 & -35.79 & 2.38 & $E$ \\
\hline $\mathrm{G} 110.11+0.04$ & 1.73 & 0.36 & 27.88 & 3.19 & -53.33 & 5.77 & $E$ \\
\hline G111.53+0.82 & 35.33 & 1.04 & 22.50 & 0.86 & -60.07 & 0.34 & $A$ \\
\hline $\mathrm{G} 112.24+0.23$ & 3.95 & 0.47 & 21.28 & 3.02 & -43.99 & 1.25 & $D$ \\
\hline G118.15+4.96 & 4.30 & 0.53 & 10.81 & 1.54 & -8.21 & 0.65 & $C$ \\
\hline $\mathrm{G} 133.72+1.21$ & 86.67 & 2.95 & 21.74 & 0.89 & -40.41 & 0.36 & $A$ \\
\hline G133.790+1.4 & 22.68 & 2.07 & 22.15 & 2.34 & -48.57 & 0.99 & $B$ \\
\hline G150.59-0.95 & 8.74 & 0.48 & 23.03 & 1.53 & -25.53 & 0.62 & $C$ \\
\hline $\mathrm{G} 151.587-0.2^{\mathrm{a}}$ & 5.99 & 0.89 & 19.80 & 3.40 & -47.93 & 1.43 & $D$ \\
\hline $\mathrm{G} 151.59-0.23^{\mathrm{a}}$ & 7.68 & 0.43 & 23.02 & 1.50 & -48.31 & 0.63 & $C$ \\
\hline G151.636-0.5 & 1.45 & 0.34 & 16.02 & 4.32 & -58.83 & 1.84 & $E$ \\
\hline $\mathrm{G} 155.36+2.61$ & 2.55 & 0.42 & 20.86 & 2.39 & -41.55 & 1.89 & $D$ \\
\hline G169.19-0.90 & 1.10 & 0.46 & 21.38 & 2.45 & -11.84 & 35.90 & $E$ \\
\hline $\mathrm{G} 173.60+2.80$ & 2.73 & 0.48 & 15.29 & 1.75 & -23.74 & 1.67 & $D$ \\
\hline G189.97+0.40 & 2.49 & 0.51 & 11.67 & 2.74 & 10.31 & 1.16 & $D$ \\
\hline G201.6+1.6 & 1.75 & 0.44 & 18.87 & 2.16 & 26.82 & 1.82 & $D$ \\
\hline $\mathrm{G} 206.122-2.3^{\mathrm{a}}$ & 2.72 & 0.54 & 12.08 & 2.79 & 20.28 & 1.19 & $D$ \\
\hline G206.618-1.8 & 1.91 & 0.38 & 19.98 & 4.60 & 18.85 & 1.95 & $D$ \\
\hline G209.01-19.4 & 467.96 & 13.26 & 19.19 & 1.07 & -3.39 & 1.36 & $B$ \\
\hline G213.71-12.6 & $\ldots$ & $\ldots$ & $\ldots$ & $\ldots$ & $\ldots$ & $\ldots$ & . \\
\hline G220.508-2.8 & $\ldots$ & $\ldots$ & $\ldots$ & $\ldots$ & $\ldots$ & $\ldots$ & $\ldots$ \\
\hline G223.7-1.9 & $\ldots$ & $\ldots$ & $\ldots$ & $\ldots$ & $\ldots$ & $\ldots$ & $\ldots$ \\
\hline G227.79-0.12 & 0.76 & 0.37 & 26.28 & 3.01 & 55.94 & 3.34 & $E$ \\
\hline G231.48-4.40 & 2.41 & 0.47 & 15.94 & 1.82 & 53.71 & 1.56 & $D$ \\
\hline
\end{tabular}


Table 3-Continued

\begin{tabular}{|c|c|c|c|c|c|c|c|}
\hline Source & $\begin{array}{c}T_{L} \\
(\mathrm{mK})\end{array}$ & $\begin{array}{l}\sigma T_{L} \\
(\mathrm{mK})\end{array}$ & $\begin{array}{c}\Delta v \\
\left(\mathrm{~km} \mathrm{~s}^{-1}\right)\end{array}$ & $\begin{array}{c}\sigma \Delta v \\
\left(\mathrm{~km} \mathrm{~s}^{-1}\right)\end{array}$ & $\begin{array}{c}V \\
\left(\mathrm{~km} \mathrm{~s}^{-1}\right)\end{array}$ & $\begin{array}{c}\sigma V \\
\left(\mathrm{~km} \mathrm{~s}^{-1}\right)\end{array}$ & $\mathrm{QF}^{\sharp}$ \\
\hline $\mathrm{G} 243.16+0.37$ & 6.93 & 0.52 & 16.19 & 1.41 & 54.28 & 0.60 & C \\
\hline G345.03+1.54 & $\ldots$ & $\ldots$ & $\ldots$ & $\ldots$ & $\ldots$ & $\ldots$ & . \\
\hline G345.23+1.03 & 7.18 & 0.29 & 21.69 & 1.43 & -11.26 & 0.39 & $E$ \\
\hline G345.31+1.47 & 12.21 & 0.32 & 17.99 & 1.19 & -12.94 & 1.13 & $D$ \\
\hline G345.40+1.41 & 24.46 & 0.31 & 18.76 & 1.24 & -14.90 & 0.98 & E \\
\hline G345.43-0.94 & 57.47 & 1.12 & 22.29 & 0.62 & -24.77 & 0.28 & $A$ \\
\hline G345.54+0.10 & $\cdots$ & $\ldots$ & $\ldots$ & $\ldots$ & $\ldots$ & $\cdots$ & . \\
\hline G347.96-0.44 & $\ldots$ & $\ldots$ & $\cdots$ & $\ldots$ & $\ldots$ & $\ldots$ & . \\
\hline G348.23-0.98 & 45.09 & 1.11 & 29.45 & 2.49 & -17.90 & 0.35 & $C$ \\
\hline G348.72-1.03 & 63.61 & 1.76 & 19.60 & 1.00 & -11.33 & 0.30 & $B$ \\
\hline G350.13+0.09 & 17.49 & 0.29 & 21.05 & 1.39 & -71.23 & 0.75 & $D$ \\
\hline G351.063+0.6 & $\cdots$ & $\cdots$ & $\cdots$ & $\cdots$ & $\cdots$ & $\ldots$ & . \\
\hline G351.192+0.7 & 29.22 & 1.23 & 23.19 & 1.18 & 1.30 & 0.41 & $B$ \\
\hline G351.201+0.4 & 28.94 & 1.60 & 18.43 & 1.18 & -7.57 & 0.54 & $C$ \\
\hline $\mathrm{G} 351.246+0.7^{\mathrm{a}}$ & 34.63 & 2.16 & 21.03 & 1.53 & -0.06 & 0.64 & $B$ \\
\hline G351.358+0.6 & 70.95 & 1.04 & 19.72 & 0.39 & -4.58 & 0.22 & $A$ \\
\hline $\mathrm{G} 351.368+0.7^{\mathrm{a}}$ & 51.07 & 2.26 & 16.68 & 0.86 & -3.77 & 0.36 & $A$ \\
\hline G351.467-0.4 & $\ldots$ & $\ldots$ & $\ldots$ & $\ldots$ & $\ldots$ & $\ldots$ & . \\
\hline G351.613-1.2 & 54.64 & 1.54 & 27.22 & 1.24 & -14.97 & 0.35 & $B$ \\
\hline G351.64-1.26 & 61.09 & 1.44 & 25.45 & 1.03 & -14.38 & 0.35 & $B$ \\
\hline G351.69-1.17 & 20.93 & 1.06 & 21.40 & 1.45 & -12.64 & 0.44 & $B$ \\
\hline G352.61-0.17 & $\ldots$ & $\ldots$ & $\cdots$ & $\ldots$ & $\ldots$ & $\ldots$ & . \\
\hline G353.035+0.7 & 24.43 & 0.81 & 30.00 & 1.85 & -6.18 & 0.52 & $C$ \\
\hline G353.08+0.36 & 22.05 & 1.63 & 18.56 & 1.58 & -3.65 & 0.81 & C \\
\hline G353.14+0.66 & 77.64 & 1.31 & 27.56 & 1.62 & -3.82 & 0.24 & $B$ \\
\hline G353.186+0.8 & 114.92 & 2.50 & 31.51 & 0.87 & -4.28 & 0.33 & $B$ \\
\hline G353.21+0.91 & 109.45 & 2.30 & 30.70 & 1.14 & -3.36 & 0.32 & $B$ \\
\hline G353.398-0.3 & 20.24 & 1.19 & 15.89 & 1.59 & -15.82 & 0.53 & C \\
\hline G353.43-0.37 & 23.48 & 1.88 & 17.59 & 2.69 & -15.67 & 0.57 & $C$ \\
\hline
\end{tabular}

${ }^{\sharp}$ Helium line quality factor. See text. QF is a qualitative evaluation of the quality of the parameters measured for the He line. Most based in the accuracy of the Gaussian fit to the line shape.

${ }^{a}$ M16, M17, NGC 6334, Rosette and S209 were observed at different positions in the ${ }^{3}$ He survey.

bobserved in the CiI survey.

${ }^{\mathrm{c}}$ Observed in the ${ }^{3}$ He survey. 
Table 4. Carbon Radio Recombination Line Parameters

\begin{tabular}{|c|c|c|c|c|c|c|c|c|c|}
\hline Source & $\begin{array}{c}T_{L} \\
(\mathrm{mK})\end{array}$ & $\begin{array}{l}\sigma T_{L} \\
(\mathrm{mK})\end{array}$ & $\begin{array}{c}\Delta v \\
\left(\mathrm{~km} \mathrm{~s}^{-1}\right)\end{array}$ & $\left(\begin{array}{c}\sigma \Delta v \\
\left(\mathrm{~km} \mathrm{~s}^{-1}\right)\end{array}\right.$ & $\begin{array}{c}V \\
\left(\mathrm{~km} \mathrm{~s}^{-1}\right)\end{array}$ & $\begin{array}{c}\sigma V \\
\left(\mathrm{~km} \mathrm{~s}^{-1}\right)\end{array}$ & morphology* & $\mathrm{RF}^{* *}$ & $\mathrm{QF}^{\sharp}$ \\
\hline $\mathrm{G} 0.605+0.325$ & 1.15 & 0.76 & 16.27 & 13.92 & -4.34 & 5.41 & $\mathrm{r}$ & $\mathrm{P}$ & $E$ \\
\hline G0.665-0.035 & 7.00 & 8.88 & 10.88 & 17.42 & 67.19 & 6.89 & $\mathrm{~b}$ & $\mathrm{P}$ & C \\
\hline G1.13-0.1 & 1.92 & 1.54 & 6.92 & 6.66 & -15.33 & 2.78 & $\mathrm{sb}$ & $\mathrm{P}$ & $C$ \\
\hline $\mathrm{G} 2.90+0.0$ & 2.15 & 0.85 & 6.10 & 2.80 & 0.20 & 1.18 & $\mathrm{sb}$ & G & $C$ \\
\hline G3.270-0.101 & 3.22 & 0.30 & 10.08 & 1.41 & 1.05 & 0.48 & $\mathrm{r}$ & $\mathrm{F}$ & $C$ \\
\hline G5.899-0.427 & 12.22 & 1.11 & 11.57 & 1.50 & 7.63 & 0.50 & $\mathrm{sb}$ & G & C \\
\hline G5.956-1.265 & 17.91 & 2.85 & 4.46 & 1.22 & 10.03 & 0.46 & $\mathrm{~b}$ & $\mathrm{~F}$ & $C$ \\
\hline G5.973-1.178 & 18.89 & 3.60 & 6.05 & 1.45 & 5.99 & 0.48 & $\mathrm{~b}$ & G & C \\
\hline $\mathrm{G} 8.137+0.228$ & 8.90 & 2.30 & 5.59 & 1.79 & 19.97 & 0.65 & $\mathrm{sb}$ & $\mathrm{P}$ & $D$ \\
\hline G10.159-0.34 & $\ldots$ & $\ldots$ & $\ldots$ & $\ldots$ & $\ldots$ & $\ldots$ & $\ldots$ & $\ldots$ & . \\
\hline G10.315-0.15 & 5.87 & 0.48 & 4.43 & 0.43 & 10.68 & 0.15 & $\mathrm{~b}$ & $\mathrm{~F}$ & $B$ \\
\hline G10.617-0.38 & 7.86 & 1.27 & 9.58 & 1.87 & -3.32 & 0.78 & $\mathrm{r}$ & G & $C$ \\
\hline G12.807-0.20 & 26.72 & 2.50 & 6.47 & 0.73 & 34.74 & 0.25 & $\mathrm{r}$ & $\mathrm{E}$ & $B$ \\
\hline $\mathrm{G} 13.875+0.28$ & $\cdots$ & $\cdots$ & $\ldots$ & $\ldots$ & $\ldots$ & $\ldots$ & $\ldots$ & $\ldots$ & $\ldots$ \\
\hline G14.626+0.08 & $\ldots$ & $\ldots$ & $\ldots$ & $\ldots$ & $\ldots$ & $\ldots$ & $\ldots$ & $\ldots$ & $\ldots$ \\
\hline G15.035-0.68 & 51.81 & 15.11 & 11.68 & 4.90 & 17.27 & 1.69 & $\mathrm{~b}$ & $\mathrm{~F}$ & $C$ \\
\hline $\mathrm{G} 15.095-0.71^{\mathrm{a}}$ & 11.39 & 3.02 & 11.57 & 3.69 & 20.32 & 1.50 & $\mathrm{~b}$ & $\mathrm{~F}$ & $C$ \\
\hline G15.181-0.62 & 12.31 & 2.04 & 6.35 & 1.23 & 21.71 & 0.50 & $\mathrm{sb}$ & $\mathrm{G}$ & $C$ \\
\hline G15.198-0.76 & $\ldots$ & $\ldots$ & $\ldots$ & $\ldots$ & $\ldots$ & $\ldots$ & $\ldots$ & $\ldots$ & . \\
\hline G16.936+0.76 & 11.38 & 4.57 & 6.06 & 3.24 & 24.40 & 1.20 & $\mathrm{r}$ & $\mathrm{P}$ & $D$ \\
\hline $\mathrm{G} 16.936+0.76^{\mathrm{a}, c, d}$ & d 3.87 & 1.31 & 6.12 & 2.66 & 25.28 & 1.08 & $\mathrm{r}$ & $\mathrm{P}$ & $C$ \\
\hline$\cdots$ & 2.78 & 1.07 & 9.57 & 4.84 & 38.23 & 1.86 & $\mathrm{~b}$ & $\mathrm{~F}$ & $C$ \\
\hline $\mathrm{G} 16.984+0.93^{\mathrm{a}, c}$ & 6.26 & 1.38 & 11.80 & 3.18 & 23.07 & 1.31 & $\mathrm{sb}$ & G & $C$ \\
\hline G16.995+0.86 & $\cdots$ & $\cdots$ & $\cdots$ & $\cdots$ & $\cdots$ & $\cdots$ & $\cdots$ & $\cdots$ & . \\
\hline G18.143-0.28 & 6.83 & 0.94 & 6.15 & 0.98 & 56.26 & 0.28 & $\mathrm{r}$ & G & $C$ \\
\hline G18.686+1.96 & 5.30 & 0.81 & 8.60 & 1.64 & 28.01 & 0.75 & $\mathrm{sb}$ & $\mathrm{F}$ & $C$ \\
\hline G19.066-0.28 & $\cdots$ & $\cdots$ & $\cdots$ & $\cdots$ & $\cdots$ & $\ldots$ & $\cdots$ & $\cdots$ & . \\
\hline G19.608-0.23 & $\cdots$ & $\cdots$ & $\ldots$ & $\cdots$ & $\cdots$ & $\cdots$ & $\cdots$ & $\cdots$ & $\cdots$ \\
\hline G20.733-0.09 & 2.20 & 0.30 & 9.47 & 1.91 & 58.14 & 0.68 & $\mathrm{sb}$ & $\mathrm{F}$ & $C$ \\
\hline $\mathrm{G} 23.421-0.21^{\mathrm{b}}$ & 9.69 & 0.62 & 19.31 & 1.72 & 100.41 & 0.61 & $\mathrm{sb}$ & G & $C$ \\
\hline G23.421-0.21 & 4.66 & 1.42 & 10.56 & 3.92 & 102.08 & 1.61 & $\mathrm{r}$ & G & $B$ \\
\hline $\mathrm{G} 23.706+0.17^{\mathrm{d}}$ & 1.53 & 1.68 & 8.21 & 4.25 & 100.05 & 1.78 & $\mathrm{r}$ & $\mathrm{F}$ & $C$ \\
\hline$\cdots$ & 3.60 & 0.79 & 6.02 & 1.54 & 116.94 & 0.65 & $\mathrm{~b}$ & $\mathrm{~F}$ & $C$ \\
\hline $\mathrm{G} 24.467+0.48$ & $\ldots$ & $\ldots$ & $\ldots$ & $\ldots$ & $\ldots$ & $\ldots$ & $\ldots$ & $\ldots$ & . \\
\hline $\mathrm{G} 24.484+0.21$ & 3.70 & 1.05 & 11.51 & 5.48 & 118.39 & 2.02 & $\mathrm{sb}$ & G & $C$ \\
\hline $\mathrm{G} 24.805+0.09$ & $\ldots$ & $\ldots$ & $\ldots$ & $\ldots$ & $\ldots$ & $\ldots$ & $\cdots$ & $\ldots$ & $\ldots$ \\
\hline $\mathrm{G} 25.382-0.18^{\mathrm{b}}$ & $\ldots$ & $\ldots$ & $\ldots$ & $\ldots$ & $\ldots$ & $\ldots$ & $\ldots$ & $\ldots$ & $\ldots$ \\
\hline $\mathrm{G} 25.382-0.18^{\mathrm{c}}$ & 7.65 & 1.88 & 3.66 & 1.02 & 64.72 & 0.70 & $\mathrm{sb}$ & $\mathrm{F}$ & $B$ \\
\hline $\mathrm{G} 25.766+0.21$ & 4.54 & 7.93 & 3.02 & 4.93 & 124.52 & 0.96 & $\mathrm{sb}$ & $\mathrm{P}$ & $C$ \\
\hline $\mathrm{G} 28.790+3.48$ & 31.01 & 3.59 & 3.74 & 0.52 & 8.46 & 0.25 & $\mathrm{r}$ & $\mathrm{E}$ & $B$ \\
\hline G29.944-0.04 & 7.26 & 1.94 & 7.51 & 2.42 & 98.36 & 1.00 & $\mathrm{sb}$ & G & $B$ \\
\hline G30.776-0.03 & 7.10 & 1.49 & 15.73 & 4.41 & 87.08 & 1.64 & $\mathrm{~b}$ & $\mathrm{~F}$ & $C$ \\
\hline $\mathrm{G} 32.797+0.19$ & $\ldots$ & $\ldots$ & $\ldots$ & $\ldots$ & $\ldots$ & $\ldots$ & $\cdots$ & $\ldots$ & $\ldots$ \\
\hline G34.254+0.14 & 17.07 & 1.53 & 10.57 & 1.34 & 57.33 & 0.36 & $\mathrm{sb}$ & G & $C$ \\
\hline G35.194-1.75 & 22.56 & 2.27 & 5.88 & 0.85 & 43.59 & 0.23 & $\mathrm{r}$ & $\mathrm{E}$ & $B$ \\
\hline
\end{tabular}


Table 4-Continued

\begin{tabular}{|c|c|c|c|c|c|c|c|c|c|}
\hline Source & $\begin{array}{c}T_{L} \\
(\mathrm{mK})\end{array}$ & $\begin{array}{l}\sigma T_{L} \\
(\mathrm{mK})\end{array}$ & $\begin{array}{c}\Delta v \\
\left(\mathrm{~km} \mathrm{~s}^{-1}\right)\end{array}$ & $\begin{array}{c}\sigma \Delta v \\
\left(\mathrm{~km} \mathrm{~s}^{-1}\right)\end{array}$ & $\begin{array}{c}V \\
\left(\mathrm{~km} \mathrm{~s}^{-1}\right)\end{array}$ & $\begin{array}{c}\sigma V \\
\left(\mathrm{~km} \mathrm{~s}^{-1}\right)\end{array}$ & morphology* & $\mathrm{RF}^{* *}$ & $\mathrm{QF}^{\sharp}$ \\
\hline $\mathrm{G} 40.505+2.54$ & 11.13 & 1.60 & 3.40 & 0.61 & 33.31 & 0.30 & $\mathrm{~b}$ & G & $B$ \\
\hline $\mathrm{G} 43.169+0.00^{\mathrm{b}}$ & 24.77 & 1.79 & 15.72 & 1.36 & 7.33 & 0.67 & $\mathrm{sb}$ & $\mathrm{G}$ & $C$ \\
\hline $\mathrm{G} 43.169+0.00^{\mathrm{c}}$ & 21.42 & 3.65 & 15.78 & 3.98 & 8.33 & 1.64 & $\mathrm{sb}$ & $\mathrm{G}$ & $B$ \\
\hline G45.451+0.06 & 8.54 & 0.68 & 6.52 & 0.65 & 57.82 & 0.24 & $\mathrm{sb}$ & $\mathrm{F}$ & $B$ \\
\hline G46.495-0.25 & $\ldots$ & $\ldots$ & $\ldots$ & $\ldots$ & $\ldots$ & $\ldots$ & $\ldots$ & $\ldots$ & . \\
\hline G48.930-0.28 & 14.16 & 1.24 & 5.63 & 0.58 & 71.18 & 0.29 & $\mathrm{sb}$ & $\mathrm{G}$ & $B$ \\
\hline G48.997-0.29 & 6.64 & 0.83 & 10.07 & 1.56 & 69.94 & 0.61 & $\mathrm{sb}$ & $\mathrm{F}$ & $C$ \\
\hline G49.204-0.34 & 9.21 & 0.98 & 7.45 & 0.96 & 66.46 & 0.54 & $\mathrm{sb}$ & G & $B$ \\
\hline G49.384-0.30 & $\ldots$ & $\ldots$ & $\ldots$ & $\ldots$ & $\ldots$ & $\ldots$ & .. & . & - \\
\hline G49.384-0.30 & 11.57 & 1.62 & 8.19 & 1.35 & 51.12 & 0.57 & $\mathrm{r}$ & $\mathrm{E}$ & $A$ \\
\hline $\mathrm{G} 49.486-0.38^{\mathrm{b}}$ & 33.03 & 3.50 & 7.97 & 1.27 & 55.29 & 1.07 & $\mathrm{sb}$ & $\mathrm{F}$ & $B$ \\
\hline $\mathrm{G} 49.486-0.38^{\mathrm{c}}$ & 23.38 & 3.27 & 13.29 & 2.47 & 58.38 & 1.04 & $\mathrm{sb}$ & $\mathrm{G}$ & $B$ \\
\hline G49.582-0.38 & $\cdots$ & $\ldots$ & $\cdots$ & $\cdots$ & $\cdots$ & $\cdots$ & $\cdots$ & $\cdots$ & . \\
\hline $\mathrm{G} 61.470+0.09$ & 23.77 & 1.87 & 6.03 & 0.55 & 22.04 & 0.19 & $\mathrm{r}$ & $\mathrm{E}$ & $C$ \\
\hline G63.168+0.46 & 3.60 & 1.95 & 4.01 & 2.81 & 22.03 & 0.70 & $\mathrm{r}$ & $\mathrm{F}$ & $B$ \\
\hline $\mathrm{G} 70.300+1.60$ & 20.01 & 1.04 & 7.99 & 0.52 & -23.81 & 0.16 & $\mathrm{sb}$ & $\mathrm{E}$ & $C$ \\
\hline G75.834+0.40 & 12.38 & 1.87 & 5.29 & 0.93 & 2.07 & 0.52 & $\mathrm{~b}$ & G & $C$ \\
\hline G76.383-0.62 & 16.06 & 0.82 & 12.34 & 1.38 & -2.26 & 0.38 & $\mathrm{sb}$ & $\mathrm{E}$ & $C$ \\
\hline $\mathrm{G} 79.293+1.30^{\mathrm{b}}$ & 5.91 & 0.93 & 7.33 & 1.81 & -40.75 & 0.35 & $\mathrm{sb}$ & $\mathrm{G}$ & $B$ \\
\hline $\mathrm{G} 79.293+1.30^{\mathrm{c}}$ & 8.35 & 1.54 & 10.97 & 2.51 & -41.09 & 1.05 & $\mathrm{sb}$ & $\mathrm{E}$ & $B$ \\
\hline G81.681+0.54 & 14.51 & 1.45 & 9.95 & 1.34 & -4.45 & 0.57 & $\mathrm{sb}$ & G & $C$ \\
\hline G93.060+2.81 & $\cdots$ & $\cdots$ & $\cdots$ & $\cdots$ & $\cdots$ & $\cdots$ & $\cdots$ & $\cdots$ & $\cdots$ \\
\hline G102.88-0.72 & $\ldots$ & $\ldots$ & $\ldots$ & $\ldots$ & $\ldots$ & $\ldots$ & $\ldots$ & $\ldots$ & $\ldots$ \\
\hline G107.18-0.95 & $\ldots$ & $\ldots$ & $\ldots$ & $\cdots$ & $\ldots$ & $\ldots$ & $\ldots$ & $\ldots$ & $\ldots$ \\
\hline $\mathrm{G} 110.11+0.04$ & 4.90 & 0.76 & 7.15 & 1.28 & -50.59 & 0.54 & $\mathrm{sb}$ & $\mathrm{E}$ & $C$ \\
\hline G111.53+0.82 & 7.02 & 1.77 & 7.63 & 2.35 & -56.00 & 0.97 & $\mathrm{sb}$ & G & $B$ \\
\hline G112.24+0.23 & $\ldots$ & $\ldots$ & $\ldots$ & $\ldots$ & $\cdots$ & $\ldots$ & $\ldots$ & . & . \\
\hline $\mathrm{G} 118.15+4.96$ & 2.63 & 0.72 & 5.96 & 1.88 & -16.74 & 0.79 & $\mathrm{r}$ & $\mathrm{F}$ & $C$ \\
\hline G133.72+1.21 & 56.39 & 4.93 & 7.68 & 0.79 & -40.10 & 0.33 & $\mathrm{r}$ & $\mathrm{E}$ & $A$ \\
\hline G133.790+1.4 & $\ldots$ & $\ldots$ & $\ldots$ & $\ldots$ & $\ldots$ & $\ldots$ & $\ldots$ & $\ldots$ & . \\
\hline G150.59-0.95 & 1.25 & 0.79 & 8.44 & 6.39 & -26.42 & 2.66 & $\mathrm{sb}$ & $\mathrm{P}$ & $C$ \\
\hline $\mathrm{G} 151.587-0.2^{\mathrm{a}}$ & 4.03 & 1.25 & 9.96 & 3.57 & -52.46 & 1.51 & $\mathrm{r}$ & G & $D$ \\
\hline $\mathrm{G} 151.59-0.23^{\mathrm{a}}$ & 5.63 & 0.84 & 5.89 & 1.01 & -52.75 & 0.44 & $\mathrm{r}$ & $\mathrm{E}$ & $A$ \\
\hline G151.636-0.5 & $\ldots$ & $\ldots$ & $\ldots$ & $\ldots$ & $\ldots$ & $\ldots$ & $\ldots$ & $\ldots$ & . \\
\hline G155.36+2.61 & 1.17 & 0.26 & 12.46 & 3.80 & -36.88 & 1.40 & $\mathrm{sb}$ & $\mathrm{F}$ & $E$ \\
\hline G169.19-0.90 & 1.99 & 0.51 & 9.75 & 3.59 & -14.82 & 1.24 & $\mathrm{sb}$ & $\mathrm{P}$ & $E$ \\
\hline $\mathrm{G} 173.60+2.80$ & 6.10 & 1.27 & 5.02 & 1.23 & -19.82 & 0.51 & $\mathrm{r}$ & $\mathrm{F}$ & $D$ \\
\hline G189.97+0.40 & 1.54 & 0.64 & 7.32 & 3.50 & 6.63 & 1.48 & $\mathrm{r}$ & $\mathrm{F}$ & $D$ \\
\hline G201.6+1.6 & $\ldots$ & $\ldots$ & $\ldots$ & $\ldots$ & $\ldots$ & $\ldots$ & $\ldots$ & $\ldots$ & $\ldots$ \\
\hline $\mathrm{G} 206.122-2.3^{\mathrm{a}}$ & $\ldots$ & $\ldots$ & $\ldots$ & $\ldots$ & $\ldots$ & $\ldots$ & $\ldots$ & $\ldots$ & $\ldots$ \\
\hline $\mathrm{G} 206.618-1.8^{\mathrm{a}}$ & $\ldots$ & $\ldots$ & $\ldots$ & $\ldots$ & $\ldots$ & $\ldots$ & $\cdots$ & $\ldots$ & $\ldots$ \\
\hline G209.01-19.4 & 199.77 & 35.14 & 6.75 & 1.54 & 9.78 & 0.62 & $\mathrm{~b}$ & $\mathrm{G}$ & $C$ \\
\hline G213.71-12.6 & 31.49 & 3.90 & 4.55 & 0.62 & 9.80 & 0.31 & $\mathrm{r}$ & $\mathrm{E}$ & $C$ \\
\hline G220.508-2.8 & $\ldots$ & $\ldots$ & $\ldots$ & $\ldots$ & $\ldots$ & $\ldots$ & . & $\ldots$ & $\ldots$ \\
\hline G223.7-1.9 & $\ldots$ & $\ldots$ & $\ldots$ & $\ldots$ & $\ldots$ & $\ldots$ & $\cdots$ & $\cdots$ & $\ldots$ \\
\hline
\end{tabular}


Table 4-Continued

\begin{tabular}{|c|c|c|c|c|c|c|c|c|c|}
\hline Source & $\begin{array}{c}T_{L} \\
(\mathrm{mK})\end{array}$ & $\begin{array}{l}\sigma T_{L} \\
(\mathrm{mK})\end{array}$ & $\begin{array}{c}\Delta v \\
\left(\mathrm{~km} \mathrm{~s}^{-1}\right)\end{array}$ & $\begin{array}{c}\sigma \Delta v \\
\left(\mathrm{~km} \mathrm{~s}^{-1}\right)\end{array}$ & $\begin{array}{c}V \\
\left(\mathrm{~km} \mathrm{~s}^{-1}\right)\end{array}$ & $\begin{array}{c}\sigma V \\
\left(\mathrm{~km} \mathrm{~s}^{-1}\right)\end{array}$ & morphology* & $\mathrm{RF}^{* *}$ & $\mathrm{QF}^{\sharp}$ \\
\hline G227.79-0.12 & $\ldots$ & $\ldots$ & $\ldots$ & $\ldots$ & $\ldots$ & $\ldots$ & $\ldots$ & $\ldots$ & $\ldots$ \\
\hline G231.48-4.40 & $\ldots$ & $\ldots$ & $\ldots$ & $\ldots$ & $\ldots$ & $\ldots$ & $\ldots$ & $\ldots$ & $\ldots$ \\
\hline $\mathrm{G} 243.16+0.37$ & $\ldots$ & $\ldots$ & $\ldots$ & $\ldots$ & $\ldots$ & $\ldots$ & $\ldots$ & $\ldots$ & $\ldots$ \\
\hline G345.03+1.54 & $\ldots$ & $\ldots$ & $\ldots$ & $\ldots$ & $\ldots$ & $\ldots$ & $\ldots$ & $\ldots$ & $\ldots$ \\
\hline G345.23+1.03 & 14.95 & 3.45 & 4.44 & 1.18 & -16.20 & 0.51 & $\mathrm{r}$ & $\mathrm{F}$ & $D$ \\
\hline G345.31+1.47 & 7.05 & 1.70 & 6.02 & 1.77 & -11.07 & 0.39 & $\mathrm{r}$ & $\mathrm{F}$ & $D$ \\
\hline G345.40+1.41 & 15.64 & 3.53 & 5.32 & 1.41 & $\ldots$ & $\ldots$ & $\mathrm{sb}$ & $\mathrm{P}$ & $C$ \\
\hline G345.43-0.94 & 18.80 & 2.36 & 6.54 & 0.98 & -21.40 & 0.61 & $\mathrm{sb}$ & G & $B$ \\
\hline G345.54+0.10 & $\ldots$ & $\ldots$ & $\ldots$ & $\ldots$ & $\ldots$ & $\ldots$ & $\ldots$ & $\ldots$ & $\cdots$ \\
\hline G347.96-0.44 & $\ldots$ & $\ldots$ & $\ldots$ & $\ldots$ & $\ldots$ & $\ldots$ & $\ldots$ & $\ldots$ & $\ldots$ \\
\hline G348.23-0.98 & 11.82 & 1.58 & 12.72 & 3.33 & -16.69 & 0.80 & $\mathrm{sb}$ & G & $C$ \\
\hline G348.72-1.03 & 22.42 & 1.91 & 6.74 & 0.96 & -11.81 & 0.53 & $\mathrm{r}$ & G & $C$ \\
\hline G350.13+0.09 & $\ldots$ & $\ldots$ & $\ldots$ & $\ldots$ & $\cdots$ & $\ldots$ & $\ldots$ & $\ldots$ & $\cdots$ \\
\hline G351.063+0.6 & $\ldots$ & $\ldots$ & $\ldots$ & $\ldots$ & $\ldots$ & $\ldots$ & $\ldots$ & $\ldots$ & $\ldots$ \\
\hline G351.192+0.7 & 31.18 & 0.73 & 5.80 & 0.19 & -2.59 & 0.22 & $\mathrm{r}$ & $\mathrm{E}$ & A \\
\hline G351.201+0.4 & $\ldots$ & $\ldots$ & $\ldots$ & $\ldots$ & $\ldots$ & $\ldots$ & $\ldots$ & $\ldots$ & $\ldots$ \\
\hline $\mathrm{G} 351.246+0.7^{\mathrm{a}}$ & 26.93 & 3.42 & 8.34 & 1.23 & -3.14 & 0.52 & $\mathrm{r}$ & $\mathrm{E}$ & $A$ \\
\hline G351.358+0.6 & 26.97 & 1.81 & 9.82 & 1.07 & -2.75 & 0.31 & $\mathrm{sb}$ & $\mathrm{E}$ & $B$ \\
\hline $\mathrm{G} 351.368+0.7^{\mathrm{a}}$ & 24.73 & 2.91 & 9.99 & 1.37 & -4.37 & 0.58 & $\mathrm{r}$ & $\mathrm{E}$ & $B$ \\
\hline G351.467-0.4 & $\ldots$ & $\ldots$ & $\ldots$ & $\ldots$ & $\ldots$ & $\ldots$ & $\ldots$ & $\ldots$ & . \\
\hline G351.613-1.2 & 16.50 & 0.78 & 8.19 & 0.68 & -12.55 & 0.21 & $\mathrm{sb}$ & G & $B$ \\
\hline G351.64-1.26 & 22.11 & 1.68 & 9.71 & 1.36 & -11.87 & 0.64 & $\mathrm{sb}$ & $\mathrm{G}$ & $B$ \\
\hline G351.69-1.17 & 8.98 & 0.33 & 4.71 & 0.31 & -9.96 & 0.69 & $\mathrm{sb}$ & $\mathrm{F}$ & $B$ \\
\hline G352.61-0.17 & $\ldots$ & $\ldots$ & $\ldots$ & $\ldots$ & $\ldots$ & $\ldots$ & $\ldots$ & $\ldots$ & $\ldots$ \\
\hline G353.035+0.7 & 8.88 & 1.24 & 15.30 & 3.07 & -7.49 & 0.47 & $\mathrm{sb}$ & G & $C$ \\
\hline G353.08+0.36 & $\cdots$ & $\ldots$ & $\cdots$ & $\cdots$ & $\cdots$ & $\ldots$ & $\ldots$ & $\cdots$ & $\cdots$ \\
\hline G353.14+0.66 & 16.19 & 1.85 & 9.90 & 2.36 & -4.30 & 0.48 & $\mathrm{~b}$ & G & $C$ \\
\hline G353.186+0.8 & 27.95 & 3.68 & 7.76 & 1.72 & -7.47 & 1.00 & $\mathrm{~b}$ & $\mathrm{~F}$ & $B$ \\
\hline G353.21+0.91 & 26.55 & 1.79 & 9.21 & 1.08 & -4.32 & 0.32 & $\mathrm{~b}$ & G & $B$ \\
\hline G353.398-0.3 & 5.65 & 1.26 & 6.43 & 1.81 & -15.55 & 0.93 & $\mathrm{r}$ & $\mathrm{P}$ & $C$ \\
\hline G353.43-0.37 & 19.20 & 1.85 & 6.09 & 0.71 & -16.65 & 0.37 & $\mathrm{r}$ & $\mathrm{E}$ & $B$ \\
\hline
\end{tabular}

${ }^{*}$ Carbon spectral lineshape morphology: resolved (r), semi-blended (sb), or blended (b). See text. It indicates the position (velocity) of the $\mathrm{C}$ line in the spectra and how distinct it is from the He line.

** Carbon line reliability factor: excellent $(\mathrm{E})$, good $(\mathrm{G})$, fair $(\mathrm{F})$, or poor $(\mathrm{P})$. See text. RF is a qualitative evaluation of the reality of a $\mathrm{C}$ line.

$\sharp$ Carbon line quality factor. See text. QF is a qualitative evaluation of the quality of the parameters measured for the C line. Most based in the accuracy of the Gaussian fit to the line shape.

${ }^{a}$ M16, M17, NGC 6334, Rosette and S209 were observed at different positions in the ${ }^{3}$ He survey.

b Observed in the C II survey.

${ }^{\mathrm{c}}$ Observed in the ${ }^{3} \mathrm{He}$ survey.

${ }^{\mathrm{d}}$ Two possible $\mathrm{C} 91 \alpha$ line detections. 
Table 5. Radio Emission Continuum Parameters (Total Power Observing Mode)

\begin{tabular}{|c|c|c|c|c|c|c|c|c|c|c|c|}
\hline Source & $\begin{array}{c}T_{C}(\mathrm{RA}) \\
(\mathrm{K})\end{array}$ & $\begin{array}{c}\sigma T_{C}(\mathrm{RA}) \\
(\mathrm{K})\end{array}$ & $\begin{array}{c}T_{C}(\mathrm{DEC}) \\
(\mathrm{K})\end{array}$ & $\begin{array}{c}\sigma T_{C}(\mathrm{DEC}) \\
(\mathrm{K})\end{array}$ & $\begin{array}{c}\Theta(\mathrm{RA}) \\
(\operatorname{arcmin})\end{array}$ & $\begin{array}{l}\sigma \Theta(\mathrm{RA}) \\
(\operatorname{arcmin})\end{array}$ & $\begin{array}{l}\Theta(\mathrm{DEC}) \\
(\operatorname{arcmin})\end{array}$ & $\begin{array}{c}\sigma \Theta(\mathrm{DEC}) \\
(\operatorname{arcmin})\end{array}$ & $\begin{array}{c}\Theta_{s r c} \\
(\operatorname{arcmin})\end{array}$ & $\begin{array}{c}\sigma \Theta_{s r c} \\
(\operatorname{arcmin})\end{array}$ & $\mathrm{QF}^{\sharp}$ \\
\hline G0.605+0.325 & 0.147 & 0.006 & 0.122 & 0.000 & 4.780 & 0.332 & 4.620 & 0.120 & 4.700 & 0.177 & $B$ \\
\hline G0.665-0.035 & 9.039 & 0.008 & 8.469 & 0.033 & 3.686 & 0.006 & 4.858 & 0.046 & 4.232 & 0.021 & $B$ \\
\hline G1.13-0.1 & $\ldots$ & $\ldots$ & $\ldots$ & $\ldots$ & $\ldots$ & $\ldots$ & $\ldots$ & $\ldots$ & $\ldots$ & $\ldots$ & \\
\hline $\mathrm{G} 2.90+0.0$ & 0.138 & 0.005 & 0.160 & 0.008 & 5.243 & 0.422 & 6.248 & 0.569 & 5.745 & 0.354 & $C$ \\
\hline G3.270-0.101 & 0.499 & 0.047 & 0.527 & 0.023 & 4.943 & 0.384 & 6.035 & 0.154 & 5.489 & 0.207 & $B$ \\
\hline G5.899-0.427 & $\ldots$ & $\ldots$ & $\ldots$ & $\ldots$ & $\ldots$ & $\ldots$ & $\ldots$ & $\ldots$ & $\ldots$ & $\ldots$ & . \\
\hline G5.956-1.265 & 1.990 & 0.003 & 2.006 & 0.004 & 9.229 & 0.251 & 7.411 & 0.132 & 8.270 & 0.135 & $C$ \\
\hline G5.973-1.178 & 5.967 & 0.007 & 5.901 & 0.005 & 4.525 & 0.015 & 4.765 & 0.015 & 4.643 & 0.011 & $B$ \\
\hline G8.137+0.228 & $\ldots$ & $\ldots$ & $\ldots$ & $\ldots$ & $\ldots$ & $\ldots$ & $\ldots$ & $\ldots$ & $\ldots$ & $\ldots$ & $\ldots$ \\
\hline G10.159-0.34 & $\cdots$ & $\cdots$ & $\cdots$ & $\cdots$ & $\ldots$ & $\cdots$ & $\cdots$ & $\cdots$ & $\cdots$ & $\cdots$ & $\ldots$ \\
\hline G10.315-0.15 & $\ldots$ & $\ldots$ & $\ldots$ & $\ldots$ & $\ldots$ & $\ldots$ & $\ldots$ & $\ldots$ & $\ldots$ & $\ldots$ & $\ldots$ \\
\hline G10.617-0.38 & $\ldots$ & $\ldots$ & $\ldots$ & $\ldots$ & $\ldots$ & $\ldots$ & $\ldots$ & $\ldots$ & $\ldots$ & $\ldots$ & $\ldots$ \\
\hline G12.807-0.20 & 9.595 & 0.006 & 9.546 & 0.011 & 3.752 & 0.006 & 3.361 & 0.013 & 3.551 & 0.008 & $A$ \\
\hline $\mathrm{G} 13.875+0.28$ & 1.174 & 0.005 & 1.239 & 0.003 & 3.254 & 0.039 & 3.510 & 0.017 & 3.380 & 0.022 & $B$ \\
\hline G14.626+0.08 & 0.834 & 0.003 & 0.834 & 0.003 & 10.474 & 0.218 & 7.436 & 0.224 & 8.825 & 0.162 & $D$ \\
\hline G15.035-0.68 & 39.337 & 0.147 & 37.847 & 0.097 & 4.706 & 0.034 & 5.829 & 0.064 & 5.237 & 0.035 & $C$ \\
\hline $\mathrm{G} 15.095-0.71^{\mathrm{a}}$ & $\ldots$ & $\ldots$ & $\ldots$ & $\ldots$ & $\ldots$ & $\ldots$ & $\ldots$ & $\ldots$ & $\ldots$ & $\ldots$ & . \\
\hline G15.181-0.62 & 3.501 & 0.004 & 3.527 & 0.013 & 6.684 & 0.035 & 5.722 & 0.074 & 6.184 & 0.043 & $C$ \\
\hline G15.198-0.76 & 1.610 & 0.003 & 1.599 & 0.003 & 7.909 & 0.093 & 6.314 & 0.065 & 7.066 & 0.055 & $C$ \\
\hline G16.936+0.76 & 1.935 & 0.004 & 1.904 & 0.004 & 7.151 & 0.062 & 8.296 & 0.094 & 7.702 & 0.055 & $C$ \\
\hline G16.936+0.76 $6^{\mathrm{a}, c}$ & 1.973 & 0.006 & 1.875 & 0.003 & 7.776 & 0.077 & 7.925 & 0.037 & 7.850 & 0.043 & $C$ \\
\hline $\mathrm{G} 16.984+0.93^{\mathrm{a}, c}$ & 1.973 & 0.006 & 1.875 & 0.003 & 7.776 & 0.077 & 7.925 & 0.037 & 7.850 & 0.043 & $C$ \\
\hline G16.995+0.86 & 1.567 & 0.003 & 1.552 & 0.003 & 9.251 & 0.242 & 9.266 & 0.127 & 9.258 & 0.137 & $C$ \\
\hline G18.143-0.28 & 1.699 & 0.003 & 1.638 & 0.004 & 3.762 & 0.015 & 4.104 & 0.022 & 3.929 & 0.013 & $B$ \\
\hline G18.686+1.96 & 1.716 & 0.003 & 1.786 & 0.004 & 4.542 & 0.023 & 4.111 & 0.019 & 4.321 & 0.015 & $B$ \\
\hline G19.066-0.28 & 1.263 & 0.003 & 1.247 & 0.003 & 5.478 & 0.094 & 4.054 & 0.037 & 4.712 & 0.046 & $B$ \\
\hline G19.608-0.23 & 1.868 & 0.003 & 1.861 & 0.004 & 3.554 & 0.012 & 3.832 & 0.025 & 3.690 & 0.014 & $B$ \\
\hline G20.733-0.09 & 1.255 & 0.004 & 1.245 & 0.003 & 5.144 & 0.044 & 5.161 & 0.039 & 5.153 & 0.029 & $C$ \\
\hline $\mathrm{G} 23.421-0.21^{\mathrm{b}}$ & 1.824 & 0.004 & 1.744 & 0.003 & 4.834 & 0.035 & 4.315 & 0.022 & 4.567 & 0.020 & $B$ \\
\hline $\mathrm{G} 23.421-0.21^{\mathrm{c}}$ & 1.675 & 0.003 & 1.649 & 0.003 & 4.595 & 0.023 & 4.700 & 0.023 & 4.647 & 0.016 & $B$ \\
\hline G23.706+0.17 & 0.675 & 0.003 & 0.705 & 0.004 & 4.097 & 0.041 & 4.151 & 0.075 & 4.124 & 0.043 & $C$ \\
\hline $\mathrm{G} 24.467+0.48$ & 1.378 & 0.003 & 1.389 & 0.003 & 3.470 & 0.020 & 3.520 & 0.022 & 3.495 & 0.015 & $A$ \\
\hline $\mathrm{G} 24.484+0.21$ & 0.724 & 0.003 & 0.757 & 0.003 & 7.677 & 0.145 & 7.132 & 0.098 & 7.399 & 0.086 & $C$ \\
\hline $\mathrm{G} 24.805+0.09$ & 1.266 & 0.004 & 1.239 & 0.003 & 4.583 & 0.043 & 5.058 & 0.071 & 4.814 & 0.040 & $B$ \\
\hline
\end{tabular}


Table 5-Continued

\begin{tabular}{|c|c|c|c|c|c|c|c|c|c|c|c|}
\hline Source & $\begin{array}{l}T_{C}(\mathrm{RA}) \\
(\mathrm{K})\end{array}$ & $\begin{array}{c}\sigma T_{C}(\mathrm{RA}) \\
(\mathrm{K})\end{array}$ & $\begin{array}{c}T_{C}(\mathrm{DEC}) \\
(\mathrm{K})\end{array}$ & $\begin{array}{c}\sigma T_{C}(\mathrm{DEC}) \\
(\mathrm{K})\end{array}$ & $\begin{array}{c}\Theta(\mathrm{RA}) \\
(\operatorname{arcmin})\end{array}$ & $\begin{array}{l}\sigma \Theta(\mathrm{RA}) \\
(\operatorname{arcmin})\end{array}$ & $\begin{array}{l}\Theta(\mathrm{DEC}) \\
(\operatorname{arcmin})\end{array}$ & $\begin{array}{c}\sigma \Theta(\mathrm{DEC}) \\
(\operatorname{arcmin})\end{array}$ & $\begin{array}{c}\Theta_{s r c} \\
(\operatorname{arcmin})\end{array}$ & $\begin{array}{c}\sigma \Theta_{s r c} \\
(\operatorname{arcmin})\end{array}$ & $\mathrm{QF}^{\sharp}$ \\
\hline $\mathrm{G} 25.382-0.18^{\mathrm{b}}$ & 3.526 & 0.004 & 3.546 & 0.004 & 4.189 & 0.010 & 4.609 & 0.020 & 4.394 & 0.011 & $A$ \\
\hline $\mathrm{G} 25.382-0.18^{\mathrm{c}}$ & 3.534 & 0.003 & 3.380 & 0.006 & 4.270 & 0.008 & 4.464 & 0.018 & 4.366 & 0.010 & $A$ \\
\hline G25.766+0.21 & 0.987 & 0.003 & 0.874 & 0.003 & 4.267 & 0.032 & 7.862 & 0.109 & 5.792 & 0.046 & $C$ \\
\hline G28.790+3.48 & 2.549 & 0.005 & 2.556 & 0.004 & 6.544 & 0.072 & 6.099 & 0.021 & 6.317 & 0.036 & $B$ \\
\hline G29.944-0.04 & 2.682 & 0.005 & 2.588 & 0.005 & 4.279 & 0.021 & 6.119 & 0.041 & 5.117 & 0.021 & C \\
\hline G30.776-0.03 & 9.544 & 0.028 & 9.449 & 0.044 & 5.215 & 0.042 & 4.671 & 0.042 & 4.936 & 0.030 & $B$ \\
\hline G32.797+0.19 & $\cdots$ & $\cdots$ & $\cdots$ & $\cdots$ & $\cdots$ & $\cdots$ & $\cdots$ & $\cdots$ & $\cdots$ & $\cdots$ & .. \\
\hline G34.254+0.14 & $\cdots$ & $\cdots$ & $\cdots$ & $\cdots$ & $\cdots$ & $\cdots$ & $\cdots$ & $\cdots$ & $\cdots$ & $\cdots$ & $\cdots$ \\
\hline G35.194-1.75 & 4.547 & 0.025 & 4.509 & 0.004 & 3.270 & 0.068 & 3.442 & 0.009 & 3.355 & 0.035 & $A$ \\
\hline G40.505+2.54 & 0.986 & 0.002 & 1.041 & 0.003 & 3.874 & 0.022 & 4.158 & 0.034 & 4.013 & 0.020 & $C$ \\
\hline $\mathrm{G} 43.169+0.00^{\mathrm{b}}$ & 12.394 & 0.020 & 12.396 & 0.009 & 4.012 & 0.012 & 3.430 & 0.004 & 3.710 & 0.006 & $A$ \\
\hline $\mathrm{G} 43.169+0.00^{\mathrm{c}}$ & 11.917 & 0.016 & 11.811 & 0.006 & 4.085 & 0.012 & 3.534 & 0.003 & 3.799 & 0.006 & $B$ \\
\hline G45.451+0.06 & 2.374 & 0.003 & 2.294 & 0.003 & 3.623 & 0.011 & 3.702 & 0.012 & 3.662 & 0.008 & $A$ \\
\hline G46.495-0.25 & 0.683 & 0.003 & 0.674 & 0.002 & 4.796 & 0.049 & 5.504 & 0.040 & 5.138 & 0.032 & $B$ \\
\hline G48.930-0.28 & 3.218 & 0.011 & 3.257 & 0.010 & 4.932 & 0.042 & 4.894 & 0.051 & 4.913 & 0.033 & $C$ \\
\hline G48.997-0.29 & $\cdots$ & $\ldots$ & $\ldots$ & $\ldots$ & $\ldots$ & $\ldots$ & $\ldots$ & $\ldots$ & $\ldots$ & $\ldots$ & . \\
\hline G49.204-0.34 & 4.025 & 0.003 & 3.994 & 0.005 & 4.106 & 0.008 & 4.349 & 0.014 & 4.226 & 0.008 & $B$ \\
\hline G49.384-0.30 & 5.225 & 0.007 & 5.224 & 0.011 & 4.400 & 0.015 & 4.583 & 0.022 & 4.491 & 0.013 & $B$ \\
\hline G49.384-0.30 & 5.058 & 0.004 & 4.985 & 0.014 & 4.358 & 0.007 & 4.519 & 0.024 & 4.438 & 0.013 & $B$ \\
\hline G49.486-0.38 & 22.253 & 0.015 & 22.234 & 0.007 & 3.981 & 0.009 & 3.609 & 0.003 & 3.790 & 0.005 & $A$ \\
\hline G49.486-0.38c & 20.993 & 0.035 & 20.869 & 0.029 & 4.043 & 0.011 & 3.789 & 0.012 & 3.914 & 0.008 & $A$ \\
\hline G49.582-0.38 & 1.484 & 0.005 & 1.428 & 0.025 & 4.120 & 0.038 & 4.310 & 0.098 & 4.214 & 0.052 & $C$ \\
\hline G61.470+0.09 & 1.866 & 0.004 & 1.845 & 0.005 & 3.290 & 0.019 & 3.125 & 0.019 & 3.207 & 0.013 & $A$ \\
\hline G63.168+0.46 & $\ldots$ & $\cdots$ & $\cdots$ & $\cdots$ & $\cdots$ & $\cdots$ & $\cdots$ & $\cdots$ & $\ldots$ & $\ldots$ & . \\
\hline G70.300+1.60 & $\cdots$ & $\cdots$ & $\cdots$ & $\ldots$ & $\cdots$ & $\cdots$ & $\cdots$ & $\ldots$ & $\cdots$ & $\cdots$ & . \\
\hline G75.834+0.40 & $\cdots$ & $\ldots$ & $\cdots$ & $\ldots$ & $\ldots$ & $\ldots$ & $\cdots$ & $\ldots$ & $\ldots$ & $\cdots$ & . \\
\hline G76.383-0.62 & 3.506 & 0.008 & 3.562 & 0.003 & 3.257 & 0.029 & 3.518 & 0.010 & 3.385 & 0.016 & $A$ \\
\hline $\mathrm{G} 79.293+1.30^{\mathrm{b}}$ & 2.477 & 0.002 & 2.355 & 0.003 & 3.874 & 0.026 & 4.135 & 0.019 & 4.002 & 0.016 & $B$ \\
\hline $\mathrm{G} 79.293+1.30^{\mathrm{c}}$ & 2.468 & 0.004 & 2.408 & 0.003 & 4.234 & 0.015 & 4.242 & 0.012 & 4.238 & 0.010 & $B$ \\
\hline G81.681+0.54 & $\cdots$ & $\cdots$ & $\cdots$ & $\cdots$ & $\cdots$ & $\cdots$ & $\cdots$ & $\cdots$ & $\cdots$ & $\cdots$ & . \\
\hline G93.060+2.81 & 0.411 & 0.002 & 0.000 & 0.000 & 7.788 & 0.106 & 0.000 & 0.000 & 0.000 & 0.000 & $C$ \\
\hline G102.88-0.72 & 0.214 & 0.002 & 0.208 & 0.137 & 11.014 & 6.786 & 13.121 & 17.303 & 12.021 & 8.749 & $E$ \\
\hline G107.18-0.95 & 0.294 & 0.003 & 0.300 & 0.002 & 6.199 & 0.176 & 9.625 & 0.170 & 7.724 & 0.129 & $D$ \\
\hline G110.11+0.04 & 0.632 & 0.003 & 0.590 & 0.003 & 3.277 & 0.032 & 3.395 & 0.028 & 3.335 & 0.021 & $A$ \\
\hline
\end{tabular}


Table 5-Continued

\begin{tabular}{|c|c|c|c|c|c|c|c|c|c|c|c|}
\hline Source & $\begin{array}{c}T_{C}(\mathrm{RA}) \\
(\mathrm{K})\end{array}$ & $\begin{array}{c}\sigma T_{C}(\mathrm{RA}) \\
(\mathrm{K})\end{array}$ & $\begin{array}{c}T_{C}(\mathrm{DEC}) \\
(\mathrm{K})\end{array}$ & $\begin{array}{c}\sigma T_{C}(\mathrm{DEC}) \\
(\mathrm{K})\end{array}$ & $\begin{array}{c}\Theta(\mathrm{RA}) \\
(\operatorname{arcmin})\end{array}$ & $\begin{array}{l}\sigma \Theta(\mathrm{RA}) \\
(\operatorname{arcmin})\end{array}$ & $\begin{array}{l}\Theta(\mathrm{DEC}) \\
(\operatorname{arcmin})\end{array}$ & $\begin{array}{c}\sigma \Theta(\mathrm{DEC}) \\
(\operatorname{arcmin})\end{array}$ & $\begin{array}{c}\Theta_{s r c} \\
(\operatorname{arcmin})\end{array}$ & $\begin{array}{c}\sigma \Theta_{s r c} \\
(\operatorname{arcmin})\end{array}$ & $\mathrm{QF}^{\sharp}$ \\
\hline G111.53+0.82 & $\ldots$ & $\ldots$ & $\ldots$ & $\ldots$ & $\ldots$ & $\ldots$ & $\ldots$ & $\ldots$ & $\ldots$ & $\ldots$ & . \\
\hline G112.24+0.23 & 0.533 & 0.003 & 0.460 & 0.003 & 4.400 & 0.043 & 6.139 & 0.084 & 5.197 & 0.044 & $C$ \\
\hline G118.15+4.96 & 0.381 & 0.063 & 0.386 & 0.051 & 12.700 & 0.156 & 18.920 & 1.485 & 15.810 & 0.747 & $C$ \\
\hline $\mathrm{G} 133.72+1.21$ & 11.877 & 0.010 & 11.970 & 0.019 & 3.632 & 0.006 & 3.590 & 0.011 & 3.611 & 0.006 & $B$ \\
\hline G133.790+1.4 & $\ldots$ & $\ldots$ & $\ldots$ & $\ldots$ & $\ldots$ & $\ldots$ & $\cdots$ & $\cdots$ & $\ldots$ & $\cdots$ & \\
\hline G150.59-0.95 & 1.270 & 0.002 & 1.247 & 0.004 & 4.163 & 0.019 & 4.302 & 0.027 & 4.232 & 0.017 & $B$ \\
\hline $\mathrm{G} 151.587-0.2^{\mathrm{a}}$ & 1.447 & 0.003 & 1.488 & 0.003 & 4.732 & 0.026 & 4.366 & 0.018 & 4.545 & 0.016 & $C$ \\
\hline G151.59-0.23 & 1.447 & 0.003 & 1.488 & 0.003 & 4.732 & 0.026 & 4.366 & 0.018 & 4.545 & 0.016 & $B$ \\
\hline G151.636-0.5 & 1.447 & 0.003 & 1.488 & 0.003 & 4.732 & 0.026 & 4.366 & 0.018 & 4.545 & 0.016 & $D$ \\
\hline G155.36+2.61 & 0.355 & 0.002 & 0.378 & 0.002 & 4.723 & 0.064 & 4.719 & 0.066 & 4.721 & 0.046 & $C$ \\
\hline G169.19-0.90 & 0.181 & 0.002 & 0.242 & 0.003 & 4.204 & 0.188 & 4.244 & 0.098 & 4.224 & 0.106 & $C$ \\
\hline $\mathrm{G} 173.60+2.80$ & 0.489 & 0.002 & 0.491 & 0.002 & 5.335 & 0.057 & 4.899 & 0.059 & 5.112 & 0.041 & $C$ \\
\hline $\mathrm{G} 189.97+0.40$ & 0.281 & 0.003 & 0.269 & 0.002 & 6.258 & 0.245 & 11.734 & 0.356 & 8.569 & 0.212 & $C$ \\
\hline $\mathrm{G} 201.6+1.6$ & 0.223 & 0.003 & 0.282 & 0.003 & 8.894 & 0.380 & 6.838 & 0.166 & 7.798 & 0.192 & $D$ \\
\hline $\mathrm{G} 206.122-2.3^{\mathrm{a}}$ & 0.242 & 0.002 & 0.189 & 0.002 & 5.845 & 0.126 & 8.668 & 0.278 & 7.118 & 0.137 & $D$ \\
\hline G206.618-1.8 ${ }^{\mathrm{a}}$ & 0.272 & 0.004 & 0.410 & 0.003 & 12.601 & 1.604 & 12.667 & 0.545 & 12.634 & 0.849 & $D$ \\
\hline G209.01-19.4 & 50.125 & 0.089 & 48.491 & 0.021 & 4.453 & 0.016 & 4.577 & 0.004 & 4.515 & 0.008 & $A$ \\
\hline G213.71-12.6 & 2.097 & 0.004 & 2.077 & 0.003 & 3.332 & 0.013 & 3.188 & 0.009 & 3.259 & 0.008 & $A$ \\
\hline G220.508-2.8 & 0.112 & 0.004 & 0.222 & 0.005 & 5.185 & 0.569 & 8.980 & 0.661 & 6.823 & 0.451 & $E$ \\
\hline G223.7-1.9 & 0.212 & 0.003 & 0.215 & 0.003 & 11.802 & 0.532 & 9.423 & 0.645 & 10.546 & 0.432 & $E$ \\
\hline G227.79-0.12 & 0.243 & 0.002 & 0.231 & 0.003 & 6.811 & 0.191 & 8.535 & 0.493 & 7.624 & 0.245 & $C$ \\
\hline $\mathrm{G} 231.48-4.40$ & 0.332 & 0.002 & 0.328 & 0.002 & 5.974 & 0.122 & 7.225 & 0.159 & 6.570 & 0.099 & $C$ \\
\hline G243.16+0.37 & 1.087 & 0.003 & 1.075 & 0.005 & 7.391 & 0.062 & 7.079 & 0.083 & 7.233 & 0.052 & $C$ \\
\hline G345.03+1.54 & 0.539 & 0.004 & 0.458 & 0.005 & 8.246 & 0.480 & 7.292 & 2.940 & 7.754 & 1.580 & $E$ \\
\hline G345.23+1.03 & $\ldots$ & $\ldots$ & $\ldots$ & $\ldots$ & $\ldots$ & $\ldots$ & $\ldots$ & $\ldots$ & $\ldots$ & $\ldots$ & $\ldots$ \\
\hline G345.31+1.47 & $\cdots$ & $\ldots$ & $\ldots$ & $\cdots$ & $\ldots$ & $\ldots$ & $\cdots$ & $\ldots$ & $\ldots$ & $\cdots$ & $\ldots$ \\
\hline G345.40+1.41 & $\cdots$ & $\ldots$ & $\cdots$ & $\ldots$ & $\cdots$ & $\ldots$ & $\cdots$ & $\ldots$ & $\cdots$ & $\cdots$ & . \\
\hline G345.43-0.94 & $\ldots$ & $\ldots$ & $\ldots$ & $\ldots$ & $\ldots$ & $\ldots$ & $\ldots$ & $\ldots$ & $\ldots$ & $\ldots$ & $\ldots$ \\
\hline $\mathrm{G} 345.54+0.10$ & $\ldots$ & $\ldots$ & $\ldots$ & $\ldots$ & $\ldots$ & $\ldots$ & $\ldots$ & $\ldots$ & $\ldots$ & $\ldots$ & $\ldots$ \\
\hline G347.96-0.44 & $\cdots$ & $\ldots$ & $\ldots$ & $\ldots$ & $\ldots$ & $\ldots$ & $\ldots$ & $\ldots$ & $\ldots$ & $\ldots$ & $\ldots$ \\
\hline G348.23-0.98 & 2.334 & 0.006 & 2.418 & 0.009 & 3.828 & 0.034 & 3.532 & 0.034 & 3.677 & 0.024 & $B$ \\
\hline G348.72-1.03 & $\cdots$ & $\cdots$ & $\ldots$ & $\cdots$ & $\ldots$ & $\cdots$ & $\cdots$ & $\ldots$ & $\ldots$ & $\cdots$ & $\ldots$ \\
\hline G350.13+0.09 & $\ldots$ & $\ldots$ & $\ldots$ & $\ldots$ & $\ldots$ & $\ldots$ & $\ldots$ & $\ldots$ & $\ldots$ & $\ldots$ & $\ldots$ \\
\hline G351.063+0.6 & 2.796 & 0.007 & 2.771 & 0.005 & 6.775 & 0.089 & 5.397 & 0.045 & 6.047 & 0.047 & $C$ \\
\hline
\end{tabular}


Table 5-Continued

\begin{tabular}{|c|c|c|c|c|c|c|c|c|c|c|c|}
\hline Source & $\begin{array}{c}T_{C}(\mathrm{RA}) \\
(\mathrm{K})\end{array}$ & $\begin{array}{c}\sigma T_{C}(\mathrm{RA}) \\
(\mathrm{K})\end{array}$ & $\begin{array}{c}T_{C}(\mathrm{DEC}) \\
(\mathrm{K})\end{array}$ & $\begin{array}{c}\sigma T_{C}(\mathrm{DEC}) \\
(\mathrm{K})\end{array}$ & $\begin{array}{c}\Theta(\mathrm{RA}) \\
(\operatorname{arcmin})\end{array}$ & $\begin{array}{l}\sigma \Theta(\mathrm{RA}) \\
(\operatorname{arcmin})\end{array}$ & $\begin{array}{l}\Theta(\mathrm{DEC}) \\
(\operatorname{arcmin})\end{array}$ & $\begin{array}{c}\sigma \Theta(\mathrm{DEC}) \\
(\text { arcmin })\end{array}$ & $\begin{array}{c}\Theta_{s r c} \\
(\operatorname{arcmin})\end{array}$ & $\begin{array}{c}\sigma \Theta_{s r c} \\
(\operatorname{arcmin})\end{array}$ & $\mathrm{QF}^{\sharp}$ \\
\hline G351.192+0.7 & $\ldots$ & $\ldots$ & .. & $\ldots$ & $\ldots$ & $\cdots$ & $\ldots$ & $\ldots$ & $\ldots$ & $\ldots$ & $\ldots$ \\
\hline G351.201+0.4 & 2.261 & 0.007 & 2.309 & 0.005 & 5.609 & 0.061 & 4.822 & 0.038 & 5.201 & 0.035 & C \\
\hline $\mathrm{G} 351.246+0.7^{\mathrm{a}}$ & 6.466 & 0.017 & 6.601 & 0.031 & 4.605 & 0.028 & 4.676 & 0.060 & 4.641 & 0.033 & $C$ \\
\hline G351.358+0.6 & $\ldots$ & $\ldots$ & $\ldots$ & $\ldots$ & $\ldots$ & $\ldots$ & $\ldots$ & $\ldots$ & $\ldots$ & $\ldots$ & . \\
\hline $\mathrm{G} 351.368+0.7^{\mathrm{a}}$ & 7.991 & 0.044 & 7.812 & 0.016 & 6.108 & 0.086 & 4.982 & 0.024 & 5.517 & 0.041 & $C$ \\
\hline G351.467-0.4 & 0.814 & 0.003 & 0.774 & 0.003 & 3.833 & 0.034 & 3.632 & 0.052 & 3.731 & 0.032 & $B$ \\
\hline G351.613-1.2 & $\cdots$ & $\cdots$ & $\cdots$ & $\cdots$ & $\cdots$ & $\cdots$ & $\ldots$ & $\cdots$ & . & $\ldots$ & $\cdots$ \\
\hline G351.64-1.26 & 6.139 & 0.006 & 6.242 & 0.011 & 3.504 & 0.011 & 3.763 & 0.022 & 3.631 & 0.012 & $A$ \\
\hline G351.69-1.17 & $\ldots$ & $\ldots$ & $\ldots$ & $\ldots$ & $\ldots$ & $\ldots$ & $\ldots$ & $\ldots$ & $\ldots$ & $\ldots$ & $\ldots$ \\
\hline G352.61-0.17 & $\ldots$ & $\ldots$ & $\ldots$ & $\ldots$ & $\ldots$ & $\ldots$ & $\ldots$ & $\ldots$ & $\ldots$ & $\ldots$ & $\ldots$ \\
\hline G353.035+0.7 & $\ldots$ & $\ldots$ & $\ldots$ & $\ldots$ & $\ldots$ & $\ldots$ & $\ldots$ & $\ldots$ & $\ldots$ & $\ldots$ & $\ldots$ \\
\hline G353.08+0.36 & 1.618 & 0.005 & 1.621 & 0.010 & 7.612 & 0.177 & 6.121 & 0.284 & 6.826 & 0.177 & $D$ \\
\hline G353.14+0.66 & $\ldots$ & $\ldots$ & $\ldots$ & $\ldots$ & $\ldots$ & $\ldots$ & $\ldots$ & $\ldots$ & $\ldots$ & $\ldots$ & $\ldots$ \\
\hline G353.186+0.8 & $\ldots$ & $\ldots$ & $\ldots$ & $\ldots$ & $\ldots$ & $\ldots$ & $\ldots$ & $\ldots$ & $\ldots$ & $\ldots$ & $\ldots$ \\
\hline G353.21+0.91 & $\ldots$ & $\ldots$ & $\ldots$ & $\ldots$ & $\ldots$ & $\ldots$ & $\ldots$ & $\ldots$ & $\ldots$ & $\ldots$ & $\ldots$ \\
\hline G353.398-0.3 & $\ldots$ & $\ldots$ & $\ldots$ & $\ldots$ & $\ldots$ & $\ldots$ & $\ldots$ & $\ldots$ & $\ldots$ & $\ldots$ & $\ldots$ \\
\hline G353.43-0.37 & $\cdots$ & $\cdots$ & $\cdots$ & $\cdots$ & $\cdots$ & $\cdots$ & $\cdots$ & $\ldots$ & $\cdots$ & $\ldots$ & $\cdots$ \\
\hline
\end{tabular}

${ }^{\sharp}$ Continuum quality factor. See text. QF is an evaluation of the quality of the parameters measured for the continuum scans. It is based on the accuracy of the Gaussian fit to the emission feature, the uncertainty in the baseline models and the contrast between the target source emission and any emission from possible sub-structures or nearby confusing sources.

${ }^{a}$ M16, M17, NGC 6334, Rosette and S209 were observed at different positions in the ${ }^{3} \mathrm{He}$ survey.

${ }^{\mathrm{b}}$ Observed in the $\mathrm{C}$ II survey.

${ }^{\mathrm{c}}$ Observed in the ${ }^{3} \mathrm{He}$ survey. 
Table 6. Radio Emission Continuum Parameters (Switched Power Observing Mode)

\begin{tabular}{|c|c|c|c|c|c|c|c|c|c|c|c|}
\hline Source & $\begin{array}{c}T_{C}(\mathrm{RA}) \\
(\mathrm{K})\end{array}$ & $\begin{array}{c}\sigma T_{C}(\mathrm{RA}) \\
(\mathrm{K})\end{array}$ & $\begin{array}{c}T_{C}(\mathrm{DEC}) \\
(\mathrm{K})\end{array}$ & $\begin{array}{c}\sigma T_{C}(\mathrm{DEC}) \\
(\mathrm{K})\end{array}$ & $\begin{array}{c}\Theta(\mathrm{RA}) \\
(\operatorname{arcmin})\end{array}$ & $\begin{array}{l}\sigma \Theta(\mathrm{RA}) \\
(\operatorname{arcmin})\end{array}$ & $\begin{array}{l}\Theta(\mathrm{DEC}) \\
(\operatorname{arcmin})\end{array}$ & $\begin{array}{c}\sigma \Theta(\mathrm{DEC}) \\
(\operatorname{arcmin})\end{array}$ & $\begin{array}{c}\Theta_{s r c} \\
(\operatorname{arcmin})\end{array}$ & $\begin{array}{c}\sigma \Theta_{s r c} \\
(\operatorname{arcmin})\end{array}$ & $\mathrm{QF}^{\sharp}$ \\
\hline $\mathrm{G} 0.605+0.325$ & $\ldots$ & $\ldots$ & $\ldots$ & $\ldots$ & $\ldots$ & $\ldots$ & $\ldots$ & $\ldots$ & $\ldots$ & $\ldots$ & $\ldots$ \\
\hline G0.665-0.035 & 8.590 & 0.368 & 8.088 & 0.300 & 4.365 & 0.157 & 5.871 & 0.102 & 5.062 & 0.101 & $A$ \\
\hline G1.13-0.1 & 1.311 & 0.016 & 1.340 & 0.014 & 4.837 & 0.091 & 6.415 & 0.088 & 5.570 & 0.065 & $C$ \\
\hline $\mathrm{G} 2.90+0.0$ & $\ldots$ & $\ldots$ & $\ldots$ & $\ldots$ & $\ldots$ & $\ldots$ & $\cdots$ & $\cdots$ & $\ldots$ & $\ldots$ & $\ldots$ \\
\hline G3.270-0.101 & $\ldots$ & $\ldots$ & $\ldots$ & $\ldots$ & $\ldots$ & $\ldots$ & $\ldots$ & $\ldots$ & $\ldots$ & $\ldots$ & $\ldots$ \\
\hline G5.899-0.427 & 3.271 & 0.006 & 3.077 & 0.013 & 5.186 & 0.011 & 4.450 & 0.023 & 4.804 & 0.014 & $B$ \\
\hline G5.956-1.265 & $\ldots$ & $\cdots$ & $\ldots$ & $\ldots$ & $\ldots$ & $\cdots$ & $\ldots$ & $\ldots$ & $\ldots$ & $\cdots$ & $\ldots$ \\
\hline G5.973-1.178 & 6.327 & 0.017 & 6.197 & 0.022 & 4.853 & 0.015 & 5.069 & 0.023 & 4.959 & 0.014 & $B$ \\
\hline $\mathrm{G} 8.137+0.228$ & 1.861 & 0.007 & 1.808 & 0.006 & 3.572 & 0.014 & 3.463 & 0.012 & 3.517 & 0.009 & $A$ \\
\hline G10.159-0.34 & 10.086 & 0.009 & 9.992 & 0.025 & 4.354 & 0.005 & 3.973 & 0.012 & 4.159 & 0.007 & $A$ \\
\hline G10.315-0.15 & 3.056 & 0.009 & 2.984 & 0.004 & 4.081 & 0.015 & 3.786 & 0.006 & 3.931 & 0.008 & $A$ \\
\hline G10.617-0.38 & 2.214 & 0.006 & 2.231 & 0.005 & 3.921 & 0.013 & 4.404 & 0.013 & 4.155 & 0.009 & $B$ \\
\hline G12.807-0.20 & 9.765 & 0.028 & 9.768 & 0.015 & 3.957 & 0.013 & 3.340 & 0.006 & 3.636 & 0.007 & $A$ \\
\hline $\mathrm{G} 13.875+0.28$ & 1.272 & 0.004 & 1.253 & 0.004 & 3.533 & 0.012 & 3.397 & 0.012 & 3.464 & 0.008 & $A$ \\
\hline G14.626+0.08 & 0.752 & 0.003 & 0.706 & 0.002 & 8.552 & 0.079 & 7.203 & 0.065 & 7.849 & 0.050 & $C$ \\
\hline $\mathrm{G} 15.035-0.68^{\mathrm{a}}$ & $\ldots$ & $\ldots$ & $\ldots$ & $\ldots$ & $\ldots$ & $\ldots$ & $\ldots$ & $\ldots$ & $\ldots$ & $\ldots$ & $\ldots$ \\
\hline G15.095-0.71 & 34.323 & 0.860 & 25.119 & 0.476 & 6.986 & 0.068 & 8.542 & 0.075 & 7.725 & 0.051 & $C$ \\
\hline G15.181-0.62 & $\ldots$ & $\ldots$ & $\ldots$ & $\ldots$ & $\ldots$ & $\ldots$ & $\ldots$ & $\ldots$ & $\ldots$ & $\ldots$ & $\ldots$ \\
\hline G15.198-0.76 & $\ldots$ & $\ldots$ & $\ldots$ & $\ldots$ & $\ldots$ & $\ldots$ & $\ldots$ & $\ldots$ & $\ldots$ & $\ldots$ & $\ldots$ \\
\hline $\mathrm{G} 16.936+0.76^{\mathrm{b}}$ & $\ldots$ & $\ldots$ & $\ldots$ & $\ldots$ & $\ldots$ & $\ldots$ & $\ldots$ & $\ldots$ & $\ldots$ & $\ldots$ & $\ldots$ \\
\hline $\mathrm{G} 16.936+0.76^{\mathrm{a}, c}$ & $\ldots$ & $\ldots$ & $\ldots$ & $\ldots$ & $\ldots$ & $\ldots$ & $\ldots$ & $\ldots$ & $\ldots$ & $\ldots$ & $\ldots$ \\
\hline $\mathrm{G} 16.984+0.93^{\mathrm{a}, c}$ & $\ldots$ & $\ldots$ & $\ldots$ & $\ldots$ & $\ldots$ & $\ldots$ & $\ldots$ & $\ldots$ & $\ldots$ & $\ldots$ & $\ldots$ \\
\hline G16.995+0.86 & $\ldots$ & $\ldots$ & $\cdots$ & $\ldots$ & $\ldots$ & $\ldots$ & $\cdots$ & $\cdots$ & $\ldots$ & $\cdots$ & $\ldots$ \\
\hline G18.143-0.28 & 1.762 & 0.005 & 1.596 & 0.004 & 4.248 & 0.014 & 4.832 & 0.022 & 4.531 & 0.013 & $B$ \\
\hline G18.686+1.96 & 1.664 & 0.002 & 1.749 & 0.003 & 4.293 & 0.007 & 4.245 & 0.009 & 4.269 & 0.006 & $B$ \\
\hline G19.066-0.28 & $\ldots$ & $\ldots$ & 1.130 & 0.008 & $\ldots$ & $\ldots$ & 3.657 & 0.029 & 3.657 & 0.029 & $B$ \\
\hline G19.608-0.23 & 1.533 & 0.012 & 1.523 & 0.009 & 3.074 & 0.030 & 3.836 & 0.026 & 3.434 & 0.020 & $B$ \\
\hline G20.733-0.09 & 1.142 & 0.024 & 1.117 & 0.020 & 4.776 & 0.060 & 6.003 & 0.133 & 5.354 & 0.068 & $A$ \\
\hline $\mathrm{G} 23.421-0.21^{\mathrm{b}}$ & 1.769 & 0.007 & 1.884 & 0.005 & 5.138 & 0.025 & 5.125 & 0.019 & 5.132 & 0.015 & $B$ \\
\hline $\mathrm{G} 23.421-0.21^{\mathrm{c}}$ & $\cdots$ & $\ldots$ & $\ldots$ & $\ldots$ & $\ldots$ & $\ldots$ & $\ldots$ & $\ldots$ & $\ldots$ & $\ldots$ & $\ldots$ \\
\hline G23.706+0.17 & $\cdots$ & $\cdots$ & $\cdots$ & $\cdots$ & $\cdots$ & $\cdots$ & $\cdots$ & $\cdots$ & $\cdots$ & $\cdots$ & $\cdots$ \\
\hline $\mathrm{G} 24.467+0.48$ & 1.389 & 0.005 & 1.372 & 0.005 & 3.640 & 0.015 & 3.621 & 0.017 & 3.630 & 0.011 & $A$ \\
\hline $\mathrm{G} 24.484+0.21$ & $\cdots$ & $\cdots$ & $\cdots$ & $\cdots$ & $\cdots$ & $\cdots$ & $\cdots$ & $\cdots$ & $\cdots$ & $\cdots$ & $\cdots$ \\
\hline $\mathrm{G} 24.805+0.09$ & 1.290 & 0.005 & 1.151 & 0.004 & 5.782 & 0.033 & 5.471 & 0.023 & 5.625 & 0.020 & $B$ \\
\hline
\end{tabular}


Table 6-Continued

\begin{tabular}{|c|c|c|c|c|c|c|c|c|c|c|c|}
\hline Source & $\begin{array}{c}T_{C}(\mathrm{RA}) \\
(\mathrm{K})\end{array}$ & $\begin{array}{c}\sigma T_{C}(\mathrm{RA}) \\
(\mathrm{K})\end{array}$ & $\begin{array}{c}T_{C}(\mathrm{DEC}) \\
(\mathrm{K})\end{array}$ & $\begin{array}{c}\sigma T_{C}(\mathrm{DEC}) \\
(\mathrm{K})\end{array}$ & $\begin{array}{c}\Theta(\mathrm{RA}) \\
(\operatorname{arcmin})\end{array}$ & $\begin{array}{l}\sigma \Theta(\mathrm{RA}) \\
(\operatorname{arcmin})\end{array}$ & $\begin{array}{l}\Theta(\mathrm{DEC}) \\
(\operatorname{arcmin})\end{array}$ & $\begin{array}{c}\sigma \Theta(\mathrm{DEC}) \\
(\operatorname{arcmin})\end{array}$ & $\begin{array}{c}\Theta_{s r c} \\
(\operatorname{arcmin})\end{array}$ & $\begin{array}{c}\sigma \Theta_{s r c} \\
(\operatorname{arcmin})\end{array}$ & $\mathrm{QF}^{\sharp}$ \\
\hline $\mathrm{G} 25.382-0.18^{\mathrm{b}}$ & 3.814 & 0.022 & 3.776 & 0.004 & 4.221 & 0.026 & 4.443 & 0.006 & 4.330 & 0.014 & $A$ \\
\hline G25.382-0.18 & 3.260 & 0.059 & 3.267 & 0.067 & 4.162 & 0.053 & 4.573 & 0.068 & 4.363 & 0.043 & $A$ \\
\hline $\mathrm{G} 25.766+0.21$ & $\ldots$ & $\ldots$ & $\ldots$ & $\ldots$ & $\ldots$ & $\ldots$ & $\cdots$ & $\cdots$ & $\ldots$ & $\cdots$ & \\
\hline $\mathrm{G} 28.790+3.48$ & 2.835 & 0.023 & 2.673 & 0.004 & 5.796 & 0.048 & 6.528 & 0.011 & 6.151 & 0.026 & $B$ \\
\hline G29.944-0.04 & 2.414 & 0.096 & 2.287 & 0.117 & 4.409 & 0.109 & 5.196 & 0.084 & 4.786 & 0.071 & $A$ \\
\hline G30.776-0.03 & 9.687 & 0.091 & 9.664 & 0.163 & 5.324 & 0.032 & 5.162 & 0.043 & 5.242 & 0.027 & $B$ \\
\hline G32.797+0.19 & 1.491 & 0.004 & 1.457 & 0.003 & 3.646 & 0.013 & 3.339 & 0.009 & 3.489 & 0.008 & $A$ \\
\hline $\mathrm{G} 34.254+0.14$ & 4.102 & 0.005 & 4.114 & 0.010 & 3.691 & 0.006 & 3.601 & 0.010 & 3.645 & 0.006 & $A$ \\
\hline G35.194-1.75 & 4.953 & 0.009 & 4.936 & 0.005 & 3.486 & 0.007 & 3.459 & 0.005 & 3.472 & 0.004 & $A$ \\
\hline G40.505+2.54 & 0.865 & 0.014 & 0.785 & 0.023 & 3.759 & 0.031 & 4.262 & 0.149 & 4.003 & 0.072 & $A$ \\
\hline $\mathrm{G} 43.169+0.00^{\mathrm{b}}$ & 12.046 & 0.036 & 12.149 & 0.034 & 4.449 & 0.016 & 3.684 & 0.012 & 4.048 & 0.010 & $A$ \\
\hline $\mathrm{G} 43.169+0.00^{\mathrm{c}}$ & 10.784 & 0.087 & 11.067 & 0.112 & 4.113 & 0.034 & 3.785 & 0.031 & 3.946 & 0.023 & $C$ \\
\hline $\mathrm{G} 45.451+0.06$ & 2.291 & 0.010 & 2.318 & 0.004 & 3.770 & 0.019 & 3.885 & 0.008 & 3.827 & 0.010 & $A$ \\
\hline G46.495-0.25 & 0.558 & 0.013 & 0.555 & 0.014 & 4.575 & 0.085 & 4.948 & 0.122 & 4.758 & 0.074 & $A$ \\
\hline G48.930-0.28 & 3.198 & 0.009 & 3.126 & 0.011 & 5.565 & 0.019 & 6.209 & 0.041 & 5.878 & 0.022 & $B$ \\
\hline G48.997-0.29 & 2.518 & 0.010 & $\ldots$ & $\ldots$ & 6.344 & 0.034 & $\ldots$ & $\ldots$ & 6.344 & 0.034 & $C$ \\
\hline G49.204-0.34 & 3.896 & 0.010 & 4.009 & 0.005 & 4.364 & 0.014 & 4.212 & 0.006 & 4.287 & 0.007 & $B$ \\
\hline G49.384-0.30 & 3.828 & 0.027 & 3.540 & 0.011 & 4.595 & 0.038 & 4.158 & 0.015 & 4.371 & 0.020 & $B$ \\
\hline G49.384-0.30 & $\ldots$ & & $\ldots$ & & .. & $\ldots$ & $\ldots$ & $\ldots$ & $\ldots$ & $\ldots$ & \\
\hline $\mathrm{G} 49.486-0.38^{\mathrm{b}}$ & 22.855 & 0.043 & 22.880 & 0.066 & 4.083 & 0.009 & 3.680 & 0.013 & 3.877 & 0.008 & $A$ \\
\hline G49.486-0.38c & 20.349 & 0.387 & 20.610 & 0.334 & 4.287 & 0.024 & 3.699 & 0.026 & 3.982 & 0.018 & $C$ \\
\hline G49.582-0.38 & $\ldots$ & $\ldots$ & $\ldots$ & $\ldots$ & $\ldots$ & $\ldots$ & $\ldots$ & $\ldots$ & $\ldots$ & $\ldots$ & . \\
\hline G61.470+0.09 & 1.835 & 0.004 & 1.823 & 0.003 & 3.547 & 0.009 & 3.274 & 0.006 & 3.408 & 0.005 & $A$ \\
\hline $\mathrm{G} 63.168+0.46$ & 0.911 & 0.016 & 0.872 & 0.010 & 4.178 & 0.048 & 4.234 & 0.137 & 4.206 & 0.072 & $B$ \\
\hline G70.300+1.60 & 3.399 & 0.015 & 3.464 & 0.007 & 3.810 & 0.020 & 3.912 & 0.010 & 3.861 & 0.011 & $A$ \\
\hline G75.834+0.40 & 2.639 & 0.004 & 2.591 & 0.009 & 3.567 & 0.007 & 3.744 & 0.017 & 3.654 & 0.009 & $B$ \\
\hline G76.383-0.62 & 3.544 & 0.008 & 3.557 & 0.005 & 3.534 & 0.009 & 3.564 & 0.006 & 3.549 & 0.005 & $A$ \\
\hline G79.293+1.30 & 2.479 & 0.005 & 2.488 & 0.007 & 4.660 & 0.012 & 4.596 & 0.014 & 4.628 & 0.009 & $B$ \\
\hline $\mathrm{G} 79.293+1.30^{\mathrm{c}}$ & 2.097 & 0.024 & 2.232 & 0.018 & 4.151 & 0.030 & 4.417 & 0.034 & 4.282 & 0.023 & $C$ \\
\hline G81.681+0.54 & 6.432 & 0.010 & 6.422 & 0.006 & 3.438 & 0.006 & 3.408 & 0.004 & 3.423 & 0.003 & $A$ \\
\hline G93.060+2.81 & $\ldots$ & $\ldots$ & $\ldots$ & $\ldots$ & $\ldots$ & $\ldots$ & $\ldots$ & $\ldots$ & $\ldots$ & $\ldots$ & $\ldots$ \\
\hline G102.88-0.72 & $\ldots$ & $\ldots$ & $\ldots$ & $\ldots$ & $\ldots$ & $\ldots$ & $\ldots$ & $\ldots$ & $\ldots$ & $\ldots$ & $\ldots$ \\
\hline G107.18-0.95 & $\ldots$ & $\ldots$ & $\ldots$ & $\ldots$ & $\ldots$ & $\ldots$ & $\ldots$ & $\ldots$ & $\ldots$ & $\ldots$ & $\ldots$ \\
\hline $\mathrm{G} 110.11+0.04$ & 0.602 & 0.009 & 0.569 & 0.005 & 3.357 & 0.047 & 3.275 & 0.048 & 3.316 & 0.034 & A \\
\hline
\end{tabular}


Table 6-Continued

\begin{tabular}{|c|c|c|c|c|c|c|c|c|c|c|c|}
\hline Source & $\begin{array}{c}T_{C}(\mathrm{RA}) \\
(\mathrm{K})\end{array}$ & $\begin{array}{c}\sigma T_{C}(\mathrm{RA}) \\
(\mathrm{K})\end{array}$ & $\begin{array}{c}T_{C}(\mathrm{DEC}) \\
(\mathrm{K})\end{array}$ & $\begin{array}{c}\sigma T_{C}(\mathrm{DEC}) \\
(\mathrm{K})\end{array}$ & $\begin{array}{c}\Theta(\mathrm{RA}) \\
(\operatorname{arcmin})\end{array}$ & $\begin{array}{l}\sigma \Theta(\mathrm{RA}) \\
(\operatorname{arcmin})\end{array}$ & $\begin{array}{l}\Theta(\mathrm{DEC}) \\
(\operatorname{arcmin})\end{array}$ & $\begin{array}{c}\sigma \Theta(\mathrm{DEC}) \\
(\operatorname{arcmin})\end{array}$ & $\begin{array}{c}\Theta_{s r c} \\
(\operatorname{arcmin})\end{array}$ & $\begin{array}{c}\sigma \Theta_{s r c} \\
(\operatorname{arcmin})\end{array}$ & $\mathrm{QF}^{\sharp}$ \\
\hline G111.53+0.82 & 4.107 & 0.026 & 4.113 & 0.025 & 4.176 & 0.021 & 4.271 & 0.025 & 4.223 & 0.016 & $B$ \\
\hline $\mathrm{G} 112.24+0.23$ & 0.451 & 0.006 & 0.455 & 0.007 & 4.360 & 0.057 & 5.511 & 0.076 & 4.902 & 0.047 & $B$ \\
\hline G118.15+4.96 & $\ldots$ & $\ldots$ & $\ldots$ & $\ldots$ & $\ldots$ & $\ldots$ & $\ldots$ & $\ldots$ & $\ldots$ & $\ldots$ & . \\
\hline $\mathrm{G} 133.72+1.21$ & 11.688 & 0.084 & 11.470 & 0.075 & 3.765 & 0.014 & 3.916 & 0.013 & 3.840 & 0.009 & $B$ \\
\hline G133.790+1.4 & 2.907 & 0.052 & 3.267 & 0.042 & 4.296 & 0.064 & 4.136 & 0.031 & 4.215 & 0.035 & $C$ \\
\hline G150.59-0.95 & 1.208 & 0.013 & 1.217 & 0.012 & 4.755 & 0.045 & 5.049 & 0.069 & 4.900 & 0.041 & $B$ \\
\hline $\mathrm{G} 151.587-0.2^{\mathrm{a}}$ & 1.341 & 0.016 & 1.369 & 0.014 & 5.021 & 0.045 & 4.220 & 0.055 & 4.603 & 0.036 & $C$ \\
\hline $\mathrm{G} 151.59-0.23^{\mathrm{a}}$ & 1.341 & 0.016 & 1.369 & 0.014 & 5.021 & 0.045 & 4.220 & 0.055 & 4.603 & 0.036 & $B$ \\
\hline G151.636-0.5 & 1.341 & 0.016 & 1.369 & 0.014 & 5.021 & 0.045 & 4.220 & 0.055 & 4.603 & 0.036 & $B$ \\
\hline G155.36+2.61 & 0.282 & 0.005 & 0.281 & 0.007 & 4.047 & 0.082 & 3.989 & 0.112 & 4.018 & 0.069 & $B$ \\
\hline G169.19-0.90 & 0.195 & 0.001 & 0.194 & 0.021 & 4.626 & 0.057 & 4.111 & 0.117 & 4.361 & 0.068 & $B$ \\
\hline $\mathrm{G} 173.60+2.80$ & 0.426 & 0.006 & 0.395 & 0.016 & 4.762 & 0.102 & 4.580 & 0.174 & 4.670 & 0.102 & $A$ \\
\hline $\mathrm{G} 189.97+0.40$ & $\ldots$ & $\ldots$ & $\ldots$ & $\ldots$ & $\ldots$ & $\ldots$ & $\ldots$ & $\ldots$ & $\ldots$ & $\ldots$ & . \\
\hline G201.6+1.6 & 0.222 & 0.007 & 0.212 & 0.006 & 5.682 & 0.175 & 5.353 & 0.171 & 5.515 & 0.123 & $C$ \\
\hline G206.122-2.3 & $\ldots$ & $\ldots$ & $\ldots$ & $\ldots$ & $\ldots$ & $\ldots$ & $\ldots$ & $\ldots$ & $\ldots$ & $\ldots$ & $\ldots$ \\
\hline G206.618-1.8 & $\ldots$ & $\ldots$ & $\ldots$ & $\ldots$ & $\ldots$ & $\ldots$ & $\ldots$ & $\ldots$ & $\ldots$ & $\ldots$ & $\ldots$ \\
\hline G209.01-19.4 & $\ldots$ & $\ldots$ & $\ldots$ & $\ldots$ & $\ldots$ & $\ldots$ & $\ldots$ & $\ldots$ & $\ldots$ & $\ldots$ & $\ldots$ \\
\hline G213.71-12.6 & 2.204 & 0.021 & 2.179 & 0.010 & 3.248 & 0.019 & 3.298 & 0.055 & 3.273 & 0.029 & $A$ \\
\hline G220.508-2.8 & 0.092 & 0.015 & 0.079 & 0.004 & 5.306 & 0.329 & 6.002 & 0.715 & 5.643 & 0.379 & $C$ \\
\hline G223.7-1.9 & 0.100 & 0.016 & 0.107 & 0.014 & 7.626 & 0.393 & 10.785 & 0.733 & 9.069 & 0.387 & $C$ \\
\hline G227.79-0.12 & 0.166 & 0.005 & 0.166 & 0.004 & 5.037 & 0.146 & 6.673 & 0.233 & 5.798 & 0.132 & $A$ \\
\hline G231.48-4.40 & 0.248 & 0.002 & 0.240 & 0.003 & 5.471 & 0.070 & 6.223 & 0.134 & 5.835 & 0.073 & $B$ \\
\hline $\mathrm{G} 243.16+0.37$ & 0.831 & 0.008 & 0.802 & 0.009 & 5.582 & 0.073 & 5.845 & 0.038 & 5.712 & 0.042 & $B$ \\
\hline G345.03+1.54 & 0.524 & 0.004 & 0.425 & 0.004 & 7.064 & 0.091 & 10.270 & 0.232 & 8.518 & 0.111 & $D$ \\
\hline G345.23+1.03 & 2.069 & 0.007 & 2.015 & 0.012 & 3.742 & 0.014 & 4.486 & 0.037 & 4.097 & 0.019 & $B$ \\
\hline G345.31+1.47 & 1.787 & 0.006 & 1.698 & 0.003 & 5.584 & 0.035 & 5.346 & 0.013 & 5.463 & 0.018 & $B$ \\
\hline G345.40+1.41 & $\ldots$ & $\ldots$ & $\ldots$ & $\ldots$ & $\ldots$ & $\ldots$ & $\ldots$ & $\ldots$ & $\ldots$ & $\ldots$ & . \\
\hline G345.43-0.94 & 7.816 & 0.017 & 8.191 & 0.010 & 3.509 & 0.009 & 3.811 & 0.006 & 3.657 & 0.005 & $A$ \\
\hline G345.54+0.10 & 0.436 & 0.004 & 0.428 & 0.003 & 3.667 & 0.035 & 4.085 & 0.043 & 3.871 & 0.028 & $C$ \\
\hline G347.96-0.44 & 0.446 & 0.002 & 0.416 & 0.002 & 4.684 & 0.032 & 4.493 & 0.030 & 4.588 & 0.022 & $B$ \\
\hline G348.23-0.98 & 2.821 & 0.004 & 2.826 & 0.004 & 3.897 & 0.007 & 3.833 & 0.007 & 3.865 & 0.005 & $A$ \\
\hline G348.72-1.03 & 7.762 & 0.041 & 7.499 & 0.018 & 3.906 & 0.024 & 4.178 & 0.012 & 4.040 & 0.014 & $B$ \\
\hline G350.13+0.09 & 1.880 & 0.007 & 1.791 & 0.009 & 3.871 & 0.016 & 3.358 & 0.020 & 3.606 & 0.013 & $B$ \\
\hline G351.063+0.6 & 3.173 & 0.008 & 3.015 & 0.013 & 7.147 & 0.030 & 5.204 & 0.038 & 6.099 & 0.026 & $C$ \\
\hline
\end{tabular}


Table 6-Continued

\begin{tabular}{|c|c|c|c|c|c|c|c|c|c|c|c|}
\hline Source & $\begin{array}{c}T_{C}(\mathrm{RA}) \\
(\mathrm{K})\end{array}$ & $\begin{array}{c}\sigma T_{C}(\mathrm{RA}) \\
(\mathrm{K})\end{array}$ & $\begin{array}{c}T_{C}(\mathrm{DEC}) \\
(\mathrm{K})\end{array}$ & $\begin{array}{c}\sigma T_{C}(\mathrm{DEC}) \\
(\mathrm{K})\end{array}$ & $\begin{array}{c}\Theta(\mathrm{RA}) \\
(\operatorname{arcmin})\end{array}$ & $\begin{array}{l}\sigma \Theta(\mathrm{RA}) \\
(\operatorname{arcmin})\end{array}$ & $\begin{array}{l}\Theta(\mathrm{DEC}) \\
(\operatorname{arcmin})\end{array}$ & $\begin{array}{c}\sigma \Theta(\mathrm{DEC}) \\
(\operatorname{arcmin})\end{array}$ & $\begin{array}{c}\Theta_{s r c} \\
(\operatorname{arcmin})\end{array}$ & $\begin{array}{c}\sigma \Theta_{s r c} \\
(\operatorname{arcmin})\end{array}$ & $\mathrm{QF}^{\sharp}$ \\
\hline G351.192+0.7 & 2.885 & 0.021 & 5.426 & 0.017 & 5.994 & 0.073 & 5.058 & 0.023 & 5.506 & 0.036 & $B$ \\
\hline $\mathrm{G} 351.201+0.4$ & 2.363 & 0.014 & 2.338 & 0.019 & 4.362 & 0.031 & 3.998 & 0.043 & 4.176 & 0.027 & $B$ \\
\hline $\mathrm{G} 351.246+0.7^{\mathrm{a}}$ & $\ldots$ & $\ldots$ & $\ldots$ & $\ldots$ & $\ldots$ & $\ldots$ & $\ldots$ & $\ldots$ & $\ldots$ & $\ldots$ & . \\
\hline G351.358+0.6 & 7.752 & 0.069 & 7.405 & 0.026 & 4.872 & 0.075 & 5.734 & 0.034 & 5.285 & 0.044 & $C$ \\
\hline $\mathrm{G} 351.368+0.7^{\mathrm{a}}$ & $\ldots$ & $\ldots$ & $\ldots$ & $\ldots$ & $\ldots$ & $\ldots$ & $\ldots$ & $\ldots$ & $\ldots$ & $\ldots$ & 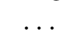 \\
\hline G351.467-0.4 & 0.898 & 0.004 & 0.900 & 0.005 & 4.310 & 0.029 & 3.815 & 0.027 & 4.055 & 0.020 & $B$ \\
\hline G351.613-1.2 & 7.172 & 0.030 & 6.976 & 0.015 & 3.580 & 0.018 & 3.570 & 0.009 & 3.575 & 0.010 & $A$ \\
\hline G351.64-1.26 & 6.632 & 0.034 & 6.442 & 0.022 & 3.622 & 0.022 & 3.670 & 0.015 & 3.646 & 0.013 & $B$ \\
\hline G351.69-1.17 & 2.389 & 0.004 & 2.398 & 0.006 & 4.319 & 0.009 & 4.434 & 0.014 & 4.376 & 0.008 & $B$ \\
\hline G352.61-0.17 & 0.652 & 0.005 & 0.647 & 0.004 & 4.434 & 0.046 & 3.474 & 0.025 & 3.925 & 0.025 & $B$ \\
\hline G353.035+0.7 & $\ldots$ & $\ldots$ & 1.911 & 0.009 & $\ldots$ & $\ldots$ & 3.789 & 0.022 & 3.789 & 0.022 & $B$ \\
\hline G353.08+0.36 & 1.492 & 0.014 & 1.497 & 0.014 & 8.511 & 0.115 & 6.579 & 0.084 & 7.482 & 0.070 & $E$ \\
\hline G353.14+0.66 & 7.745 & 0.044 & 7.287 & 0.068 & 5.960 & 0.043 & 4.874 & 0.053 & 5.390 & 0.034 & $B$ \\
\hline G353.186+0.8 & 13.112 & 0.058 & 13.416 & 0.049 & 4.917 & 0.032 & 3.955 & 0.016 & 4.410 & 0.017 & $B$ \\
\hline G353.21+0.91 & 12.510 & 0.048 & 13.141 & 0.014 & 5.025 & 0.024 & 3.745 & 0.005 & 4.338 & 0.011 & $B$ \\
\hline G353.398-0.3 & 2.987 & 0.019 & 2.926 & 0.009 & 3.404 & 0.024 & 3.605 & 0.012 & 3.503 & 0.014 & $A$ \\
\hline G353.43-0.37 & 2.707 & 0.013 & 2.716 & 0.011 & 3.245 & 0.018 & 3.804 & 0.019 & 3.514 & 0.013 & $B$ \\
\hline
\end{tabular}

${ }^{\sharp}$ Continuum quality factor. See text. QF is an evaluation of the quality of the parameters measured for the continuum scans. It is based on the accuracy of the Gaussian fit to the emission feature, the uncertainty in the baseline models and the contrast between the target source emission and any emission from possible sub-structures or nearby confusing sources.

${ }^{a} \mathrm{M} 16, \mathrm{M} 17$, NGC 6334, Rosette and S209 were observed at different positions in the ${ }^{3} \mathrm{He}$ survey.

b Observed in the $\mathrm{C}$ II survey.

${ }^{\mathrm{c}}$ Observed in the ${ }^{3} \mathrm{He}$ survey. 


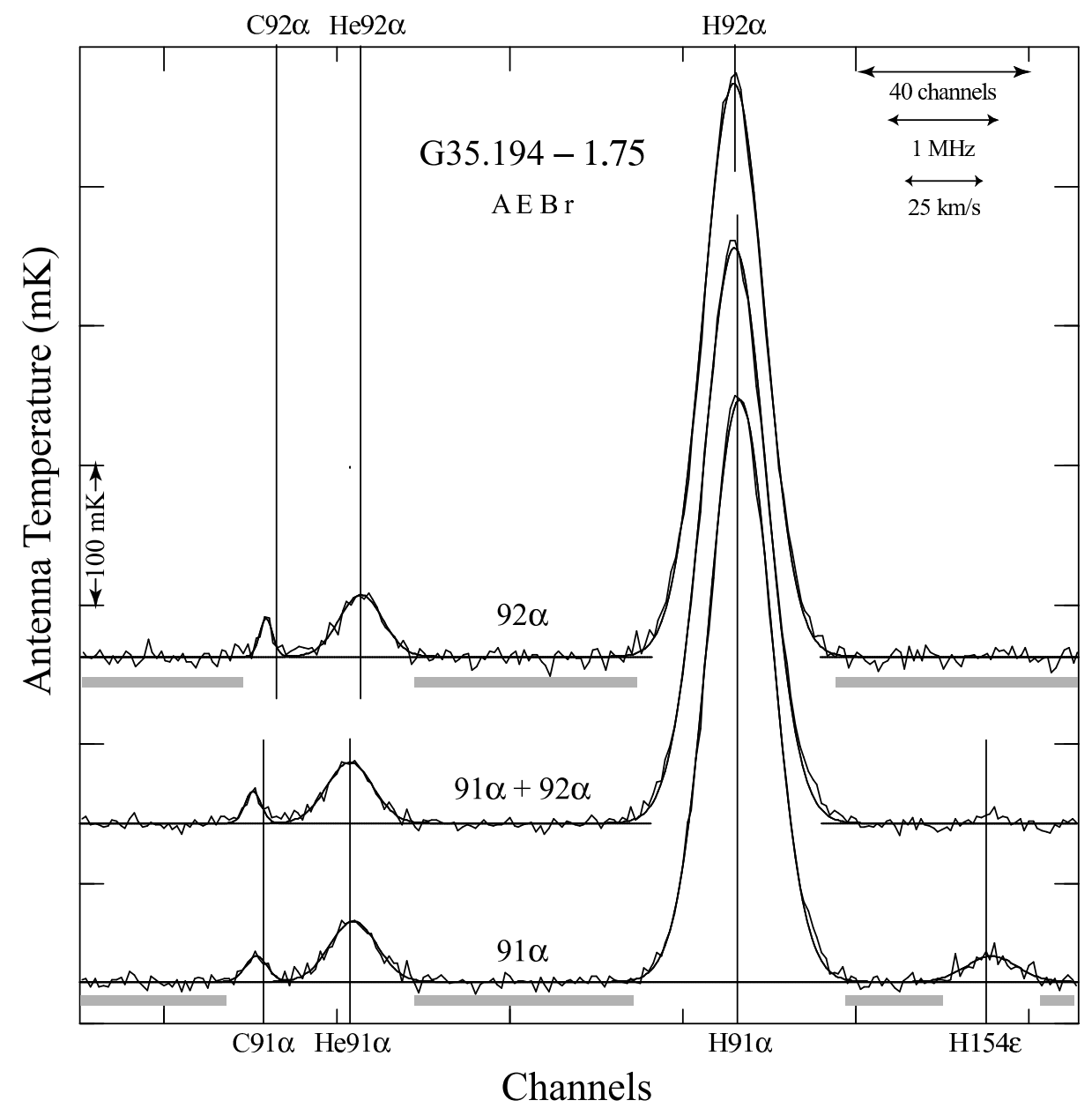

Fig. 1.- Spectra for the Galactic H II region G35.194-1.75. Shown are the $91 \alpha$ (lower spectrum) and $92 \alpha$ (upper spectrum) transitions together with the average spectrum: $\langle\mathrm{H}\rangle \alpha$ (center spectrum). The vertical lines flag the expected line center positions, and the gray bars denote the channel regions used for the baseline fit. A baseline was removed from all these spectra. Gaussian fits to the lines are also shown. The H $154 \epsilon$ line is not used for the baseline fit to the $\langle\mathrm{H}\rangle \alpha$ spectrum. The four letters under the source name give the overall quality factor $(\mathrm{QF}=\mathrm{A})$, the reliability factor $(\mathrm{RF}=\mathrm{E})$, the $\mathrm{C}$ line quality factor $(\mathrm{QF}(\mathrm{C})$ $=\mathrm{B}$ ), and the $\mathrm{C}$ line morphology ( $\mathrm{r}$ or resolved). See the text for further explanation. 


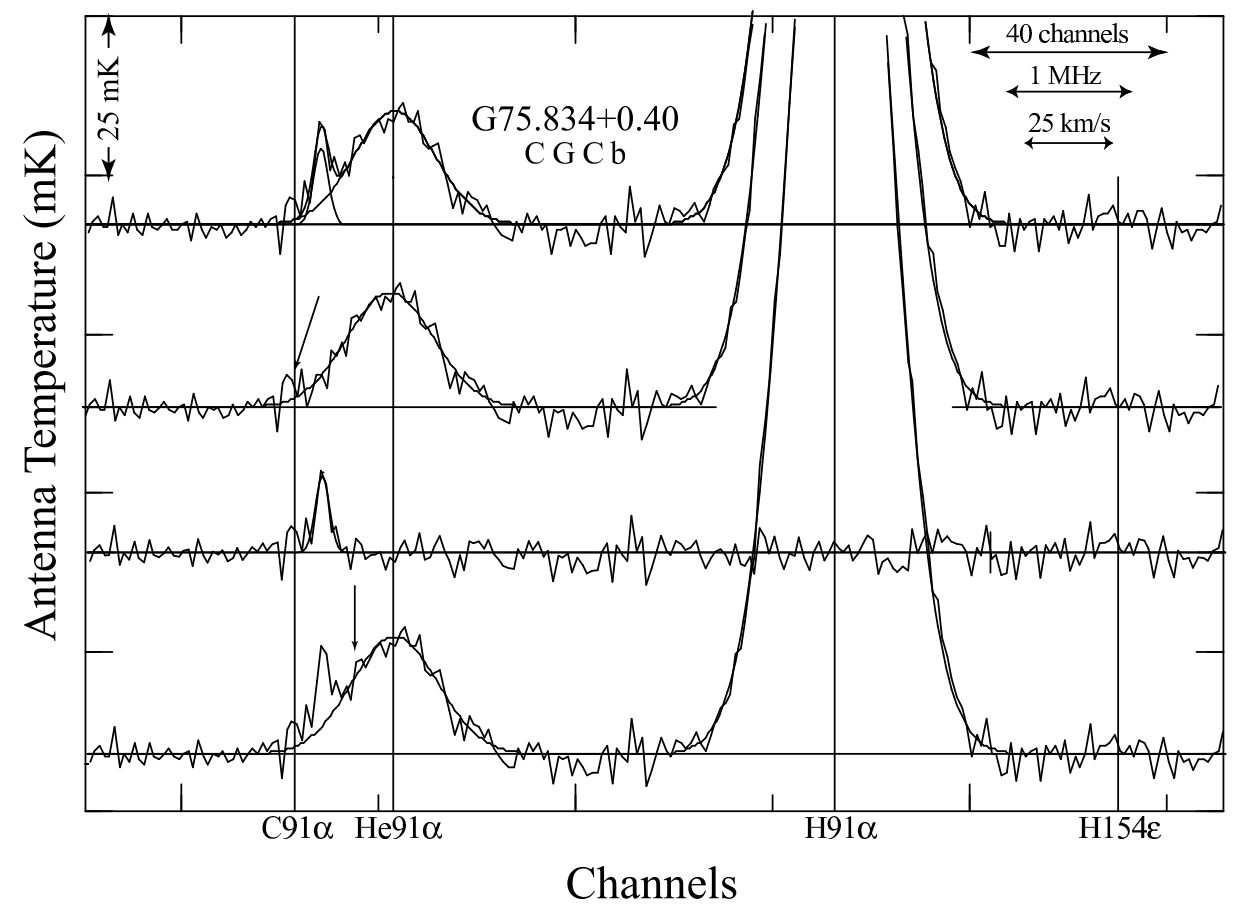

Fig. 2.- An example showing how blended $\mathrm{C}$ line parameters are determined. The lower plot shows the spectrum for the $\mathrm{H}$ II region G75.834+0.40 after a baseline has been removed. The Gaussian has been fit to that part of the He line to the right of the arrow-avoiding the $\mathrm{C}$ line. The second plot shows the spectrum with the fit subtracted. A Gaussian fit to the $\mathrm{C}$ line is then subtracted from the original spectrum yielding the third spectrum. The Gaussian fit to this spectrum extends through the full He line as indicated by the arrow and shows that the He line is symmetric. Finally the full spectrum and fits are shown in the upper plot. 


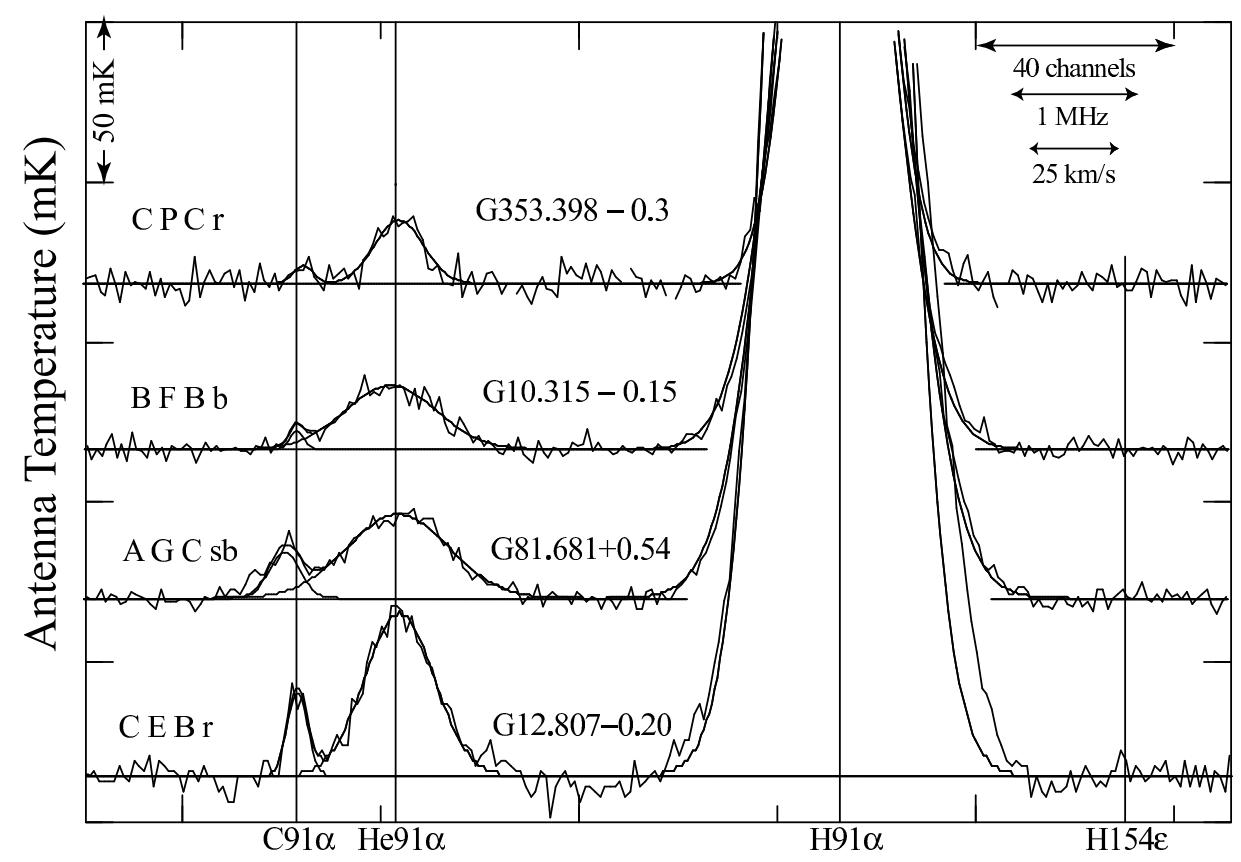

Channels

Fig. 3.- Examples from the C II survey of the morphological classification of C $91 \alpha$ RRL emission. Spectra with differing quality factors $(\mathrm{QF} \& \mathrm{QF}(\mathrm{C}))$ and reliability factors are shown. Each spectrum is labeled from left to right with $\mathrm{QF}, \mathrm{RF}, \mathrm{QF}(\mathrm{C})$, and morphology. The H II region G12.807-0.20 has a carbon recombination line emission line classified as resolved (r). The $\mathrm{C}$ line in G81.681+0.54 is classified as semi-blended since it occurs in the wings of the very wide He line. Both of these are solid detections with reasonably well determined line parameters. In contrast the blended (b) C line in G10.315-0.15 and resolved C line in G353.398-0.3 are weak and their reality might be debated. 


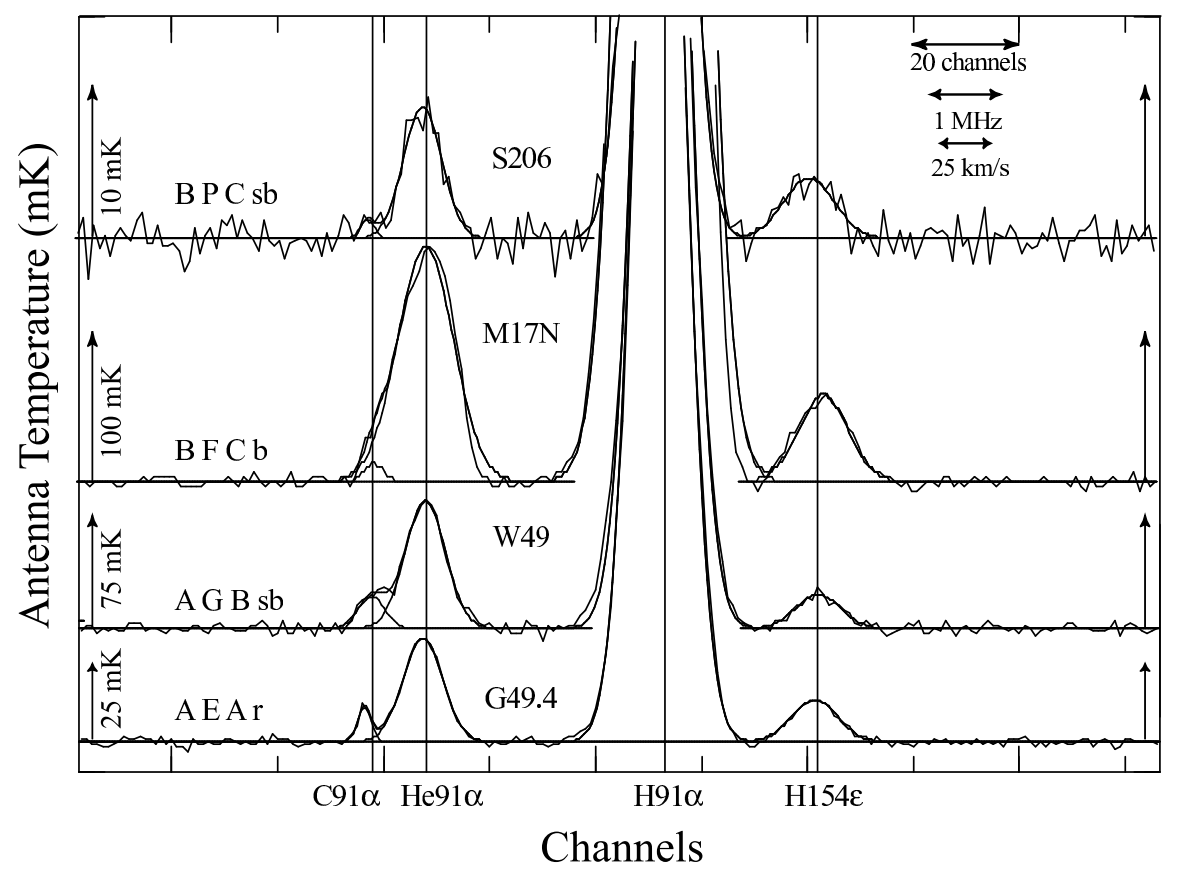

Fig. 4. - Examples from the ${ }^{3}$ He survey of the morphological classification of C $91 \alpha \mathrm{RRL}$ emission. The intensity scale varies from spectrum to spectrum and is indicated by the length of the arrows at the left of each. Spectra with differing quality factors $(\mathrm{QF} \& \mathrm{QF}(\mathrm{C}))$ and reliability factors are shown. Each spectrum is labeled from left to right with QF, RF, $\mathrm{QF}(\mathrm{C})$, and morphology. The H II region G49.4 is in the highest category of each ranking; the $\mathrm{C}$ and He line data are indistinguishable from the Gaussian fit. 


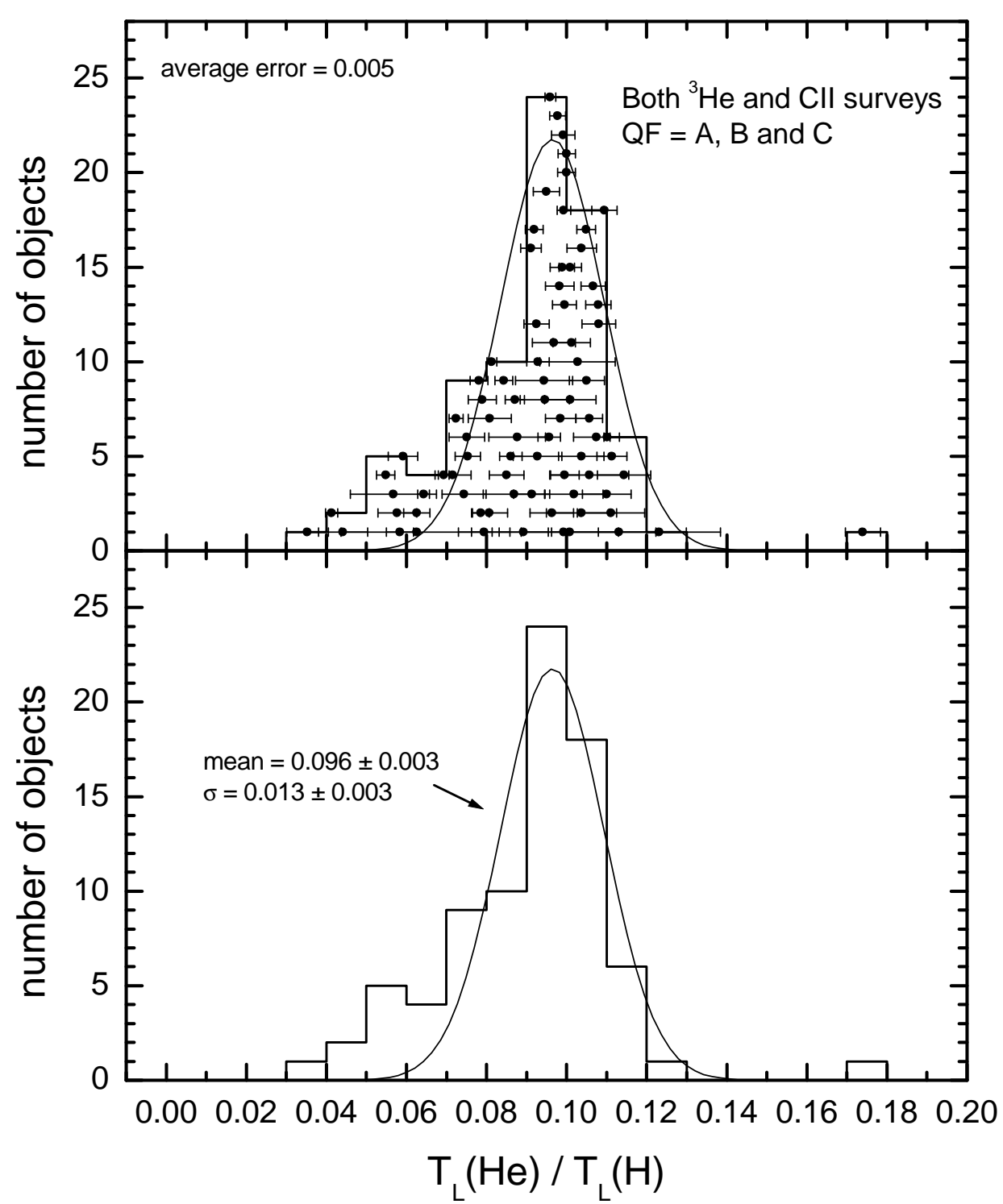

Fig. 5.- The distribution of the ratio of $\mathrm{He}$ and $\mathrm{H}$ line intensities. Only the highest quality data $(\mathrm{QF}=\mathrm{A}-\mathrm{C})$ are used. The lower plot shows a histogram of the distribution and the best fit Gaussian. These are repeated in the upper plot now with each data point shown along with its error bars. Within each histogram bin the points are plotted with their measured $x$ (in this case $T_{L}(\mathrm{He}) / T_{L}(\mathrm{H})$ ) and the points are added to each bin in order of increasing $T_{L}(\mathrm{H})$. 


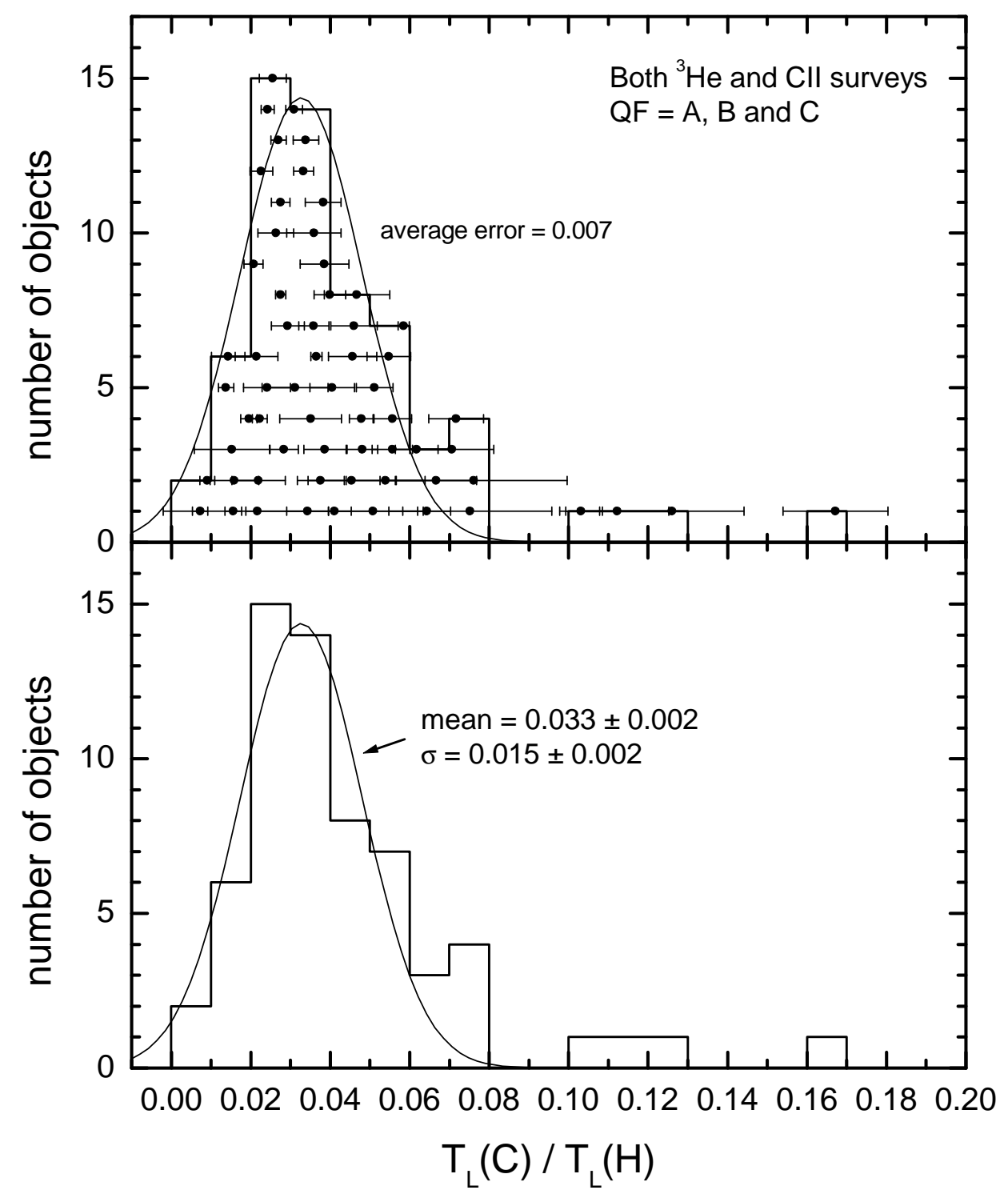

Fig. 6. - The distribution of C line intensities. See Figure 5. 


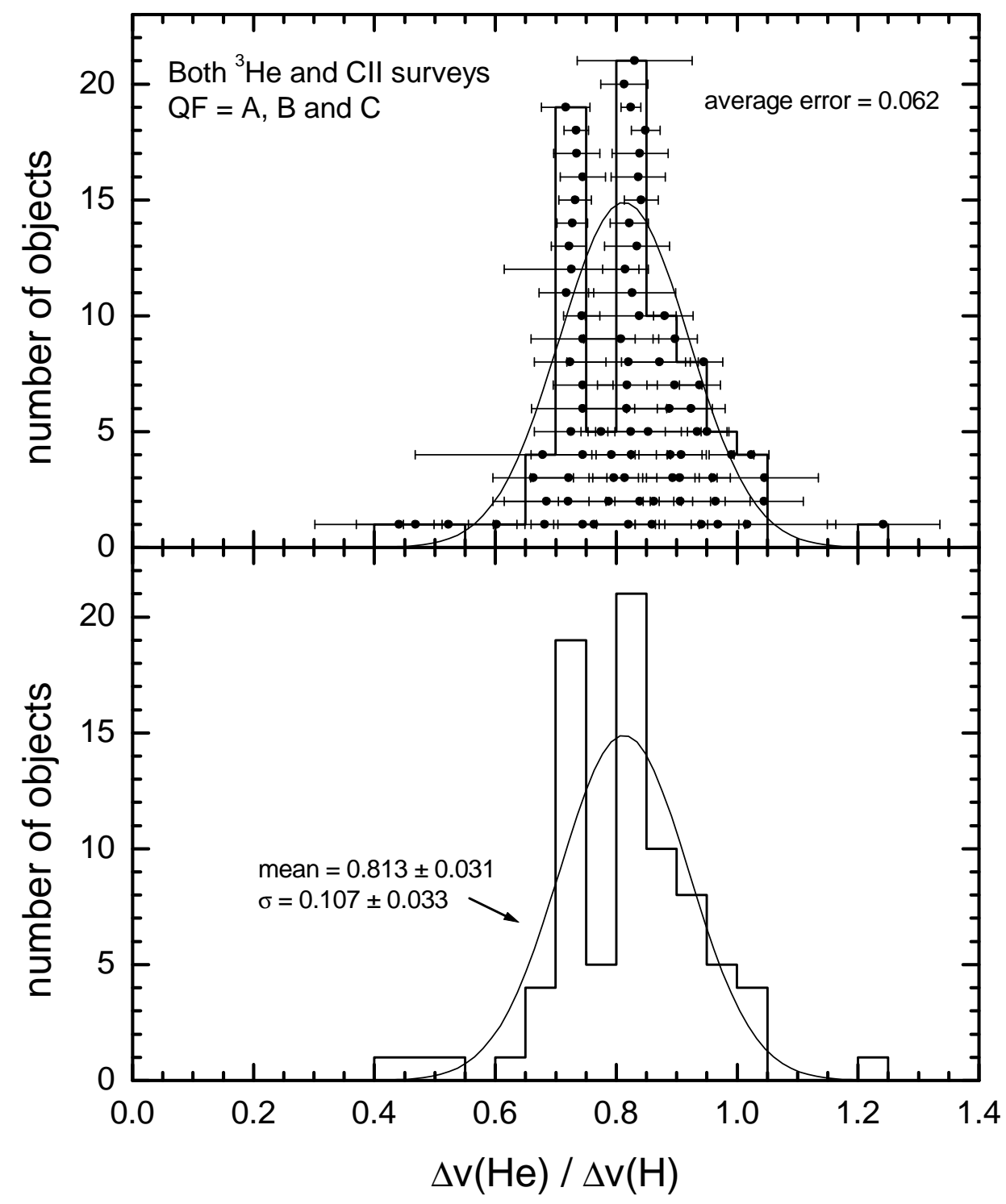

Fig. 7.- The distribution of He line widths. See Figure 5. 


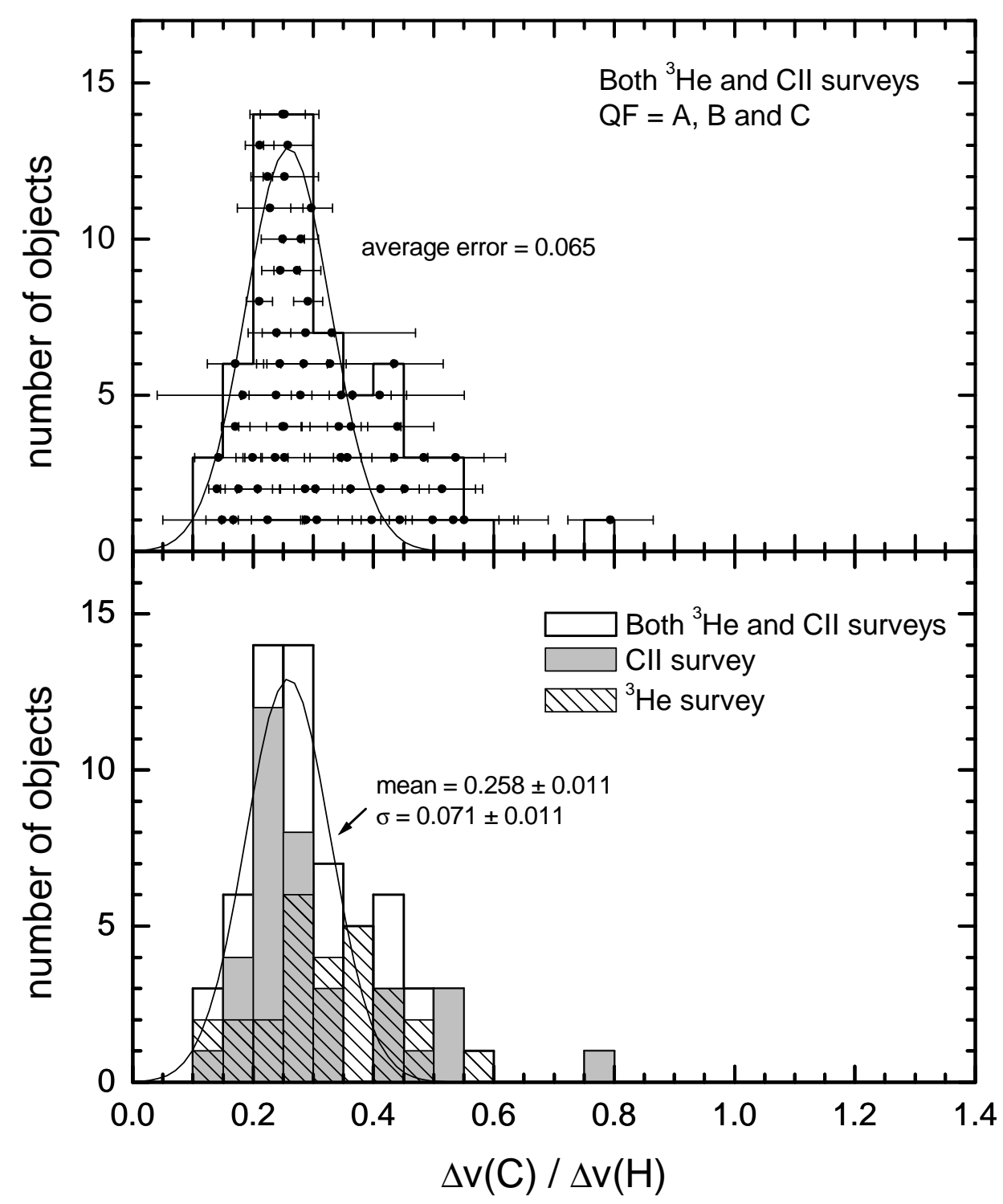

Fig. 8. - The distribution of $\mathrm{C}$ line widths for the combined $\mathrm{C}$ II and ${ }^{3} \mathrm{He}$ surveys. In the lower panel the component of the distributions from the ${ }^{3} \mathrm{He}$ and $\mathrm{C}$ II surveys are shown. See Figure 5. 


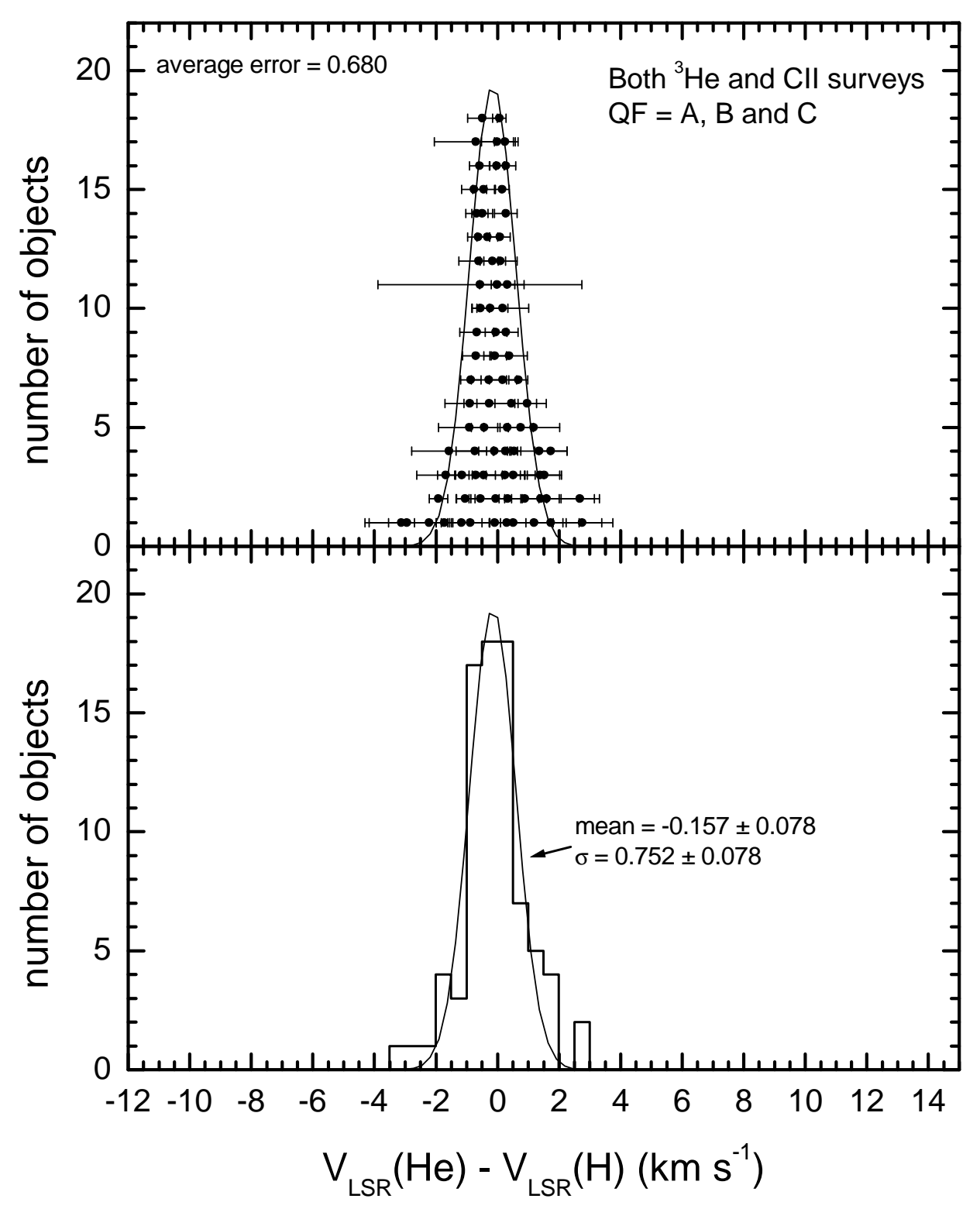

Fig. 9. - The distribution of He line velocities. See Figure 5. 


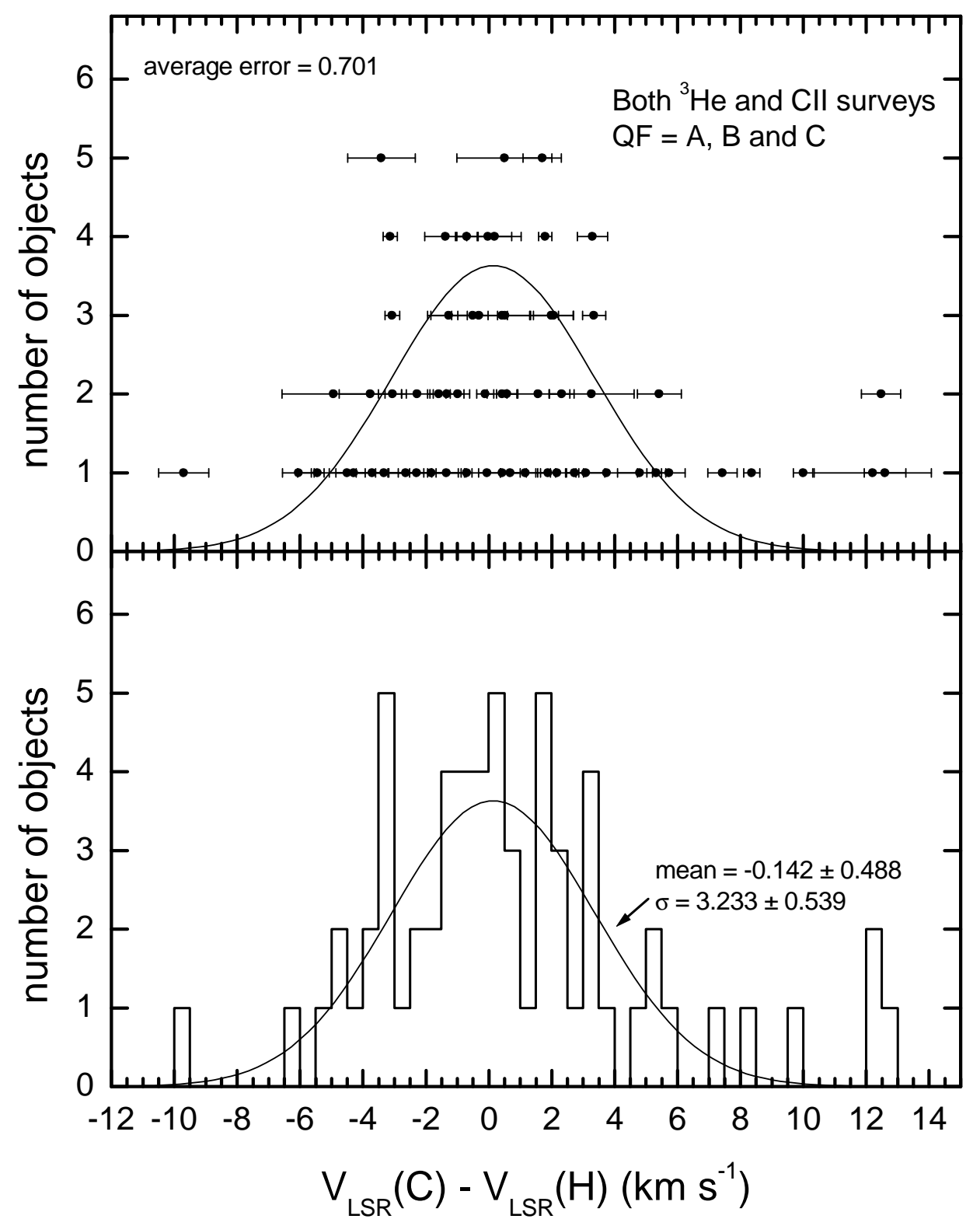

Fig. 10.- The distribution of C line velocities. See Figure 5. 


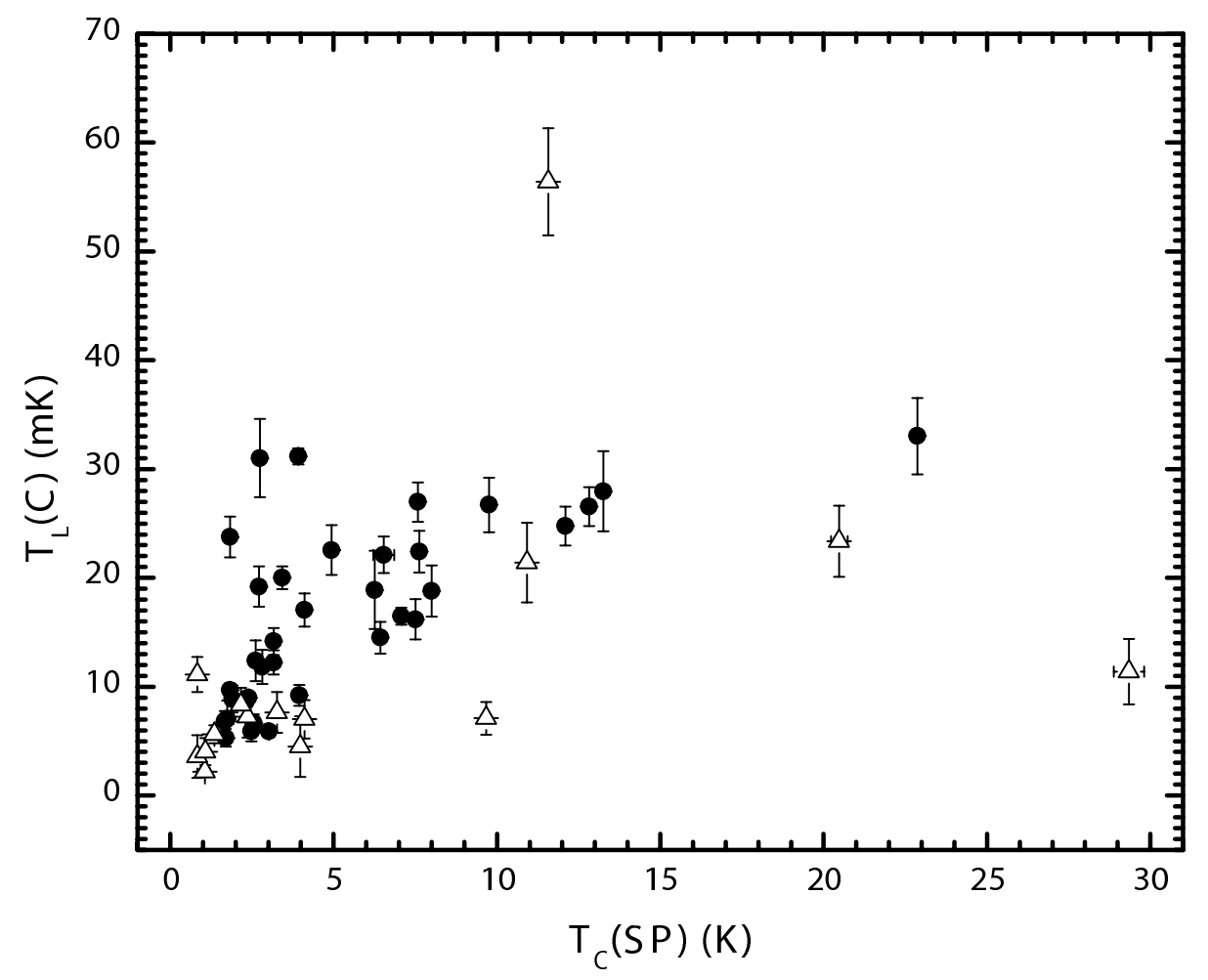

Fig. 11. - Carbon line intensity versus continuum intensity for sources with best QFs ( $C$ or better) for both line spectra and continuum. The solid circles and open triangles correspond to the $\mathrm{C}$ II and ${ }^{3} \mathrm{He}$ surveys, respectively. A linear least-squares fit including both surveys yields $T_{\mathrm{L}}(C)=(9.52 \pm 1.73)+(0.90 \pm 0.22) T_{\mathrm{C}}(S P)$. Only sources with continuum measured using SP are included. 